University of San Diego

Digital USD

\title{
The Development of the Tavistock and Tavistock-Inspired Group Relations Movement in Great Britain and the United States: A Comparative and Historical Perspective
}

Amy L. Fraher EdD

University of San Diego

Follow this and additional works at: https://digital.sandiego.edu/dissertations

Part of the Leadership Studies Commons

\section{Digital USD Citation}

Fraher, Amy L. EdD, "The Development of the Tavistock and Tavistock-Inspired Group Relations Movement in Great Britain and the United States: A Comparative and Historical Perspective" (2002). Dissertations. 692.

https://digital.sandiego.edu/dissertations/692

This Dissertation: Open Access is brought to you for free and open access by the Theses and Dissertations at Digital USD. It has been accepted for inclusion in Dissertations by an authorized administrator of Digital USD. For more information, please contact digital@sandiego.edu. 
THE DEVELOPMENT OF THE TAVISTOCK AND TAVISTOCK-INSPIRED GROUP RELATIONS MOVEMENT IN GREAT BRITAIN AND THE UNITED STATES:

\title{
A COMPARATIVE AND HISTORICAL PERSPECTIVE
}

\author{
By \\ Amy L. Fraher \\ A dissertation submitted in partial fulfillment \\ of the requirements for the degree of
}

Doctor of Education

University of San Diego

2002

Dissertation Committee

Robert Donmoyer, Ph.D., Chair

Theresa Monroe, Ed.D.

Michael Gonzalez, Ph.D. 


\begin{abstract}
In order to gain a deeper understanding of authority, people must analyze human behavior in groups. To study these behaviors, a group relations movement was spawned approximately 60 years ago and has influenced people's thinking about leadership and authority in groups and organizations ever since. This study analyzed primary and secondary historical sources, including data from extended videotaped interviews the researcher conducted with thirteen group relations experts throughout the United States and Great Britain, as a way to reconstruct the history of a significant part of the group relations movement. These videotaped interviews are available for viewing. Specifically, the study first details the foundational theories of the group relations movement, and then explores the emergence of methods developed in post-World War II England by the Tavistock Institute of Human Relations. It follows the exportation of the Tavistock method to the United States and the evolution of the A. K. Rice Institute (AKRI) that was developed to work within the Tavistock tradition in America. Since the AKRI has maintained limited primary sources and generated few historical records, interview data were especially important in reconstructing its history. In addition, an indigenous American group relations model, the National Training Laboratories Institute for Applied Behavioral Science (NTL) model, was examined as part of an effort to indicate how factors in the United States context led to significant modifications in the Tavistock approach when it was transported to America.
\end{abstract}


Copyright by Amy L. Fraher, 2002

All Rights Reserved 
Dedication

In memory of Dr. Eric J. Miller

(1924-2002) 


\section{The Second Coming}

\section{By William Butler Yeats}

Turning and turning in the widening gyre

The falcon cannot hear the falconer;

Things fall apart; the centre cannot hold;

Mere anarchy is loosed upon the world,

The blood-dimmed tide is loosed, and everywhere

The ceremony of innocence is drowned;

The best lack all conviction, while the worst

Are full of passionate intensity.

Surely some revelation is at hand... 


\section{Acknowledgements}

Although my interest in the field of group relations began only three years ago, my fascination with human behavior in groups and the influence of organizational systems on work life started well over twenty years ago. While on this path of discovery, my journey included exciting explorations to far off places and conversations with astute people from a variety of walks of life-all of whom welcomed me warmly, often into their homes, with a prodigious respect for both my personal quest for inner knowledge as well as the merit of my dissertation research. My life has been enriched by this quest and by the creation of this dissertation. For this enrichment, I owe many people a debt of gratitude.

I would first like to thank my dissertation committee: Dr. Bob Donmoyer for his patient editing lessons and hours of guidance and support over lattes at Peets; Dr. Terri Monroe for exposing me to the field of group relations and for the idea of researching the history of group relations; and Dr. Michael Gonzalez for your support and good-natured critiques.

I would next like to thank the informants in my study for their time and interest in my research: Wesley Carr, Larry Gould, Vangie Holvino, Ed Klein, Gordon Lawrence, Isabel Menzies Lyth, Eric Miller, Terri Monroe, Anton Obholzer, Diane Porter, Ed Shapiro, Mannie Sher, and Kathy White. Without their 
assistance, this project would not have been completed as smoothly or expeditiously.

I am grateful to the staff of the Tavistock Institute, the Tavistock and Portman NHS Trust, the A. K. Rice Institute, in particular Anne-Marie H. Kirkpatrick, and the National Training Laboratories for their support and assistance.

I would like to thank Rudi Vaca of San Diego State University for his assistance with videotaping techniques and Karen Sharpe of the University of San Diego's Copley Library.

I would like to thank my fellow doctoral students at the University of San Diego for their camaraderie and support, in particular, Bob Brown, Cristina Chiriboga, Helen Eckman, John McCloskey, Alana Nicastro, and Shelly Marks.

I would also like to thank the women of the "Let's Finish" writing group for helping me to "finish."

I am grateful to Mary Rafferty and Marian Urquilla for their ideas and critiques, for reading drafts of this document, and most of all, for letting me vent.

I would like to thank my family and friends for their patience and nurturing support when I communed, yet again, with my computer for the day. I also appreciate that-even though you often had no idea what I was talking about-you always asked and listened anyway. 
Finally, I would like to thank my partner Kathy Jones for her unconditional love, selfless support, and solid strength. Your immeasurable confidence in me, especially at times when my own convictions wavered, allowed me to test the outer boundaries of my psyche. I am a better person because of you. 
Table of Contents

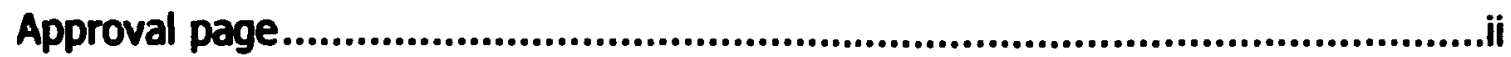

Human Subjects Committee Clearance.............................................................iii

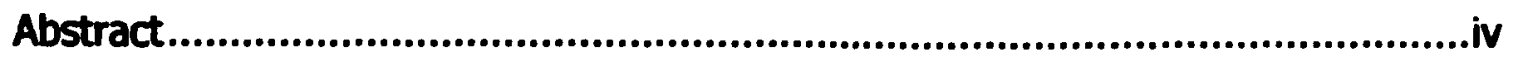

Copyright

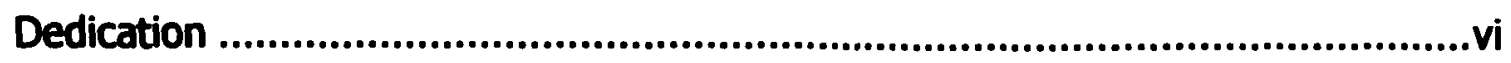

Acknowledgements....................................................................................... vii

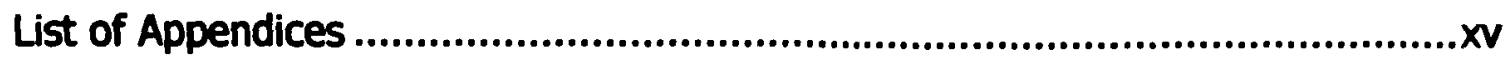

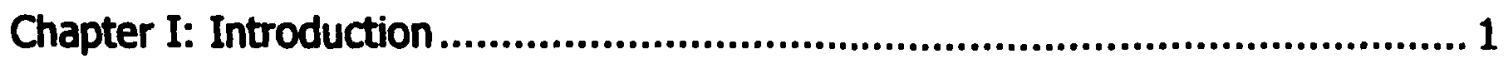

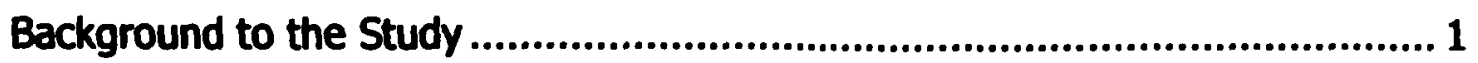

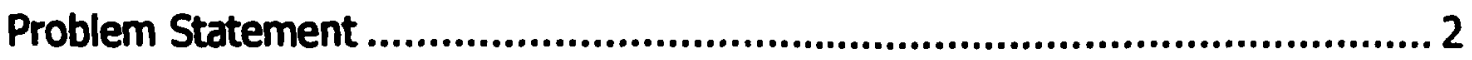

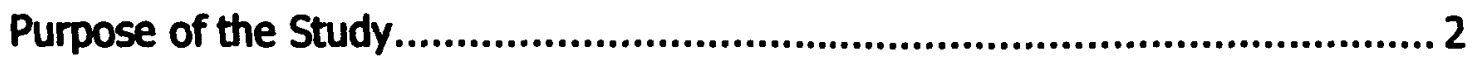

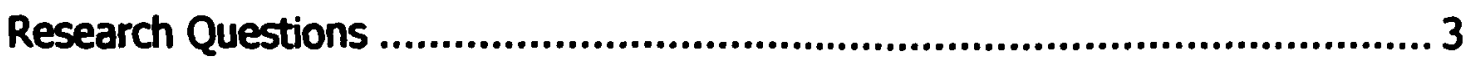

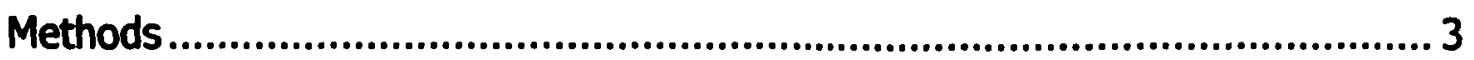

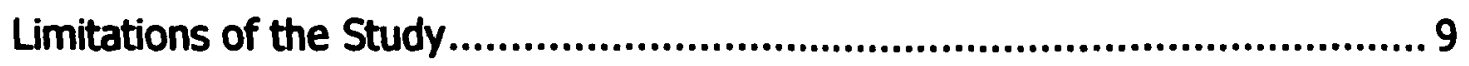

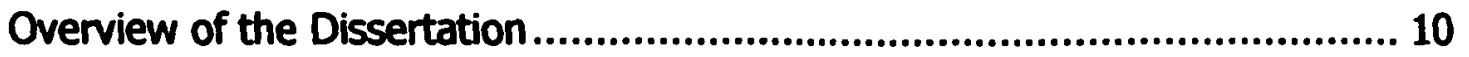

Chapter II: Intellectual Foundations of the Group Relations Movement............ 11

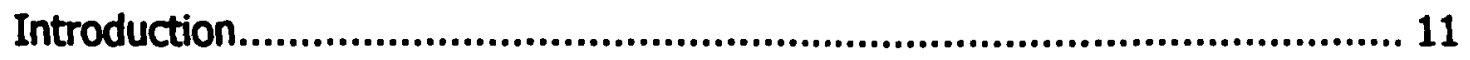

The Psychoanalytic Tradition ............................................................. 11

The Influence of Other Traditions.................................................................18

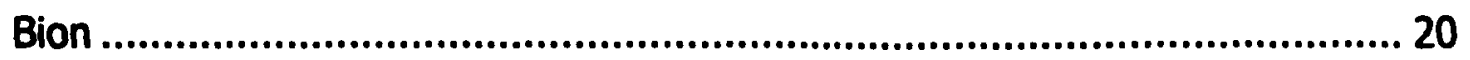

The Tradition of Open Systems Theory................................................... 28 
Systems Psychodynamic: Naming an Emerging Tradition 35

Chapter III: The Emergence of the Group Relations Movement In the United

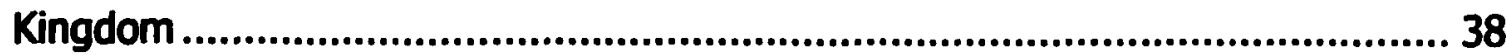

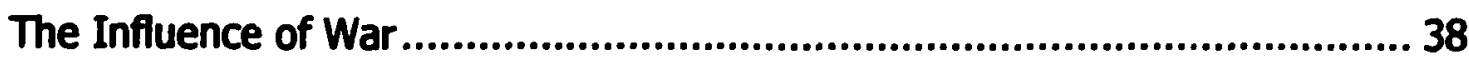

The Development of Group Therapy during the War and Post-War Years..... 41

The Northfield Experiments ....................................................................... 43

The Development of the Tavistock Clinic in the Post-World War I Period....... 54

The Tavistock Institute of Human Relations (Tavistock Institute).................. 59

Exchanging Theories, Methods, and Language: The Influence of the NTL ..... 65

Evolution of the Group Relations Conference........................................... 72

The Centre For Applied Social Research (CASR) ...................................... 87

Exportation of the Tavistock Model .........................................................99

Chapter IV: Tavistock Transferred-Stories of the Group Relations Movement in America: The Cultural Context (Including the Story of an Indigenous Group

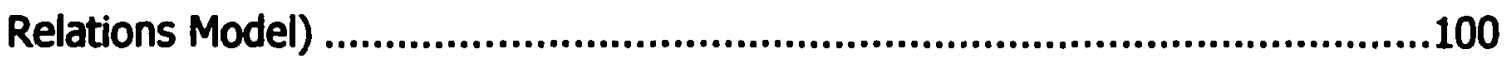

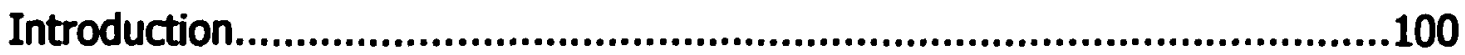

Post-War Culture in the United States ..................................................101

An Indigenous Group Relations Model: Lewin and the NTL ........................105

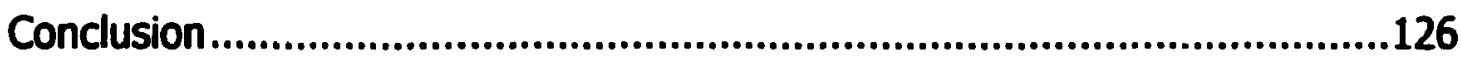

Chapter V Tavistock Transferred-Stories of the Group Relations Movement in America: The "Great Mother" Story .........................................................128

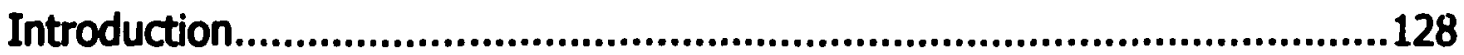


Rioch's Personal and Professional Background ........................................128

The Tavistock Model Goes To America ....................................................132

The Mother of Group Relations in America..............................................135 Chapter VI: Tavistock Transferred-Stories of the Group Relations Movement in America: The Organizational Structures Story .........................................151

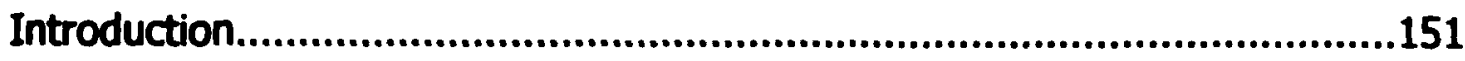

An "Organization-In-The-Mind" with an Oral Tradition ...............................152

Group Relations Conferences as Organizational Structure .........................154

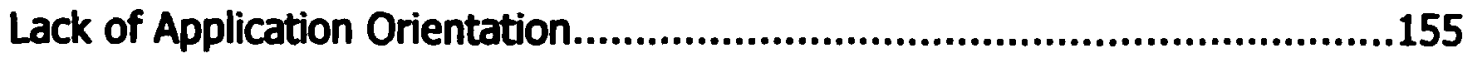

Centralized, Decentralized, and the Resultant Confederation.......................160

An Organization with Exclusionary Cultural Norms...................................169

Lack of Attention to Succession in a Charismatic Leadership Structure.........176

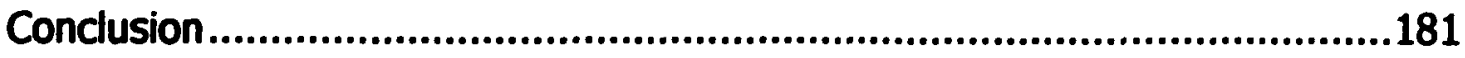

Chapter VII: Tavistock Transferred-Stories of the Group Relations Movement in America: The Story of Change...............................................................183

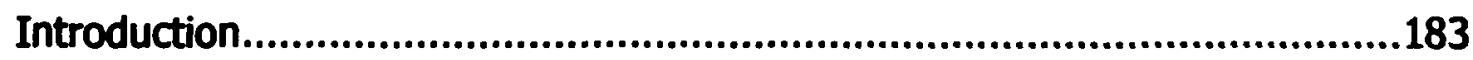

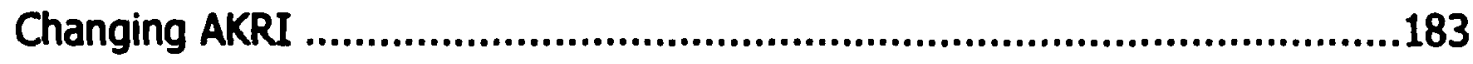

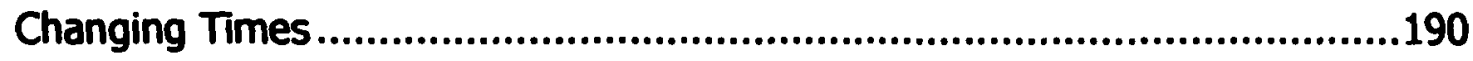

Changing Faces ..............................................................................192

A Watershed Event: 1990 AKRI National Conference................................197

A Changing Group Relations Movement ...............................................207

AKRI History Project: A Retrospective.....................................................215 
"A Center That Holds": Where is AKRI Headed Now? ................................216

Changing Group Relations Approaches ..............................................219

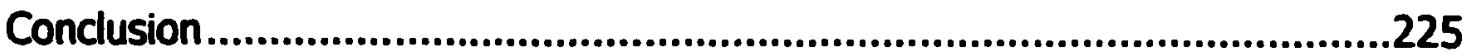

Chapter VIII: Analysis and Recommendations for Further Research................226

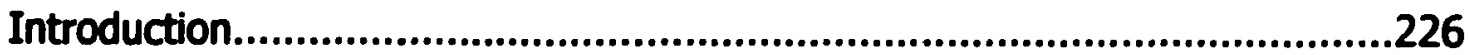

Research Question 1: What were the Historical Origins of the Tavistock Model

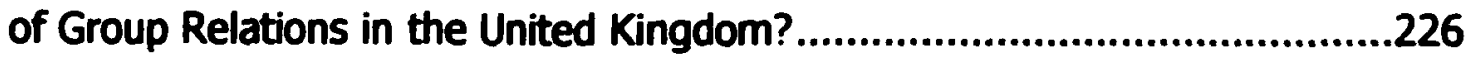

Research Question 2: What Circumstances Led to the Tavistock Model's

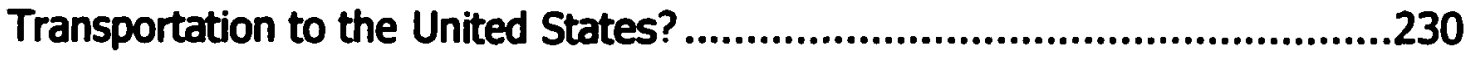

Research Question 3: What Factors Influenced the Evolution of the Group

Relations Movement in the United States? ............................................231

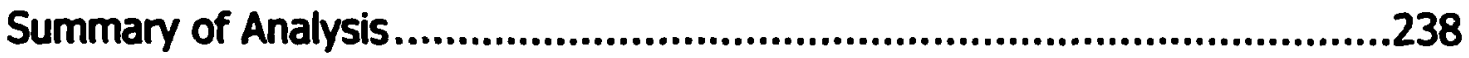

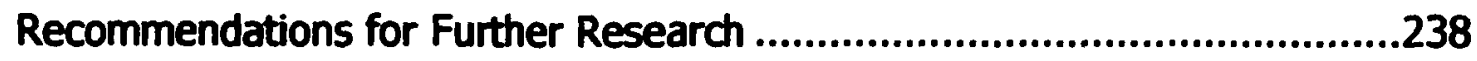

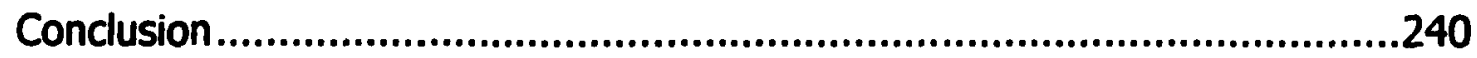

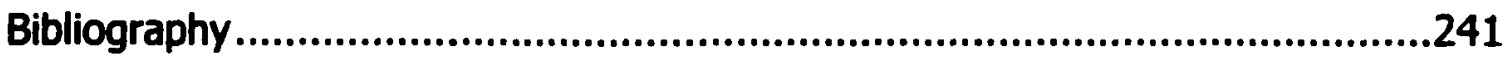

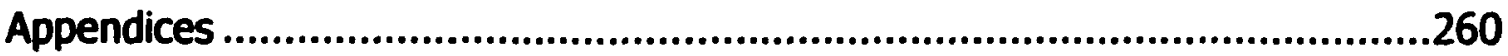


List of Appendices

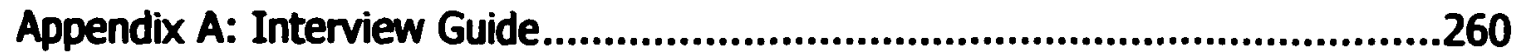

Appendix B: A. K. Rice Institute's Scientific Meetings ................................262

Appendix C: A. K. Rice Institute's Centers .............................................264 


\section{Chapter I: Introduction}

\section{Background to the Study}

"Human living has always been in groups" (Foulkes \& Anthony, 1957, p. 23). In our complex society, people find themselves associated with other individuals in both formal and informal situations, through conscious and unconscious decisions, based on personal and professional relationships, for work and for pleasure. As the assembled individuals start to identify as a group, a behavioral transformation begins to occur. (Bion, 1961; Freud, 1959; Le Bon, 1896; McDougall, 1920). Gabriel (1999) wrote:

Our experiences as members of groups can be overpowering. Feelings of being valued, of belonging, of contributing, can be off-set by anxieties about being intimidated, excluded or swamped. There are moments when we observe ourselves behaving irrationally as members of crowds or audiences, yet we are swept by the emotion, unable to check it. In smaller groups too, like committees or teams, we may experience powerful feelings of loyalty, anxiety or anger. (p. 112)

Given that the power of groups is evident throughout society and that so much of our lives are spent associated with one group or another, it is not surprising that scholars developed group relations theories and methods in order to study the enigmatic nature of group life. 
Many of the developments of group relations theories and methods occurred during World War II and in the post-war period at the Tavistock Institute of Human Relations (Tavistock Institute) in London, England. Much has been written about this history. Yet, a need exists for a fresh historical analysis examining the development of the Tavistock methods and the subsequent Tavistock-inspired group relations movement in Great Britain and the United States.

\section{Problem Statement}

Although there is an ample amount of sources detailing the formative years of the group relations movement, particularly the development of the Tavistock model in England and the National Training Laboratories Institute for Applied Behavioral Science (NTL) model in America, a need remains to synthesize this history and analyze each model's development in light of the political, social, economic, and cultural influences of their respective time and location. In addition, an interesting literature gap exists in the history of the transference of the Tavistock method to the United States and the subsequent development of the A. K. Rice Institute (AKRI) in America.

\section{Purpose of the Study}

This study provides perspectives on the history of the development of the Tavistock and Tavistock-inspired group relations movement in Great Britain and the United States by filling an identified literature gap in the history of the Tavistock model in America and the development of the AKRI. 


\section{Research Questions}

In order to explore perspectives on the history of the development of the Tavistock and Tavistock-inspired group relations movement, this study asked the following questions: (1) What were the historical origins of the Tavistock model of group relations? (2) What circumstances led to the Tavistock model's transportation to the United States? (3) What factors influenced the evolution of the group relations movement in the United States?

\section{Methods}

This study employed a mixed methodology design in order to explore the research questions identified above. One element of this study consisted of archival analysis and the other element consisted of qualitative interviewing.

Archival analysis. In order to support its findings, the present study gathered data through primary historical sources, such as personal correspondences, original conference brochures, corporate reports, newspaper clippings, corporate annual statements, minutes of meetings, bylaws, and a symposium video, and secondary sources, such as scholarly books, journal articles, unpublished papers, theses, and dissertations. These materials were supplemented with another method geared toward developing primary source material-qualitative interviewing.

Qualitative interviewing. For this study, thirteen group relations experts were interviewed in various locations in the United States and Great Britain. In order to locate the most information-rich sources, informants were selected 
based on two purposeful sampling techniques, criterion and snowball sampling (Merriam, 1998; Patton, 1990). Criterion sampling was used to target specific group relations experts who secondary sources indicated would be able to provide key pieces of historical data. These informants were selected to provide data that could not be gleaned from other sources. Snowball sampling was used to ensure that key people, as identified by other informants, were included in the study.

Triangulation. In order to insure that findings that got reported were valid, two forms of triangulation were employed: data triangulation, the combination of different kinds of data, and methodological triangulation, the combination of different methods. Triangulation enhances the validity of research findings by helping to eliminate bias and increase the potency of the findings. Mathison (1988) noted: "Good research practice obligates the researcher to triangulate" (p. 13).

The informants. A brief biography of each informant is provided below so that the reader will be better able to situate an informant's comments as they are cited in this dissertation.

- Dr. A. Wesley Carr is Dean of Westminster Abbey in London, England. Since 1975, he has been involved in the group relations movement in both the United States and the United Kingdom using the Tavistock and AKRI traditions. 
- Dr. Laurence Gould, a professor of psychology in the Clinical Psychology Doctoral Program at the City University of New York, is a psychoanalyst and an organizational consultant. Working closely with Margaret Rioch, Gould was one of the early founders of the A. K. Rice Institute and has been involved in the group relations movement in America and the England since 1966.

- Dr. Evangalina Holvino is a senior researcher at the Center for Gender in Organizations at Simmons Graduate School of Management in Boston. She has been involved in the group relations movement since 1972 using both the Tavistock and NTL traditions, and has developed her own model called the Third Way.

- Dr. Edward Klein is a professor of psychology at the University of Cincinnati in Ohio. He has been involved with the Tavistock, NTL, and AKRI traditions in the group relations movement since 1965 in both the United States and the United Kingdom.

- Mr. W. Gordon Lawrence is an organizational consultant and Director of IMAGO East-West in London. Co-director of the Tavistock Institute's Group Relations Programme for eleven years, Lawrence has experience with the Tavistock and AKRI methods in both the United States and the United Kingdom and has been involved in the group relations movement since 1965. 
- Dr. Isabel Menzies Lyth is a retired psychoanalyst and one of the original group at the Tavistock Institute after World War II. She has been involved in the group relations' movement since 1946 including completing analysis with Wilfred Bion. She was active in the development of the Tavistock model and attended one of the first NTL human laboratories in the United States in 1949.

- Dr. Eric J. Miller (recently deceased) was the Director emeritus of the Tavistock Institute in London and the Group Relations Training Programme. He had extensive experience in the group relations movement around the world including assisting in the development of both the Tavistock and the AKRI traditions. Miller died in London on April $5^{\text {th }}, 2002$.

- Dr. Theresa Monroe is a professor of leadership studies at the University of San Diego in California. She has been involved in the group relations movement in the United States since 1986, and has experience with the AKRI tradition. She has developed her own San Diego mode/ of group relations.

- Dr. Anton Obholzer is a psychiatrist, organizational consultant, Chief Executive of the Tavistock \& Portman NHS Trust, and Associate Director of the Tavistock Institute's Group Relations Training Programme in London. He has been involved in the group relations movement predominantly in the United Kingdom using the Tavistock tradition. 
- Ms. Diane Porter is the current President and Director of the National Training Laboratory. While she is not an NTL "trainer," per se, she has been involved in the organization administratively since 1994 .

- Dr. Edward Shapiro is a psychoanalyst and the Medical Director and CEO of the Austen Riggs Center in Stockbridge, Massachusetts. He has been involved in the group relations movement since 1975 in the United States using the AKRI tradition.

- Dr. Mannie Sher is a psychiatrist and successor to Miller as the Director of the Tavistock Institute and the Group Relations Training Programme in London. Sher has been involved in the group relations movement since 1971 predominantly using the Tavistock tradition.

- Dr. Kathleen Pogue White is a psychologist-psychoanalyst and faculty member in the William Alanson White Psychoanalytic Institute's Program in Organization Development and Consultation in New York. She has been involved in the group relations movement since 1973 in both America and England using the Tavistock and AKRI traditions.

Informants group relations experience. Of the thirteen informants, eleven (85\%) had experience ${ }^{1}$ with the A. K. Rice Institute (AKRI) in the United States, nine $(69 \%)$ informants had experience with the Tavistock model in the United Kingdom, and four (31\%) of the informants had experience with the $\mathrm{NTL}$ model in America. Nine (70\%) of the informants had experience with two different

\footnotetext{
1 "Experience" is defined as having attended an event sponsored by the respective parent organization either as a participant or as a staff member.
} 
traditions, and one had experience with all three. Although only $31 \%$ of the informants in this study had direct experience with the NTL model, there is a plethora of archival data available that detailed the NTL's history.

Interview procedures. A topical interview of approximately two hours in length was conducted with each informant, at a location of their choosing, using a general interview guide approach (Patton, 1990, p. 288). The interview guide (Appendix A) provided an outline (or checklist) of topics to be covered with the informant. The guide, however, did not stipulate an order in which topics were to be discussed. Rather the interviews were allowed to unfold more or less naturally, as a good conversation does.

In most cases, the interview began with a grand tour question: "How was it that you first became involved in the group relations movement?" Building on the themes of the informant's response, it then proceeded to investigate their answers using mini-tour questions (Spradley, 1979, P. 87).

An advantage of the interview guide approach was that it provided a flexible frame within which to work. Yet this flexibility also was a weakness, since topics were sometimes discussed in substantially different ways with different informants, thus making the comparability of findings more problematic (Patton, 1990).

The interviews were videotaped in order to obtain the best quality audio, and the audio-track was transcribed and coded. Prior to the interview, informants signed a consent form stating this study would use real names when quoting 
informants, and that the video of their interview would be used for educational purposes only.

\section{Limitations of the Study}

No research method is without its limitations and this mixed methodology of historical and qualitative research was no exception. One limitation of the historical study is the available record. Historians can only study the documents, artifacts, records, or people that have survived. If a certain perspective or opinion has not been documented or is not recalled by a living person, that view is lost. Yet, at the same time, no assumption about the past can be made or excluded simply because no record could be found. This leaves the historian in the challenging role of playing historical detective, searching for evidence, and then weighing the value of a piece of evidence against the source's credibility.

One of the limitations of the qualitative interviews was that the subject sample consisted only of group relations experts selected through snow ball sampling. It is beyond the scope of this study to attempt to represent fully all opinions about the group relations movement. In addition, many events investigated occurred years ago. The study relied upon informant's ability to recall memories that may have faded with time or been influenced by more current events or relationships. Although these experts were able to provide valuable data to the study, one may assume that there were some perspectives and opinions that were not represented. Therefore, there is some bias in the presentation of history based on only these data. Yet, by carefully comparing the 
results of the interviews with the findings from the archival analysis, the bias was controlled as effectively as possible.

Overview of the Dissertation

In this final section of chapter one, I will provide a brief overview of this study. This dissertation begins by detailing the intellectual foundations of the Tavistock Institute's group relations model and the burgeoning field of group relations in chapter two. Chapter three considers how war-time experiences and changing cultural assumptions and social values shaped the emergence of the Tavistock model of group relations in England after World War II. Chapters four through seven explore the circumstances that led to the transportation of the Tavistock model to the United States in 1965, and assessed the factors that influenced the evolution of the group relations movement in the United States. Chapter eight provides an analysis of this study's findings as well as makes recommendations for areas that warrant further research. 
Chapter II: Intellectual Foundations of the Group Relations Movement

\section{Introduction}

This chapter discusses the intellectual foundations of the Tavistock model of group relations that emerged in England after World War II and that, in time, was transported to the United States. The contributions of Sigmund Freud, Melanie Klein, Wilfred Bion, Albert Kenneth Rice, and Eric Miller, among others, are reviewed.

The Tavistock method is an amalgam of two intellectual traditions: (1) the psychoanalytic tradition (in particular the aspects of that tradition which focused on groups and group therapy), and (2) the tradition of open systems theory. Eventually these traditions merged into a hybrid tradition called systems psychodynamics. Each of these traditions is discussed briefly in this chapter.

\section{The Psychoanalytic Tradition}

Freud. The discussion of the psychoanalytic traditions begins, as one might expect, with a discussion of the father of modern psychiatry and psychology, Sigmund Freud (Gabriel, 1999). Freud is often referred to as the "Darwin of the Mind." (Hale, 1995). Freud's first explorations of the mind began in the late 1800's in Vienna. He was influenced by Charcot's use of hypnosis to treat the hysterical symptoms of his patients, almost all of whom were women. 
Although Freud began his work by using hypnosis as a "means to provoke recollection of the emotional conflicts that originally gave rise to the symptoms" (Bernheimer \& Kahane, 1985, p. 8), he eventually abandoned hypnosis, in favor of his free association method. The free association method took the "apparently wandering thoughts" that patients produced "when encouraged to remember the circumstance of their symptom's origin" (Bernheimer \& Kahane, 1985, p. 9) as psychic clues to the existence of unconscious motivations governing behavior. Freud argued that these wandering thoughts were evidence of the patient's resistance to articulate unpleasurable ideas. Freud's application of this method of treatment to his own patient's led to his development of the theory and practice of psychoanalysis (Anthony, 1972).

Freud's major contribution was his construct of the unconscious. This notion was developed in an effort to distinguish the physiological factors from the psychological factors contributing to the pathology of neurosis (Bernheimer \& Kahane, 1985, p. 7). He saw resistance as an unconscious defense mechanism that sprang into motion as a way to enable the patient to avoid the direct articulation of painful memories. Yet, Freud took "what first appeared as an obstacle to treatment and transform[ed] it into a means of achieving progress. The interpretation of resistance became his essential analytic tool in the gradual unveiling of unconscious motivation" (Bernheimer \& Kahane, 1985, p. 9).

Freud postulated a dynamic view of the self. At its heart was an understanding that the self drove toward unity, even though it was frequently 
operating within the context of "forces which seek to break the self apart" (Gabriel, 1999, p. 15). Using a tripartite schemata, Freud described three aspects of the self-the id or instinctual domain, the ego or reality principle, and the super-ego or conscience.

Freud gave the name ego to the region of the mind that he believed acted as an intermediary between the id and the external world. "The ego, then, is the mental agency specifically responsible for the sense of unity and integrity, which we each experience as 'self' " (Gabriel, 1999, p. 17). A major contribution of Freud to our understanding of the self is his assertion that a self is something achieved rather than given (Gabriel, 1999, p. 15).

Freud's psychotherapy work was conducted with individuals rather than groups. Not surprisingly, therefore, there are disagreements about the "father of psychiatry's" direct contributions to, and influence on, group theory. Indeed, there has been no more lively disagreement about the nature and scope of early theorist's work on the development of the field of group dynamics than the debate about Freud's influence. Freud's biographer Ernest Jones (1955) claimed that Freud's work represented the "first example of group analysis" (p. 55) when he discussed dreams with his fellow psychoanalysts while enroute to the United States to give a lecture in 1909. Anthony (1972) made a similar claim, "In 1921, Freud first outlined a group psychology that was and still is meaningful to the group psychotherapist" (p. 4). The reference here is to Freud's 1921 book, Group Psychology and the Analysis of the Ego. 
Interestingly, even Wilfred Bion, the acknowledged "father of group relations," observed, "Using his psycho-analytic experiences Freud attempted to illuminate some of the obscurities revealed by Le Bon, McDougall, and others in their studies of the human group" (Bion, 1957, p. 440). Yet Rosenbaum (1976) adamantly disagreed with these claims, observing that Freud focused on individual psychotherapy for more affluent patients and was specifically not a group psychotherapist. Rosenbaum contended that although freud may have outlined a concept of group psychology in 1921, Freud rarely spoke of a group larger than two except in his references to the work of Le Bon, a sociologist whose work will be discussed later in this chapter.

It is interesting to note that in Group Psychology and the Analysis of the Ego, Freud spent 13 of the book's 75 pages quoting and paraphrasing the work of Le Bon. Yet, Freud (1959) dismissed Le Bon with the following comment: None of that author's [Le Bon] statements bring forward anything new. Everything that he says to the detriment and depreciation of the manifestations of the group mind had already been said by others before him with equal distinctness and equal hostility, and has been repeated in unison by thinkers, statesmen and writers since the earliest periods of literature. (p. 14)

Freud's obvious inconsistency, and apparent frustration with emerging theories of group psychology and group therapy techniques, such as those found in the writings of Le Bon, might better be understood by considering an observation by 
Rosenbaum (1976). Rosenbaum postulated that although some writers claimed Freud as a group psychotherapist because he held weekly meetings with his followers between 1900 and 1910, "it is possible that Freud's interest in the group was soured by his own problems leading his group of prima donnas" ( $p$. 4).

Although authors of books on group relations may dispute the extent of Freud's influence on group dynamics theory, no one can discount Freud's contributions to psychoanalytic philosophies in general. Furthermore, in his writings, Freud raised significant questions---"What, then, is a group? How does it acquire the capacity for exercising such decisive influence over the mental life of the individual? And what is the nature of the mental change which it forces upon the individual?" (Freud, 1959, p. 4). These questions are at the heart of group relations theory and, even today, remain open and debatable.

In addition to raising these questions, Freud's revolutionary discovery of the unconscious and his recognition that it operated, in part, as a defense mechanism activated to repress threatening ideas, remains an essential concept in understanding group life (and a key element of the Tavistock model which will be discussed in depth in chapter four). Group relations theorists and practitioners used the mobilization of free associations expressed by individuals within a group as a way to explore the defenses that were alive in the group. Instead of examining recollections of emotional distress surrounding individual's neurotic symptoms, as Freud did, group relations practitioners took the "apparently 
wandering thoughts" expressed about organizations by people in groups as their field of focus (Armstrong, 1997).

Klein. Melanie Klein was also a psychoanalyst and, in the early 1900 s, a faithful follower of Freud. While Klein is not known as a group relations theorist per se, her work is credited for laying the theoretical foundation for much of the group relations theories. Her theories about defense mechanisms and her development of object relations theory were extremely influential in the earty days of the group relations movement. Gabriel (1999), for instance, has noted that "Klein's theories outlining the basic mechanisms of splitting and projective identification have provided, for several group theorists, the link between the individual unconscious experience and an experience that is 'shared' at the group level" (p. 118).

Klein's object relations theory, which both built upon and departed from the work of Freud, elaborated on the complex ways that our early connections to objects in the world continue to affect us throughout our lives. Gabriel (1999) noted:

In Klein's view, young children relate to their world through phantasy [sic]; when their emotional state is happy and contented, they experience the world (and adults) as sustaining and nurturing. When they are distressed and angry, they can experience the world as attacking and dangerous. (p. 118) 
Klein proposed that people learn from a very early age ways to cope with these unpleasant emotions, and the resultant confusion and anxiety they create, by using two predominant psychological defenses: splitting and projective identification. For example, Klein theorized that in order for the infant to reconcile the confusion between the nurturing and satisfying breast/mother and the frustrating and withholding breast/mother--the infant splits the breast/mother into two separate beings, or objects. one object is nurturing and good; the other object is frustrating and bad. In a similar manner, infants also learn psychological ways to distance themselves from these negative and destructive emotions by disowning their uncomfortable feelings and projecting them onto someone else (Gabriel, 1999).

Although Klein's work predominantly focused on children, her observations that people split objects into good and bad parts and disown uncomfortable feelings through projection were later applied to adults and their behaviors by group theorists, in particular the acknowledged "father of group relations" Wilfred Bion. Applying Klein's theories, Bion argued that when adults first join a group, the experience often elicits some of the same conflicting emotions that Klein indicated children experience: a desire to fuse with the group/mother yet a fear of losing one's individuality/feeling smothered. These primitive feelings influence the way that people operate in organizations and groups as well as affect their relationships to leaders and co-workers. Thus one of the major contributions of object relations theory to group relations work has been its shift 
in focus away from Freud's "world of instincts, sexuality and pleasure, towards the modes of relating to others" (Gabriel, 1999, p. 23).

As noted, one of the vehicles for transporting Klein's thinking to the group domain was her analysand, Bion. In 1957, in fact, Bion wrote, "I must make it clear, for the better understanding of what I say, that even where I do not make specific acknowledgement of the fact, Melanie Klein's work occupies a central position in my view" (p. 220). Bion's theories will be discussed in more detail later in this chapter; first, however, influences of other traditions on the group relations movement will be discussed.

\section{The Influence of Other Traditions}

Pratt. Although Bion is normally credited with being the "father of group relations," others, including scholars and practitioners from outside the field of psychoanalysis, experimented with group psychotherapy and theorized about the nature of groups prior to Bion making his contributions. The most direct historical connection to group psychotherapy is the work of Joseph Pratt in 1905 (Rosenbaum, 1976). In the early twentieth century, Pratt, a physician living and working in the Boston area, began treating tuberculosis patients. He observed that meeting weekly with a group of 25 patients instilled in them a spirit of camaraderie and hope for the future and contributed positively to their recovery efforts. Pratt called his method emotional reeducation and persuasion, but his success was considered by the medical community to be more a matter of his charismatic personality than a replicable scientific technique (Rosenbaum, 1976). 
Le Bon and MCDougall. In addition to Pratt's early influences from the field of medicine, the emerging field of sociology also contributed insights to the intellectual development of group relations theory. In 1896, French sociologist Gustave Le Bon published his now renowned observations about large, unorganized groups that he called a crowd.

Given the amount of space Freud (1959) devoted to criticizing Le Bon's theories in Group Psychology and the Analysis of the Ego, Le Bon's work must have been taken more seriously by the psychoanalytic tradition then was the work of Pratt. Le Bon theorized that a person sacrifices a part of his or her individuality when joining a group, especially a large group, and becomes more easily influenced and susceptible to suggestion. Le Bon described the ability of a charismatic leader to sway a crowd by playing on the crowd's child-like credulity and un-tethered emotions. He observed that the group mind was illogical, intolerant, prejudiced, rigid, uninhibited, and submissive to any dominant force that exerted its authority. According to Le Bon (1896), "An individual in a crowd is a grain of sand amid other grains of sand, which the wind stirs up at will" ( $p$. 33).

Although Le Bon's work was frequently cited within the psychoanalytic tradition, not everyone agreed with his theories about groups. As noted above, Freud deprecated Le Bon's observations. For instance, Freud wrote, "This detrimental and deprecatory appraisal of the group mind reflects the contempt with which certain thinkers view the masses" (cited in Anthony, 1972, p. 3). 
Kraskovic also criticized Le Bon's theories for being overly negative, arguing, "The group contained within itself the seeds of both success and failure" (Anthony, 1972, p. 3).

Despite these criticisms, in 1920, William McDougall expanded upon Le Bon's work and developed important insights that helped lay the intellectual foundation for group relations theories and the Tavistock tradition. Like Le Bon, McDougall (1920) believed that unorganized groups are emotional, impulsive, violent, and suggestible and, at times, act almost like a wild beast. McDougall added, however, that when a group is organized and task-oriented, a mental shift occurred along with a marked change in group behavior. This shift caused an intensification of emotion in each individual group member that was seldom attained under any other conditions. This intensified emotion could be harnessed effectively for positive group achievement (Anthony, 1972; McDougall, 1920).

Bion

As noted earlier, Bion is widely regarded as the "father of the group relations movement." His interpretation of Klein's theories of individual behavior, and his application of those interpretations to groups, proved to be pivotal to the development of the field of group relations. Although Bion was not very involved in the application of his theories via group relations conferences and eventually abandoned the study of groups later in his life to return to his work in individual psychoanalysis, the theoretical grounding Bion provided to the group relations movement cannot go unrecognized. 
Although his nationality was British, Bion was born in India in 1897 to a family that had served there as missionaries, had been employed as Indian policemen, and occupied other positions in the Department of Public Works for generations. His father was an irrigation engineer whose specialty was building dams. As was the custom at the time, Bion was sent to England for schooling at the age of eight; he never returned to India again.

Prior to his eighteenth birthday, Bion joined the Tank Corps and served with distinction as a Tank Officer in France in World War I. This front-line battle experience proved to be invaluable to him, and British army psychiatry, when he helped shape army psychiatry's development of treatment for traumatized soldiers in World War II (F. Bion, 1982).

After World War I, Bion read history at the Queen's College in Oxford. A man of large stature, he was also active in athletics, excelling as Captain of the swimming and water polo teams and leader of the rugby scrum. After Oxford, he took a position as a schoolmaster for two years (Pines, 1985, p. 387). Yet, "by 1924 it was dear to him where his interest lay-in psychoanalysis" (F. Bion, 1982, p. 6). Bion began medical training at University College Hospital in London and then became a trained psychoanalyst, making critical contributions to the field of psychiatry in the 1930 s (F. Bion, 1982; Pines, 1985; Talamo, Borgogno, and Mercai, 1997; Talamo, et. al., 2000).

Even after the war, "when World War II and its aftermath in the period of peace and reconstruction were the preoccupation of us all, Wilfred Bion came 
forward with a number of ideas which changed the face of social psychiatry" (Trist, 1985, p. 1). Responding to the great demand for treatment by soldiers returning from war, Bion pioneered the use of small study groups, rather than individual counseling sessions, to treat his patients at the Tavistock Cinic, the details of which will be discussed in chapter four.

In 1948, Bion was asked to take therapeutic groups, a colloquialism for employing the group techniques he had honed through his experiences in World War II (Trist, 1985). While working with this small group of patients in the adult department of the Tavistock Clinic in London, Bion decided to provide the group with no direction and no structure in order to assess the group's reaction. Rosenbaum (1976) observed that the reason for this abrupt break from traditional methods was twofold: "First, he wasn't sure what he was doing so he decided to remain silent. Second, he is a rather withdrawn individual" (Rosenbuam, 1976, p. 27). As a result of Bion's silence, the patients were puzzled, upset, and angry and responded in a variety of ways. Bion's unique contribution was that he interpreted these reactions not as the behavior of individual group members, but as the group's dynamic.

Eventually what may have started as a response to uncertainty and/or a reflection of Bion's personality was transformed into therapeutic technique central to the Tavistock tradition. Trist (1985) wrote the following observation of Bion's methods for taking groups: 
Several features characterized Bion's group 'style'. He was detached yet warm, utterly imperturbable and inexhaustibly patient. He gave rise to feelings of immense security - his Rock of Gibraltar quality. But the Rock of Gibraltar is also powerful and he exuded power (he was also a very large man). (p. 30)

In Kleinian terms, Bion seemed to be inviting, whether consciously or not, the group's projective identification with him. That is, he made himself available for the group to disown their uncomfortable feelings and project them onto him as a means for understanding the group's unconscious behavior (Gabriel, 1999). As Trist (1985) put it, "He made it safe for the group to dramatize its unconscious situation" (p. 31).

As this example suggests-and as noted above-Bion's methods were heavily influenced by the theories of Melanie Klein especially her ideas about basic defense mechanisms, such as splitting and projective identification. These theories proved to be the link Bion needed to join theories describing the individual's unconscious experience with those he was developing to represent experiences of group membership (Gabriel, 1999). Bion extended Klein's theories by exploring how group membership often evoked some of the very same contradictory feelings as those experienced during childhood in response to the mother. Through Bion's lens, Klein's object relations theory explained how experiences in groups trigger "primitive phantasies [sic] whose origins lie in the earliest years of life" (Gabriel, 1999, p. 118). For example, one unconscious 
desire is for the individual to join with others in an undifferentiated entity, like the infant fusing with the breast. While comforting, this desire also creates resultant opposing fears, such as the fear of becoming overwhelmed or consumed by the undifferentiated mass of the group or the fear might be of being rejected or abandoned by the group (Gabriel, 1999).

In his articles, Bion outlined his theories of group behavior based largely on observations made while working with small groups over the years. He hypothesized that groups have two modes of operation. One mode he called the productive "sophisticated group," more commonly called a "work group," (Bion, 1961, p. 98). The work group focuses intently on the group's task and maintains close contact with reality. The other mode of group operation Bion called basic assumption. Its primary task is to ease the group's anxieties and avoid the pain or emotions that further work might bring. As an example, Bion identified three types of basic assumption modes: basic assumption of dependence (baD), basic assumption of pairing (baP), and basic assumption of fight-fight (baF) (Bion, 1961, p. 105). When a group is operating in the basic assumption mode of dependency, one person is always felt to be in a position to supply the needs of the group, and the rest in a position to which their needs are supplied...having thrown all their cares on the leader, they sit back and wait for him to solve all their problems...the dependent group soon shows that an integral 
part of its structure is a belief in the omniscience and omnipotence of some one member of the group. (Bion, 1961, p. 74, 82, 99). The group assumes this "leader," whether selected formally or informally, is to have clairvoyance of thought and supernatural powers and that the rest of the group is powerless and dependent. When the leader fails to meet the group's unrealistic expectations, as he or she inevitably does, the group becomes quickly frustrated and disappointedly "selects" another member for the daunting task. This leader will also fail eventually, of course (Bion, 1961; Gabriel, 1999).

The basic assumption mode of pairing is evident in a group when it invests irrational hopefulness for the future in two of the group members. Regardless of gender, the group assumes that these two individuals have paired either for a "sexual" experience, which would provide the birth of a new group, a religious experience, which would provide a messiah, or a reparative experience, which would produce world peace (Bion, 1961; Gabriel, 1999).

When a group is operating in the basic assumption mode of fight-flight, Bion (1961) wrote,

the group seems to know only two techniques of self-preservation, fight or flight...the kind of leadership that is recognized as appropriate is the leadership of the man who mobilizes the group to attack somebody, or alternatively to lead it in flight...leaders who neither fight nor run away are not easily understood. (p. 63, 65) 
In 1961, Bion published his influential book, Experiences in Groups which was a compilation of his series of articles printed separately over the years in different journals such as the Tavistock Institute of Human Relations' (Tavistock Institute) journal, Human Relations. Since then, his ideas about groups have had a widespread impact in many different fields from social psychology and sociology to organizational development and leadership studies. Pine (1985) observed:

Experiences in Groups is probably the shortest and most influential text in psychoanalytic group psychotherapy. Whether you agree or disagree with Bion, ignore him you cannot for he looms up at you from the darkness of the deepest areas of human experience, illuminating it with his 'beams of darkness.' (p. xi)

Similarly, Miller (1998) observed, "Bion's theory has generated a voluminous literature, mainly in the field of psychoanalysis, group psychotherapy, and group dynamics" (p. 1498).

Yet, Bion's (1961) thinking also has had its share of critics. Some writers, such as Gould, (1997) Stokes, (1994) and Slater, (1966) challenged Bion's view that groups are either in work mode or basic assumption mode, forever in a pendulum-like swing between the two, and that basic assumptions are always debilitating to the group's task (Gabriel, 1999). For example, Gabriel (1999) noted that, in contrast to Bion's notion that groups are forever locked into repetitive basic assumption defenses, Slater proposed that groups can "change 
over time in predictable ways as group members gradually substitute conscious bonds for the unconscious links that dominate group life in the early stages" ( $p$. 125).

Gould argued that basic assumptions are not always debilitating to the group's task and can sometimes be engaged with for a productive purpose. For example, he wrote that the defense mechanism fight/flight "can act as the basis of sensitivity to dangers and threats as well as the force for loyalty, commitment and self-sacrifice" (Gabriel, 1999, p. 124). Gould also proposed that a dependency relationship could also be viewed as a mentoring relationship or a way to leam from an authority figure (Gabriel, 1999).

Higgin and Bridger (1965) also took issue with some of Bion's theories. They wrote: "Whether he intends it or not, this later work suggests that Bion considers that, at any one time, the members of a group are alike in their shared absorption in one or other of the group processes" (p. 2). Instead, these authors hypothesized that members of a group can be in different modes of group process, some in work group mode and some in a basic assumption mode, at any one time. Higgin and Bridger (1965) wrote:

In achieving a goal a group not only needs to do work at the conscious sophisticated level required to achieve its task; it also needs to do work of an emotional, less conscious sophisticated kind, to contain or appropriately direct the basic assumptions arising from the anxieties which it will inevitably face. (p. 2) 
Despite these different assessments of Bion's work, a number of theoreticians followed Bion's lead and continued to apply his theories to working with groups. Rice, Miller, and other social scientists affiliated with the Tavistock Institute carried Bion's theories about covert group dynamics, such as unconscious defense mechanisms, into their continued exploration of how best to understand organizations. These theorists amalgamated Bion's group-oriented psychoanalytic work with open systems theory, an intellectual tradition that was becoming highly influential in a number of social science fields.

\section{The Tradition of Open Systems Theory}

From the early 1950 s onward, the work of the Tavistock Institute was heavily influenced by what was then a new tradition called open systems theory. Miller (1993) recalled that "Systemic thinking was not, of course, novel," (p. 8) even in the human relations field, and noted the influence of other research, such as that of American Kurt Lewin as well as some early Tavistock Institute studies of coal mining and textile mills. This early research led to the development of the concept of the socio-technical system. The socio-technical system provided a way to optimize both human elements and technological imperatives within organizations without subverting either. Miller (1993) wrote:

The concept of socio-technical system, therefore, opened up possibilities of jointly optimizing the two types of variables and thus organizational choice. But its immediate application was at the level of the primary work group rather than the wider organization. The notion of the open system 
made it possible to look simultaneousty both at the relationships between the part and the whole, the whole and the environment [italics added]...between individual and group, individual and enterprise. (p. 8) In other words, open systems theory built upon, yet expanded, the premise of the socio-technical system in ways that permitted an understanding of the operation of the organization's internal dynamics and its interaction with its external environment. The remainder of this section will detail two elements of open systems theory that were especially important to the burgeoning Tavistock tradition: boundary management and the primary task. The integration of both of these organizational ideas with thinking from the psychoanalytic tradition will be highlighted.

Extending the Concept of Boundaries. Open Systems theory is the study of movement across organizational boundaries. The concept of boundary was also used in psychoanalysis. In psychoanalysis, the boundary concept referred both to the separation between the individual and the external world, and to the division within the self between the ego, id, and super-ego. Systems theory extended the concept of boundary to organizational studies (Gabriel, 1999, p. 97-98).

As Rice (1965) described it, the classic model of an organization is one of a closed system, a mechanically self sufficient organization neither importing nor exporting across the boundaries of the organization. Rice noted, "Open systems, in contrast, exist and can only exist by the exchange of materials with their 
environment...the process of importing, converting, and exporting materials is the work the system has to do to live" (cited in Miller, 1993, p. 10).

Miller (1993) provided examples to illustrate Rice's point:

Thus a manufacturing company coverts raw materials into saleable products (and waste), a college converts freshmen into graduates (and drop-outs) and there are the other resources that are required to bring about the processing: the production workers, the teachers, the machinery, the supplies, etc. The boundary across which these materials flow in and out both separates the enterprise from and links it with its environment. (p. 11)

This permeable boundary region came to be viewed by open system theorists as a critical area for the exercise of leadership. If the boundary is too loose, it is possible that the outside environment can become too influential and disruptive to the internal work of the organization. But if the boundary is too rigid, the internal organization can stagnate and become inflexible to market or environmental changes. Miller (1993) wrote, "Survival is therefore contingent on an appropriate degree of insulation and permeability in the boundary region" ( $p$. 11).

As was indicated earlier, the idea of boundary management has also been applied to thinking about an individual's boundary management. Both Miller (1993) and Rice (1965) incorporated Freud and Klein's theories into their own thinking by equating the ego function in individuals with the boundary region. 
Rice (1965) described this notion as follows: "In the mature individual, the ego-the concept of the self as a unique individual--mediates the relationships between the internal world of good and bad objects and the external world of reality, and thus takes, in relations to the personality, a 'leadership' role" (p. 11). There are other unconscious influences involved as well--what Klein (1946) called objects. As discussed previously, these unconscious factors largely result from earty childhood experiences. Miller (1993) wrote:

Thus the individual, when he engages in adult life with, for example, a new boss, will not simply respond in a rational way to what the boss actually says and does, but he will bring forward, from his internal repertoire of objects and part-objects, his experience of earlier authority figures including mother and father. (p. 16)

Therefore, when one is involved in organizational or group life, one is influenced both by the external environment of the work setting, as well as by one's own internal environment that is largely a product of previous work and childhood experiences. In Rice's (1965) words, "The mature ego is one that can define the boundary between what is inside and what is outside, and can control the transactions between the one and the other" (p. 11). However, the group can also evoke more primitive feelings in the individual, such as those "in the areas of dependency aggression and hope. The individual is usually unaware of this process: these basic emotions slip under the guard, as it were, of his ego function" (Miller, 1993, p. 19). 
Yet, even though these primitive feelings and defenses might go undetected by the individual, they often have an impact on the group and are sensed by others within the organization. According to Rice (1965), "The tendency for most human beings to split the good from the bad in themselves and to project their resultant feelings upon others is one of the major barriers to the understanding and control of behaviour [sic]" (p. 11). When people come together in groups, individuals' primitive feelings and defenses can get mobilized on behalf of, and in service to, the group and the bad feelings are often the split off and projected onto authority figures, whose task it is to regulate the boundary region. In order to study people's struggles with these types of authority issues, the Tavistock Institute developed group relations conferences in the late 1950s. In this way they created an experiential learning method that linked psychoanalytic theory with the notion of open systems theory that was developed in the social sciences. These concepts will be explored in more detail later in this dissertation.

Redefining the Notion of a Group's Task. A second result of the amalgamation of open systems theory with psychoanalytic theory was an expanded definition of Bion's notion of a group's task. As discussed previously, Bion postulated that a group can be understood to potentially operate at two levels: the work group level, which is oriented towards overt task completion, and the basic assumption level which sometimes supports, but more often hinders, the overt task by acting out one of three possible defenses (Bion, 1961; 
Gabriel, 1999; Miller, 1993). Rice (1965) used open systems theory and its notion of external influences to reconceptualize the notion of the group's task. Rice (1965) called the task that an organization or group "must perform if it is to survive" (p. 17) the group's primary task.

Yet, Rice's definition of primary task is nuanced. His appreciation of the contextual factors constraining any organization's performance included an implicit recognition of the importance of examining an organization in its full environmental context, to include historical and social influences. Rice recognized how important the contextual factors constraining an organization's performance were to an assessment of that organizations ability to survive.

In Learning for Leadership, Rice (1965) acknowledged the complex set of tasks that most "enterprises" must perform simultaneously. Yet he argued that, in most cases, one task above all was the critical one an organization needed to perform if it was to continue to be the organization it claimed to be. Thus, he wrote, "The overall primary task of industrial enterprises is to make profits; that of educational institutions is to provide opportunities for learning; and therapeutic institutions must cure at least some of their sick" (Rice, 1965, p. 17).

Rice recognized that primary tasks differed depending on organizational contexts and that a variety of constraints operated to limit task performance. For instance, although all educational institutions must provide opportunities for learning, the decisions to teach, or not to teach, specific subjects or to reach particular audiences constrains the performance of any educational institution's 
"primary task" (Rice, 1965, p. 18). In addition to the way that such necessary decisions to limit the scope of one's primary task constrain an organizations performance, Rice further argued that "the environment in which [primary tasks] are performed also imposes constraints on what can be done and how it can be done" (p. 18). These environmental constraints included such factors as the political, economic, legal, and social contexts within which an organization operates, as well as "the human and physical, scientific and technological resources available for performance" (Rice, 1965, p. 18).

Summary. Thus Rice and others within the group relations movement in general, and the Tavistock Institute in particular, used open systems theory to look beyond a group for factors that influence the group's behavior. Rice (1965) made this point nicely when he wrote:

Groups of all sizes, as well as individuals, develop their own 'identities,' and behave at both conscious and unconscious levels. Attitudes and beliefs of groups about themselves, and about others outside, are determined not only by the rationale discussions and decisions taken within the group but also by the unconscious beliefs and assumptions on which the group works. Hence the behavior of any group is determined not only by what its members bring to it but also by the culture they develop in the group and the interaction of this culture with their previous expectations. (p. 16-17) 
As we will see later in this dissertation, institutions within the group relations movement itself were influenced not only by the culture they developed in the group, but by a variety of environmental and resource factors as well. Some of these influences enhanced and some limited the institution's ability to perform its primary task.

Systems Psychodynamic: Naming an Emerging Tradition

As the concepts of open system, primary task, and boundary management were amalgamated with concepts from the psychoanalytic tradition, an interdisciplinary field began to emerge largely based on the pioneering work of the Tavistock Institute in the 1950 s and 1960s. This burgeoning field was referred to as systems psychodynamics, a construct that was explicated in 1967 by Miller and Rice in their book Systems of Organizations. Gould (2001) wrote, "It was not until this volume was published that [these ideas] were put into a systematic framework that could rightly be called an interdisciplinary field which attempted to integrate the emerging insights of group relations theory, psychoanalysis, and open systems theory" (p. 2).

The thrust of system psychodynamics theory is that people create institutions to satisfy many needs, some of which are overt and oriented towards task accomplishment while others are covert, primal and defensive. Yet, all of these needs are potentially present within all groups of people and must be considered when working with organizations. Gould (2001) wrote: 
The systems psychodynamic framework is specifically intended to convey the notion that the observable and structural features of an organizationeven quite rational and functional ones-continually interact with its members at all levels in a manner that stimulates particular patterns of individual and group dynamic processes. (p. 3)

As noted earlier, some of the individual and group dynamic processes that get stimulated are productive and help to accomplish the organization's work. Other processes are counterproductive to the primary task of the organization and often subvert the accomplishment of the organization's task by stimulating individual and group unconscious anxieties and defenses. Gould (2001), for example, noted:

Major organizational change efforts pose great psychic challenges to their members and require, in response, distinctive conditions in order to adequately contain the profound anxieties evoked by such upheavals; and further, if these conditions are absent, efforts to change are likely to fail. (p. 12)

Here the systems psychodynamic perspective has been treated as a set of theoretical ideas that provided the intellectual grounding for further application of group relations methods. It must be remembered, however, that this intellectual foundation was not created prior to the application work conducted by the Tavistock Institute. Rather, the relationship between theory and practice in the field of group relations was symbiotic. Rice (1965) made this point clearly: 
In recent years there has been increasing understanding of the behaviur [sic] of individuals and of groups. But knowing about group processes and human behavior does not necessarily mean that use can be made of the knowledge and understanding. More over, knowledge, let alone its effective use, cannot generally be gained from reading, lectures, or seminars. Both the acquisition of knowledge and learning how to use it required direct experience. (p. 6)

Therefore, in order to gain direct experience, an experiential learning model was developed for studying and implementing systems psychodynamics and became known as the Tavistock model. The next chapter presents a detailed explication of this model and how it developed in Great Britain in the post-war period. 
Chapter III: The Emergence of the Group Relations Movement in the United Kingdom

\section{The Infiuence of War}

The impact of the war against Hitler was especially pronounced in Great Britain. In England, post-war changes in cultural assumptions and social values were just as influential in the development of the Tavistock Institute of Human Relations (Tavistock Institute) and its group relations model as were the evolving theories outlined in the previous chapter. World War II was the cataclysmic event that stimulated most of these changes. The historian Hennessy (1999) noted:

However many generations of historians in the future rearrange the particles of the years 1939-1945, none of them, without gross distortion, can deny the absolutely pivotal role of Britain in the twelve months from the fall of France to Hider's invasion of the Soviet Union. If Britain hadn't stood alone and had gone down at any point in that year, it's difficult to see how the Nazis could have been prevented from dominating Europe for generations to come. With existing levels of air, naval and military technology, it would have been impossible in the early 1940 s even for the 
mighty United States to have mounted a successful attack on Hitler's 'Fortress Europe' from across the Atlantic Ocean. (p. 27)

The effects of this war were felt in England in many ways. For example, nearly everything was rationed in the United Kingdom and continued to be well after the war was over. Rationing provided a stark awakening to the different privileges associated with class distinctions. Ironically, for many English of the underclass, this highly rationed diet was a great improvement over what they had been subsisting on prior to the war.

The war influenced Great Britain in many other ways as well. For example, a shortage of labor blurred previous social taboos about what constituted women's and men's work. Also, the evacuation of millions of children away from the dangerous manufacturing centers, and therefore their families, to safer locations in the English countryside, often resulted in prolonged family separations. Hennessy (1993) noted the following:

By the time peace came, the abrasions of war had scoured every avenue of life, every channel of activity in Britain. New assumptions gleamed where old certainties had been whisked away under the pressure and motion uniquely applied by total war. Everything--the parameters of politics, the organization of industry, the place of labour [sic], the status of women, the philosophy of economics, the power and reach of the State--had altered visibly. (p. 10) 
The changes alluded to above set the stage for the development of the Tavistock Institute and its group relations model in at least three ways. First, the development of the Tavistock Institute can be seen, at least in part, as an attempt to help heal the psychic wounds that Hitler and his war created within Great Britain. In other words, the Tavistock Institute and its group relations model was one manifestation of what Krantz (1993) described as the great hope and expectation that the social sciences would be instrumental in re-building a superior post-war social order...Along with this was a hope that social science might do something about the terrible wickedness and human destructiveness that had been exposed for all to see during the War. (p. 239-240)

Neuman, Holvino, and Braxton (2000) made this point even more precisely. They noted that the group relations movement in Great Britain, like the group relations movement in the United States, was "developed as part of post-WWII social movements to introduce more democracy and less alienation into workplaces and other social systems" (p. 1).

Second, England responded to its increased awareness about class inequities with more state supported programs in the post-war period. It was from this stress-filled era in British history that the Tavistock Institute and its Tavistock model emerged, in part, to fill this niche by helping the British people to address post-war anxieties about social changes engendered by a new awareness of inequality. 
Third, the World Wars helped establish the importance of psychotherapy, in general, and group therapy in particular. Prior to World War I, any instability exhibited by a soldier was classified as cowardice, malingering, a failure of will, or a character flaw--not symptoms of a mental illness-- and was often punishable by denial of leave, imprisonment, electric shocks, or even death (Hale, 1995; Harrison, 2000). World War I ushered in a period of more humane thinking and this new way of thinking-and acting-was more fully developed during and immediately after World War II.

Operationally, more humane ways of thinking and acting took the form of psychotherapeutic treatment, especially in group settings. This work, in turn, represented one of the most concrete examples of how the war years influenced developments in the group relations movement in the United Kingdom. The discussion now examines psychotherapeutic work in the United Kingdom during the war and post-war years and then moves on to the history of the Tavistock Clinic, the development of the Tavistock Institute, and the emergence of the Tavistock model of group relations within the Tavistock Institute setting.

The Development of Group Therapy during the War and Post-War Years

World War I necessitated the development of ways to treat large numbers of traumatized, so-called shell-shocked, soldiers. During World War II, researchers concluded that it was neither fear nor the physical conditions of war that wes the greatest cause of battlefield breakdowns; rather, it was exhaustion. Military studies showed that "all soldiers in the front line were under intense 
emotional stress and would break down sooner or later" (Harrison, 2000, p. 123). Furthermore, the sheer number of shell-shocked soldiers that had to be treated during, and also after, World War II required that therapists move beyond an individual treatment model. Thus, World War II contributed further to the development of group psychotherapy through the innovation and use of therapeutic communities, and expanded this method to include application to civilians, as well as soldiers, in the post-war period. The Tavistock group relations model, in fact, grew out of experiments with psychotherapeutic techniques conducted both during and after the world wars.

The Tavistock group as an invisible college during the war years. During World War II a group of individuals, formerly employed at the Tavistock Clinic before the war, was making its impact on army psychiatry. Referred to as the Tavistock group or the invisible college, this group included Wilfred Bion and John Rickman, as well as Harold Bridger, Tom Main, Eric Trist, Tommy Wilson, John Bowlby, Ron Hargreaves, and John Sutherland, among others. Although these men were not all dinicians, they were all interested in psychoanalysis and shared many of the same philosophies about working with groups. This invisible college stayed in close communication throughout the war, and after the war many of them returned to their former employer, the Tavistock Clinic in London, and helped establish a subsidiary, the Tavistock Institute in 1946 (Harrison, 2000; Trist, 1985). As we will see later in this chapter, much of the Institute's 
post-war work was based on the experimentation that this interdisciplinary group conducted during these war years.

\section{The Northfield Experiments}

Some of the most significant experimentation in group psychotherapy has often been credited to treatment conducted at the Northfield Hospital during World War II. This story really begins between the World Wars when a number of individuals simultaneously were wrestling with similar concepts about group treatment. The premise was that it was possible to employ the entire hospital environment as a therapeutically engaged social field useful in the treatment of patients (Trist, 1985). Yet it was Bion, working under the guidance of Rickman at the Wharncliffe Hospital in Shetfield between 1938 and 1939, who actually prepared a document known as the Wharncliffe Memorandum which outtined this thinking. Trist (1985) noted the following about the Wharncliffe Memorandum: "This document contained a prospectus for a therapeutic community. In the sense of making systematic use of the happenings and relationships in a hospital, it was the first time the concept had been formulated" (p. 6). The events that transpired next had widespread impact on the field of psychiatry both during, and after, the war and set the stage for the development of a new field called group relations.

Traditionalists both within the medical communities and outside of it were resistant to the idea of thinking of hospitals as therapeutic communities. In 1939, however, war broke out once again; a new war and a new cadre of shell-shocked 
soldiers necessitated innovative leadership in treatment. This need provided an opportunity to implement the ideas in the Wharncliffe Memorandum.

The First Northfield Experiment. Early in 1942, Rickman was commissioned as a Major in the British Army's Psychiatric Division. In July he took over psychiatry at the Northfield Military Hospital, a psychiatric institute. Bion joined Rickman in late 1942 and took charge of the Military Training and Rehabilitation Wing that housed between one hundred and two hundred men, roughly half the soldiers receiving care at Northfield at any one time (Harrison, 2000; Trist 1985). Trist (1985) recalled the following:

Northfield was a large military psychiatric hospital which functioned as a clearing house. According to a man's condition, he would be discharged from the army, return to his unit or found alternative military employment. The need for manpower was at its height. Any method was welcome which would encourage a body of disaffected men displaying a bewildering variety of symptoms in different degrees of acuteness, to reengage with the role of being a soldier in an army at war. Methods so far tried had yielded poor results. (p. 14)

Bion seized the opportunity to put ideas he had outlined in the Wharncliffe Memorandum into practice by operationalizing his concept of the therapeutic community at Northfield. Commonly referred to as the First Northfield Experiment, Bion and Rickman developed the notion of a therapeutic community by shifting the focus from individual treatment to that of group process, 
leadership concepts, and social obligation. Paramount was the notion that the group analyze its own dynamics rather than wait for outside direction (Harrison, 2000; Trist 1985). Bion outlined his ideas about this First Northfield Experiment in a memo:

Throughout the whole experiment certain basic principles, believed to be absolutely essential, were observed. In order of their importance they are set down here...

1. The objective of the wing was the study of its own internal tensions, in a real life situation, with a view to laying bare the influence of neurotic behavior in producing frustration, waste of energy, and unhappiness in a group.

2. No problem was tackled until its nature and extent had become clear at least to the greater part of the group.

3. The remedy for any problem thus classified was only applied when the remedy itself had been scrutinized and understood by the group.

4. Study of the problem of intra-group tension never ceased-the day consisted of 24 hours.

5. It was more important that the method should be grasped, and its rationale, that some solution of a problem of the Wing should be achieved for all time. It was not our object to produce an ideal training wing. It was our object to send men out with at least some understanding of the 
nature of intra-group tensions and, if possible, with some idea of how to set about harmonizing them.

6. As in all group activities the study had to commend itself to the majority of the group as worth while and for this reason it had to be the study of a real life situation. (cited in Trist, 1985, p. 15-16)

Even as Bion and Rickman began to enjoy some success with their new experiment at Northfield, their progressive and experimental group theories and methods disturbed the rest of the organization. Their new philosophies challenged traditional medical models and, as a result, created a great deal of animosity among the other psychiatrists on staff. In addition, the commanding officer of the Northfield hospital at the time, Lieutenant Colonel J.D.W. Pearce, was known to be a rigid thinker and "a terribly conventional little man" (Harrison, 2000, p. 191). The opposition that Bion and Rickman had predicted might occur, back when the Wharncliffe Memorandum was first created, came to an ugly fruition only six weeks after the start of the First Northfield Experiment.

The demise of the First Northfield Experiment. What actually caused the demise of the First Northfield Experiment is less than clear and the facts are difficult to determine. Trist (1985) recalled that Bion, who was the messing officer in addition to his other duties, detected an inaccuracy within the officer's mess account and concluded that a person of high rank would be implicated. Rather than chance a scandal that might reflect badly on army psychiatry, 
superiors unceremoniously ordered Bion and Rickman back to the War Office effectively terminating the First Northfield Experiment.

Harrison (2000) tells a somewhat different story. He claimed that it was Bion and Rickman's irreverent attitude towards the rest of the hospital staff, and the commanding officer in particular, that led to their removal. He claimed they displayed an insular and arrogant attitude towards their peers, and used a contemptuous approach in dealing with the bureaucracy of the hospital system and military administration. Harrison (2000) wrote, "It was with a sense of relief that the general body of psychiatrists saw them leave" (p. 191).

Trist (1985) contended that Bion was livid about what had occurred. Even though after Northfield, he had been "posted to a Board in Winchester where the other senior officers had been through World War I and held him in esteem and affection," (p. 17) Bion felt betrayed. He had even given serious thought to making the incident at Northfield public and face the consequences. But, eventually he dropped the matter. Trist (1985) recalled, Bion "had wanted to finish the Northfield; to demonstrate once and for all that the conventional concept of a military psychiatric center with all its medical paraphernalia was obsolete; and that there was an alternative" (p. 18). Fortunately, the work that was started by Bion and Rickman during those early years at Northfield did not go to waste.

The Second North Field Experiment. In 1944, Lieutenant Colonel Dennis Carroll became commanding officer at Northfield, heralding a new beginning. 
Unlike his predecessors, Lieutenant Colonel Carroll embraced a psychoanalytic approach to treatment at the hospital, having been influenced by the work of Anna Freud. The atmosphere with regard to group therapy began to change as other staff psychiatrists embraced this new philosophy towards treatment and the Second Northfield Experiment was born (Harrison, 2000). The Second Northfield Experiment differed from the first in that it "was concerned with reclassification, redevelopment and rehabilitation, but for those returning to civilian life as well as for those continuing in the Army and for other ranks rather than officers" (Trist, 1985, p. 21). In other words, the Second Northfield Experiment included soldiers of all ranks, not just officers, who either were returning to army duties or civilian life.

Although it may have seemed logical that Bion would have sought to return to Northfield to direct this project, when asked, he was insistent that the Training Wing of which he had been in charge during the First Northfield Experiment should be situated outside of direct medical control and be led by a regimental officer. Since Bion was a medical officer not a regimental officer, he bowed out gracefully in hopes that this new structure would foster greater success than the First Northfield Experiment. Therefore Harold Bridger, who was not a psychiatrist, was selected to head the initiative and the Second Northfield Experiment was begun (Trist, 1985). As this example suggests, Bion displayed sensitivity to the need for an organizational design that was flexible, interdisciplinary, and outside of traditional medical structures. These 
characteristics become central features of the Tavistock model of group relations developed after the war and will be discussed in more depth later in this dissertation.

In addition to the structural differences between the First and Second Northfield Experiments detailed above, the war-time experiences and mental problems of the patients had also changed. Many patients were returning from frontline fighting and D-Day landings in France after having psychologically broken down in battle. Other patients, called Chindits, arrived from fighting with Orde Wingate behind Japanese lines in Burma after having endured horrendous treatment including extreme food and sleep deprivation along with disease and infection. Harrison (2000) wrote, "This brought a new sense of reality to the hospital-a realisation [sic] that there was real work to be done and that the unit needed to change its way of operating to achieve this" (p. 199).

It was an exciting and innovative time for the staff at Northfield. Bridger, Bion, Foulkes, Rickman and the invisible college all kept in regular contact and Bridger saw an opportunity to reinstitute many of the ideas attempted by his predecessors. Harrison (2000) reported, "Bridger met with his social therapy team and explained his intention that all activities of the organisation [sic] were to be integrated into one 'hospital-as-a-whole-with-its-mission' " (p. 209). No longer were staff to direct tasks to be carried out, instead they were to leave decisions to the patients and then watch for clues as to the real needs of the individuals. This philosophy was the essence of Bion's therapeutic community, 
outlined in the Wharncliffe Memorandum, and attempted during the First Northfield Experiment. This philosophy would become central in the post-war development of the Tavistock model.

Meanwhile, Bion was involved in another special project exploring uncharted areas of military psychiatry called $21 \mathrm{Ammy}$ group. "In North Africa it had been found that patients deteriorated once removed from the battle zone, arriving in base hospital in schizophrenic-like states. The need was to keep them as close to their units as possible" (Trist, 1985, p. 19). Therefore, the premise of the 21 Army group project was revolutionary: to bring psychiatric treatment directly to the battle front--rather than evacuate the soldiers out of the battle zone to the hospital. Unfortunately, before Bion could really get the project going, the unexpected death of his wife forced his recall back to England and the 21 Army group project went on without him. As a result, he was posted to a reclassification and rehabilitation Board at Sanderstead in Surrey that ultimately allowed him to continue his group work involving therapeutic communities in different ways. Trist (1985) wrote:

The war had reached a phase where the reclassification and redeployment of officers and their attendant rehabilitation had become more important than their selection. Under Bion's guidance the Board was turned into a special form of therapeutic community which provided the model for the transformation of other Boards. (p. 19) 
Another major success for Bion, and a clear example of his influence, was that these reclassification and rehabilitation units were not under medical control so patients did not have to be diagnosed with, or think of themselves as suffering from, a mental illness.

After the war, key participants began to transfer out of Northfield back to civilian life. The new staff only stayed for short periods of time, even though patients, including ex-prisoners of war, continued to arrive steadily for treatment. Consequently, the enthusiasm, energy and innovation of the earlier days at Northfield evaporated, and the old system restored itself. The army vacated the hospital in 1948, leaving it in a dirty and dilapidated condition (Harrison, 2000).

Northfield's impact and the lessons learned. Wartime therapeutic experiences in general and the Northfield experiments, in particular, can be credited with exposing a generation of psychiatrists to a new treatment method called group therapy and introducing the idea of a therapeutic community. On a more generous scale, Northfield could also be considered the beginning of a whole new way of working experientially with groups and the start of a new professional field called group relations. Key figures at Northfield including members of the invisible college went on to make major contributions to psychiatry and mental health in the post-war period influencing numerous organizations $^{1}$ after the war. Examples include the development of the Tavistock Institute and the Institute of Group Analysis, which was founded by S. H. Foulke.

\footnotetext{
${ }_{1}^{1}$ Furthermore, there were lessons extrapolated from the Northfield experiments which eventually become the underpinnings of another field that emerged in the 1970 s called organizational
} 
In addition, another innovation gleaned from Northfield was to situate treatment outside of the medical system, thereby avoiding the stigma of a patient being sick, as a means of accelerating the patient's recovery. It was also found that including non-medical personal as consultants to groups accelerated a patient's recovery while helping to save money by making it possible to cutback on more expensive medical personnel. Trist (1985) recalled how this tactic was especially prevalent during the development of the CRUs where:

There were only two psychiatrists in the entire organization. Regimental officers were trained to handle group discussions, and each unit had a Ministry of Labour [sic] official to advise on vocational problems and a social worker to advise on family problems...Bion's concept that the psychiatrist's job was to create conditions which would enable him largely to leave the scene and allow ordinary resources of the society to do their work was closely approximated. (p. 22)

These lessons learned during wartime experimentation at Northfield elevated the importance, and broadened the application, of psychotherapy in general and group therapy in particular. In fact, the work done by British army psychiatrists during World War II challenged traditional psychiatry, people's attitudes towards treatment, and the entire structure of the medical system. It is

development and will be discussed in chapter four. For example the first Northfield experiment proved that social innovations, which often have a start in a special part of an organization, are not likely to survive unless the whole system changes in the direction of the innovation as well. As Trist (1985) recalled, "By the time of Northfield II there were enough psychiatrists and other professionals who espoused the new approach and enough understanding in the wider environment to permit a whole psychiatric institution, for the first time, to be transformed into a therapeutic community" (p. 22). 
this quest for a deeper understanding of groups and a wider application for group relations theories and practices, originated at Northfield, which became the foundation of the Tavistock model.

Summary. The war that was fought "to make the world safe for democracy" sensitized people to the evils of authoritarianism and the need to create more democratic organizations. By the end of World War II, every element of British life had changed drastically: politics, industry, economics, labor, the status of women, issues of race, and the very definition of what constituted English qualities. Between 1945 and 1951 the Labour government set in place the basic outlines of Britain's social democratic system, outlines that remained fundamentally unchanged until the election of Margaret Thatcher in 1979: a commitment to a mixed economy, the belief that the state should intervene in economic life for the maintenance of full employment, a nationalized health service, and a social security system that guaranteed a minimum standard of living for all. Although one could hardly argue with the egalitarian philosophies behind these ideals, making them operational became a lofty goal, with unforeseen repercussions (Hennessy, 1993; Veldman, 1994). Veldman (1994) wrote:

The construction of the welfare state and the emergence of a consumption economy significantly changed the material structure of most [English] people's lives. The coming of affluence, however, was accompanied by greater standardization and an increase in the size and 
scale of the institutions and organizations that an individual encountered daily. For some individuals, the gains of affluence could not outweigh the losses resulting from the bureaucratization, the 'masses' of modern society. They sought instead an alternative path, a way that would allow them to overcome their feelings of alienation, powerlessness, and fragmentation. (p. 304)

As a result, the time was ripe for the development of a way to study leadership, authority, and organizations in an effort to rehumanize life within the ubiquitous institutions and organizations emerging in England's modern society. The story of how the Tavistock Clinic, through its Tavistock Institute, developed just such a method as a way to help the population better cope with these new institutional anxieties will now be explored.

The Development of the Tavistock Clinic in the Post-World War I Period

The Tavistock Clinic, originally known as the Tavistock Institute of Medical Psychology, was founded in London in 1920 as a result of psychological studies conducted in Europe during World War I. This clinic was established as "one of the first out-patient clinics in Great Britain to provide systematic major psychotherapy on the basis of concepts inspired by psychoanalytic theory" (Dicks, 1970, p. 1) for patients unable to afford private fees. In addition, it "subsequently became an important centre for training for psychiatrists and allied professionals" (Miller, 1989, p. 3). The clinic was founded based on the vision and energy of its director, Dr. Hugh Crichton-Miller, who conceived of it as 
a model clinic for other psychiatric departments. His hopes in this regard were dashed as other clinics were slow to become established and the ones that were available, were slow and halting in their development (Dicks, 1970).

The original Tavistock Clinic staff as of September 1920 consisted of nine doctors: Dr. Hugh Crichton-Miller (Honorary Director), Dr. J .R. Rees (Deputy Director in 1926), Dr. Mary Hemingway, Dr. J. A. Hadfield, Dr. E. A. Hamilton Pearson, Dr. Leslie Tucker, Dr. Neill Hobhouse, Dr. W. A. Potts, and Dr. Evelyn Saywell (Dicks, 1970, p. 14). This group of key doctors joined professionals from a variety of backgrounds including anthropology, psychology, psychiatry, neurologists, and physicians, to found the clinic. This uniquely eclectic group showed from the beginning their desire to link the social sciences with general medicine and psychiatry which has remained a common element in the clinic's work ever since. Along with this new direction of analysis, the varied backgrounds of the participants fostered an early tolerance of differing professional viewpoints (Klein, 1978; Trist \& Murray, 1989).

Contributions to the war effort. As noted above, the staff of the Tavistock Clinic heartily participated in the war effort during World War II. Two members joined the Royal Nay, thirty-one the Army, and three staff members joined the Royal Air Force. Dicks (1970) recalled, "The ranks held in the Services by members of the Tavistock staff included two brigadiers (J. R. Rees and E. A. Bennet), twelve Surgeon Commanders, Lieut.-Colonels or Wing Commanders, and nineteen Majors or squadron leaders" (p. 118). 
But the clinic was also proud of its contributions to the war effort at home as well as on the front. Although the clinic did move its offices to a safer location at the Westfield Women's College of the University of London in Hampstead in 1939, it never closed its doors, continuing service throughout the war. Because of this move, much of the Clinic's records and furniture were put into storage on Store Street in London. Unfortunately this storage facility was later bombed by German airplanes. Dicks (1970) noted, "This is the main reason why the records for this history are so scanty; no correspondence, minutes of Council or of Committee meetings of pre-1939 survive[d]" (p. 94).

Picking up the pieces after the war. Like many organizations after the war, the Tavistock Clinic was challenged to pick up the pieces that remained of their once thriving organization and rebuild. Dicks (1970) wrote:

We had lost more than we had gained in pride and prestige. We had lost our building and our hope of extension, most of our records, most of our library; we had had to stop most of our training activities and research, which was beginning to pay off so handsomely both to the Fellows themselves and to our reputation as a serious scientific institution. We had a paltry sum with which to restart. We were once more a beggarly small outfit by no means in the main stream of British psychiatry and anxious to find a role in the post-war world. (p. 119-120)

While the staff of the Tavistock Clinic may have felt a bit behind in the work being done at other, larger psychiatric hospitals, they still had a 
"remarkable spirit of group cohesion and a broad consensus on the kind of aims which the Tavistock should pursue" (Dicks, 1970, p. 120). They vowed not to attempt to compete or play catch-up with these larger, more mainstream mental health institutions, but rather to develop a new model by which to structure their organization. By capitalizing on input from a less traditional, more diverse group of scholars, including social scientists, general psychiatrists, Jungians, and more progressive members of the psychoanalytic movement--many with wartime experience in army psychiatry--they began to formulate their plan. One of the hallmarks of this new Tavistock model was a self conscious recognition of, and dedication to, creating and nurturing an evolving new model. Ironically, other organizations in the United States that appealed to Tavistock's legacy, like the A.K. Rice Institute, often seemed unable to sustain this goal for reasons that will be explored in subsequent chapters.

Articulating a new mission. After the war in 1945, an Interim Planning Committee was established to consider the future of the Tavistock Clinic and to redefine the clinic's mission in light of experiences gained during the war. This committee was chaired by Bion, who modeled his new findings about groups, helping to clarify issues and reduce conflicts within the committee itself which facilitated the committee's approval of his report by year's end. This report diagramed the clinic's tasks as: (1) exploration of the role of outpatient psychiatry based on a dynamic approach and oriented toward the social sciences in the as yet undefined settings of the new National Health Service and (2) 
incorporation of the Tavistock Institute of Human Relations for the study of wider social problems not currently seen as being within the purview of the mental health profession (Trist \& Murray, 1989).

Confronting new challenges. This psycho-dynamically grounded social science approach to the study of wider social problems and their amelioration was visionary. Yet, although the Tavistock Clinic was now armed with visionary goals, post-war debt and economic decline put Britain in a financial slump. Veldman (1994) wrote:

Although the seeds of Britain's economic decay were sown in the Victorian period, the full fruits were not harvested until the decades after 1945, when Britain's productivity problem manifested itself in a series of financial crisis's and an ever-worsening manufacturing slump. (p. 3) But financial troubles were only one issue affecting post-war Britain. Political and social challenges such as tensions around the issue of English citizenship, the expansion of the welfare state, the establishment of the National Health Service, and consumerism all played a major part in redefining English culture after 1945 (Veldman, 1994).

Thus, the larger culture was sending mixed signals. On one hand, the time was ripe for the development of a new way to research and evaluate organizations in an effort to understand the wider social implications of society's post-war restructuring. Yet, a pressing problem remained: How could such research and learning about wider social problems be funded? 
There was also an internal problem: What methods of investigation and application could be used to study and ameliorate these social problems? The answers to both problems were found over the next few years by a sub-unit of the Tavistock Cinic, the Tavistock Institute of Human Relations.

The Tavistock Institute of Human Relations (Tavistock Institute)

The post-war reorganization of the Tavistock Clinic was so heavily influenced by the military experiences of its staff, most of whom were members of the invisible college, that it was jokingly nicknamed Operation Phoenix by the participants (Dicks, 1970). The group's wartime experiences, especially those gleaned from the Northfield experiments, suggested that the best solution to their restructuring challenge would be found in group treatment and Bion was asked to pioneer this endeavor. Trist and Murray (1989) described what happened next: Bion's "response was to put up a notice which became celebrated-'You can have group treatment now or wait a year for individual treatment" " (p. 7). Not surprisingly, people chose the former and the rest is history.

The Tavistock Institute is established. On July 5, 1945, the National Health Service took over in the United Kingdom, essentially ushering in an era of socialized medicine. Dicks (1970) recalled, "At this point we can say that 'Phoenix' had risen from the ashes, and the National Health era began" (p. 177). By the end of 1945 there already was growing financial support for the Tavistock's new ideas, including a Rockefeller foundation grant of 22,000 pounds 
over three years beginning on February 1, 1946. Dicks (1970) noted, "As always, the Americans saw more in our work and ideas than our own people" (p. 133).

It was agreed that the "new social and preventative psychiatric work" (Dicks, 1970, p. 133) would be done under the guise of a new division rather than the Tavistock Clinic itself. Therefore, the Tavistock Institute of Human Relations was founded in 1946 as a separate institute which still functioned within the matrix of the original, psychotherapeutic Tavistock Clinic. The original founders of the Tavistock Institute included "Dr A. T. Macbeth 'Tommy' Wilson, who was the first chairman of the Institute, along with Wilfred Bion, Eric Trist, Elliot Jaques, A. K. Rice, and Harold Bridger" (D. Sorkin, personal correspondence, June 20, 2002).

It was a time of introspection as both the Tavistock Clinic and the newly formed Tavistock Institute struggled to establish and sustain their own separate identities (Gray, 1970, p. 206). The Tavistock Institute Annual Report (1960-61) defined their organization in the following way:

The Tavistock Institute studies human relations in conditions of wellbeing, conflict or breakdown, in the family, the work group and the larger organization. The members of staff have been trained in different disciplines but share a belief that integration will yield fresh insights into human relations. (p. 1)

This interdisciplinary perspective with an application oriented focus will become foundational in the ethos of the Tavistock model of group relations, yet not all 
staff members in the early days of development of the Tavistock Institute embraced this philosophy.

Questions about theory and purpose. The post-war period was a time of significant restructuring and refocusing on organizational purpose for the Tavistock Institute. While many of the staff supported these changes, "it was not expected that all members of the staff would be able to accept the proposals which were promulgated from time to time during 1945" (Dicks, 1970, p. 134). Indeed, there were a number of resignations by senior staff as a philosophical struggle ensued over new ideas about social psychiatry which challenged more traditional notions of individual methods. Dicks (1970) wrote:

The closer link with psychoanalysis as the most serious and more rigorous method of study, training and treatment within the psychotherapeutic sphere could have appeared as a considerable threat to the older Crichton-Miller and Hadfield traditions among us. But it also functioned the other way. The more orthodox, old-fashioned Freudian group were also alarmed at the hobnobbing with the Army group, and regarded it as not far removed from betrayal of their principles (p. 136).

Despite the conflicts around the military experiences among its staff, questions about the new ideas about social psychiatry, and debate about the relevance of group psychoanalytic theories versus more traditional notions of individual treatment, a new multidisciplinary model was slowly emerging at the 
Tavistock Institute. In time, these ideas would evolve to form the foundation of the Tavistock model of group relations.

In addition to philosophical disputes, there were other debates about new ideas and changes at the Tavistock Institute. One such discussion occurred about the idea of a forum for research and publication. After much debate on the topic, Tavistock Publications Ltd. was incorporated on October 28, 1947 in order to publish work on the intersection of social science and psychoanalytic thought. This included the publication of a quarterly journal, Human Relations (Gray, 1970).

The first volume of Human Relations, published in 1947, was actually a jointly sponsored venture backed by Kurt Lewin's Research Center in Group Dynamics in America and the Tavistock Institute in England. This first volume included Lewin's last major paper, Frontiers in Group Dynamics, published after his untimely death. This joint sponsorship and the publication of Lewin's paper is one of the first demonstratable links between the group relations work being pioneered in the United States under Lewin's leadership and that being accomplished at Tavistock Institute ${ }^{2}$. Eventually the Tavistock Institute took over as the sole publisher of Human Relations, an arrangement that continues for this mainstay journal in the field of group relations today (Miller, 1989).

Funding challenges. By 1948 the British economy was in serious trouble and grants for research were scarce. The government formed an Industrial Productivity Committee whose goal was to make money available for research

\footnotetext{
${ }^{2}$ The nature of these connections will be elaborated on further, later in this dissertation.
} 
intended to improve worker productivity through better use of human resources. The Tavistock Institute seized this opportunity to test the applicability of its theories and models developed in war-time settings to non-military environments. The Institute applied for and was awarded three separate grants that sustained its work over the next three years. Although these projects were all successful, with one study resulting in the publication of the Institute's first major book, The Changing of a Factory by Jacques (1951), the response from the field was silence--much of the Tavistock Institute's work was too experiencebased and ahead of its time to receive much attention or support (Dicks, 1970).

Continuous organizational restructuring. During the first decade of its existence, the Tavistock Institute was organized into various committees and defined two areas in which Tavistock staff would predominenetly work: the first area was medically oriented and concerned with family and social psychiatry services provided in conjunction with the Tavistock Clinic; the second area was research oriented and concerned with the study of work, organizations, and social change (Tavistock Institute Annual Report, 1956-1960, p. 1).

Yet, the late 1950 s once again challenged the Tavistock Institute to evolve in new directions in order to sustain itself financially. As a result, it turned to consultancy and the needs of private industry as a new source of funding. This new direction ultimately paid dividends in allowing the institute to find support for the long-term social science projects that were too unconventional to be supported by foundations or the government (Dick, 1970, p. 292). 
The amelioration of wider social problems. Although the Tavistock Institute had managed its first pressing problem adequately by the $1950 \mathrm{~s}-$ financial support for its programs-the second challenge about what methods of investigation and application could be used to study and ameliorate wider social problems still remained largely unaddressed. Fortunately, a means to address this challenge would emerge during a highly collaborative period between early group theorists in the United States and those at the Tavistock Institute in England. As a result of this collaborative period, the Tavistock Institute solved this second challenge by developing a unique experiential learning workshop as a means to study and ameliorate wider social and organizational problems-the group relations conference.

The first group relations conference was held in conjunction with the University of Leicester, outside of London, in 1957. Commonly referred to as the Leicester Conference, this event was influenced by the training pioneered by the National Training Laboratories (NTL) in the United States and has continued as an annual (and sometimes semi-annual) event to this day. Miller (1989) estimated that if you added all of the events that have been based on this conference model, the number of people exposed to this innovative way of thinking "is well into five figures" (p. 1). This annual conference is just one example of a cross-fertilization process that occurred between the Tavistock Institute in England and the NTL in the United States. The next section describes this and other cross fertilization efforts. 
Exchanging Theories, Methods, and Language: The Influence of the NTL

Working in concert, but from a distance, early group theorists in the 1940 s and 1950 s realized that a conceptual framework needed to be developed in which relationships within groups and organizations could be examined. During these early days of the movement, the distinctions that now clearly separate the different models had not yet crystallized. The group relations models were still in their formative stages and scholars shared common theories, methods, and even language about working with groups. Powerful individual contributions were occurring on both sides of the Atlantic, influencing this exciting post-war period.

Lewin's influence. In the United States, Lewin's work with Lippitt, Benne, and Bradford, and their development of a human relations training laboratory at the historic 1946 conference in Connecticut, had worldwide impact. (The details of this historic event will be discussed in chapter four.) In the United Kingdom Bion's theories about people's behavior in groups, based in part on his observations at Northfield and Klein's theories about individuals, were also becoming foundational to the group relations movement in England.

Many authors described these early collaborative times. Back (1972) noted:

Lewin's work especially was known and appreciated by the Tavistock staff even in the 1930's and personal contact was made between Trist and Lewin in 1945-46. In fact, Lewin was invited to spend 1947-48 (the years 
of the first workshop) at Tavistock, but his sudden death prevented this plan. (p. 44)

Miller (1983) also recalled that "Lewin had significant influence on my early Tavistock colleagues in the late 1940s. The Tavistock group shared his conviction that conventional modes of scientific analysis would not uncover the 'Gestalt' properties of complex human systems" (p. 5).

In an effort to further explore the potential for these two organizations to collaborate in their study of the complexities of human systems, two British psychoanalysts from the Tavistock Institute, Tom Main and Isabel Menzies Lyth, traveled to Bethel, Maine in 1948 to experience first hand an NTL human laboratory event (Freedman, 1999).

The influence of the laboratory method on the Leicester Conference design. The influence of the cross-pollination between American and English group relations theorists and practitioners cannot go unrecognized. Miller makes this point clear: "The first Leicester Conference was explicitly a British 'translation' of NTL, using Bion's group-as-a-whole perspective from group psychotherapy" (E. J. Miller, personal correspondence, Sept 30, 2001). In addition, Trist and Sofer (1959) published a report of their experiences at the first Leicester Conference held in 1957 and noted that it was "the first full-scale experiment in Britain with the 'laboratory' method of training in group relations" (p. 5). Miller (1989) described how this reference to "the laboratory method," was an obvious reference to the NTL and its human laboratory method "which 
had strongly influenced the early Tavistock group" (p. 2). In their introduction, Trist and Sofer (1959) also observed Lewin's extensive influence on their thinking and thanked H. S. Coffey of the NTL for providing guidance as a consultant during the planning stages of this first Leicester Conference.

Citing the NTL's growing influence over the study of group dynamics, Trist and Sofer (1959) stated:

It was to meet the need for a course of training harnessing new knowledge and understanding about groups, but rooted in British as well as American experience, that the first inter-professional Training Conference in Group Relations, to be held at Leicester, was planned as a pilot experiment. (p. 11).

In addition to the evidence that the Leicester Conference design incorporated theories and methods adapted from the NTL, there also is evidence that the Tavistock conferences appropriated some NTL terminology as well.

Trist and Sofer's 1959 report of the first Leicester Conference often used NTL-like language-e.g. laboratory, here-and-now, and social islands-when describing Tavistock's group relations conference events. All of these terms, of course, were made famous by Lewin and the NTL. Yet despite the evidence of early cross pollination between the Tavistock and NTL models, differences soon emerged.

Differences begin to emerge. Although the evidence is clear that there were frequent exchanges of theories, methods, and even language between 
Tavistock and NTL during their respective formative periods, there were also distinct differences beginning to emerge as early as the 1950 s. These differences would later become defining trends for these separate models. Menzies Lyth, a British psychoanalyst from the Tavistock Institute, recalled, in her interview, differences emerging in the burgeoning models from the very beginning:

We had a huge conference, about 1947 in England, when a lot of the people came across from America, the [NTL] people from Michigan...It was interesting because the differences began to appear, very clearly. The major difference between the American group and ours in England was, of course, our basis in psychoanalysis--that was a huge difference. I can remember that conference quite clearly and being quite surprised sometimes at the things the Americans said. Because they hadn't got our psychoanalytic-I mean I was an absolute babe in psychoanalysis at the time-but nevertheless it permeated our thinking...It was all very new...[NTL was] much more 'scientific'. You know there was a lot of research, open research going on. And that again struck me as being extremely odd. Because they didn't take any account of the effect the research was having on the members of the conference, on their behavior. It was really quite strange to me...It ceased really to have much effect on our work [after that]. (Menzies Lyth Interview, 2002, p. 6) As Menzies Lyth pointed out, gradually the theories and methods of the Tavistock Institute began to drift away from their early connections to Lewin and 
the NTL. In addition to the NTL's fixation on "scientific" methods, Menzies Lyth added that it was also NTL's lack of focus on the psychoanalytic that ultimately impacted the Tavistock Institute's ability to continue their cross-pollination:

I think we were a little shocked by their naiveté in psychoanalytic terms and I think sometimes we made it rather plain that we thought so. I can remember one of the American gentleman said 'Let's take a simple example, let's take milk' and we all went 'What! Milk?'...We couldn't see how-why-anybody could possibly think that milk was simple. I think they actually said bread, but we didn't think bread was all that simple either. The differences began to appear and we began to fear that we had perhaps got more, better bedfellows elsewhere. And then through Margaret Rioch we met people like Larry Gould...Kathy [White] was later...Margaret [Rioch] came with these various bright young men. (Menzies Lyth Interview, 2002, p. 41)

Through this initial connection with Margaret Rioch, and her young men, the Tavistock Institute found a more psychoanalytically-versed connection in the United States which better matched their own interests. The nature of this connection and the subsequent exportation of the Tavistock model to America will be discussed in more detail in the following chapters.

Neither Lewin nor Bion attended respective event. Interestingly, while the influence of both Lewin and Bion is clearly evident in the development of the NTL's human laboratory and the Tavistock Institute's concept of the group 
relations conference-neither man ever attended a laboratory or conference sponsored by their respective organizations. Lewin died in 1947, the year of the very first NTL human laboratory, and Bion had seemingly moved out of group relations work in order to pursue his psychoanalytic work by 1957, the year of Tavistock's first Leicester group relations conference. Therefore, it was the next generation of group relations scholars and practitioners that operationalized these early founders' ideas into the highly successful experiential learning events.

These learning events, when held in the Tavistock tradition were called group relations conferences, or simply conferences for short. The participants were members and the staff were referred to as consultants.

When conducted in the NTL tradition, the experiential learning events were called human laboratories or labs while the staff were called trainers. Rice (1965) wrote "The [Tavistock] study group is the equivalent of the 'T-groups' of training laboratories in both America and Europe though it tends to be smaller than the T-group" (p. 4).

Much about these initial experiential learning events remains largely unchanged even today. One could only speculate how a group relations conference might have differed if Bion had organized it rather than Rice, or if Lewin had lived long enough to influence the labs at the NTL.

Bion's only group relations conference experience. It was in 1969 that Bion attended his first, and only, group relations conference. This was an A. K. 
Rice Institute (AKRI) conference held in the United States and, as Rioch (1993) recalled, it was a fascinating year when Wilfred Bion, our spiritual ancestor, appeared for the first time on the staff of an American conference. It was the first time and the last time, as a matter of fact, that he had been on any Group Relations Conference staff. Roger Shapiro invited him to make his way from Los Angeles, where he then lived, to Amherst, Massachusetts. ( $p$. 233)

At Amherst, Bion joined Director Roger L. Shapiro and Associate Director Margaret Rioch and an all-star staff including Jane Donner, Marvin H. Geller, William Hausman, Edward B. Klein, Donald N. Michael, Garrett J. O'Conner, A. Kenneth Rice, and William D. Trussell (Group Relations Brochure, 1969, p. 8). This was a particularly historic event because not only was this Bion's only experience at a group relations conference, it was also the only time that Rice, the mastermind behind the group relations conference design, and Bion, the father of group relations theory, had worked together at a group relations conference ${ }^{3}$. Lawrence recalled Bion's reaction to the group relations conference structure:

For years I always had the fantasy of if there hadn't been Ken Rice, there wouldn't be [group relations] conferences. And then the next fantasy is, if Bion had been asked to run a conference it would be a dud. There is a

\footnotetext{
${ }^{3}$ Rice had participated in small groups with Bion at the Tavistock Institute in the post-war 1940 s in London.
} 
wonderful description in [Bion's] letters about being at [the AKRI 1969 Amherst College conference] and it was clear that he didn't know the rules.' And he was talking with a member at a plenary and suddenly the staff gets up and disappears, but [Bion] still carries on with the memberthen went up to his room. And then Ken Rice came looking for him saying 'we are having a staff meeting.' And Bion ruefully writes to his wife 'I didn't know that Ken Rice's model of group relations rested on split second timing.' (Lawrence Interview, 2002, p. 27-28)

Lawrence's comments are particularly poignant because there are not really supposed to be any "rules," per se, but as in any culture, certain routines and etiquettes become established and enforced as norms. Clearly Bion was not privy to the nuances of Rice's group relations conference design.

\section{Evolution of the Group Relations Conference}

As discussed previously most of the people who had been involved in establishing the Tavistock Institute in 1946, had gained valuable experience working with groups from World War II in places such as the War Office Selection Boards, the Northfield Hospital, and the Civilian Resettlement Units. Their success in these areas during war-time, led them to search for wider application of their newfound theories and methods in peace-time as well.

Rice. The first civilian training group, as opposed to those for military members during and after the war, was held in 1945 under the direction of Bion, Rickman and Sutherland at the Tavistock Clinic. It consisted of twelve members, 
one of whom was A. Kenneth Rice. Although it only lasted six sessions it seemed to have a profound influence over many group members-especially Rice. Rice was so taken by these new methods that he volunteered to become a member of the Training Group at the Tavistock Institute, again under the direction of Bion. This Training Group met weekly as a small study group for a period of two years between 1947 and 1948. Although this particular program was suspended at the Tavistock Institute shortly thereafter, due mostly to cost, the study group concept was later revived by Rice, and others, who applied it to their work with groups.

Rice, an anthropologist by training, had been a businessman and consultant to organizations around the world, most notably to textile industries in India. One of his most famous projects was with the Ahmedabad Manufacturing and Calico Printing Company, Ltd, in India from 1953 to 1956 where he finetuned the application of his theories (detailed in chapter two). In 1958, Rice published a book about his experiences entitled Productivity and Social Organization the Ahmedabad Experiment (Wing, 1989). Prior to his experiences in India, Rice had been an officer "in colonial Africa where his liberal convictions and lack of sympathy with racial prejudice made him unpopular with the British colonial administration at the time" (Rioch, 1996, p. 11). Rioch (1996) recalled that when she met Rice in 1963:

He was already the author of several books and the creator of important concepts having to do with organizations and management. He was 
enormously attractive personally-articulate, entertaining, brilliant, and clear both in conversation and in writing. (p. 11)

Although Bion provided the foundational theories for the group relations conference, it was Rice, along with a cadre of others, who developed the design of the group relations conference further expanding the application of group relations theories and practices. Sher, current Director of the Tavistock Institute, reported:

Rice would have been talking to people like Trist, Mary [Barker], Turquet, Gosling, and Eric Miller of course, and others. It started off the idea of a laboratory. And that no doubt A. K. Rice's clients would come to this laboratory, and Miller's clients, and Turquet's clients, would come to this laboratory. And learn about things and take the stuff back into their organizations and, at times, take the consultants back with them into the organizations. So there would be a fruitful link between the Leicester Conference, or whatever it was called then, and the ongoing consultation that Rice and others were having with their client organizations. (Sher Interview, 2002, p. 32)

The basic model of the Tavistock group relations conference. This new way of thinking, learning, and then applying this knowledge back into organizations quickly became known as the Tavistock method. This model used group relations conferences as a way to relieve dients of the organizational distractions of their business world by bringing them into a temporary institution 
which would provide an experiential learning environment. This environment would provide a common language and experience with which to build upon when the clients and consultants returned to the client's organization. It is not too difficult to see the vestiges of Bion's therapeutic community, as well as the influence of Lewin and the NTL's human laboratory, in the design of this experiential learning community.

The basic model of the Tavistock group relations conference is based on Rice's (1965) "import-conversion-export model derived from open system theory" (p. 7) discussed in chapter two. In other words, the conference imports members and staff from a variety of organizations with many different jobs skills. Yet, it also requires the importation of other items such as food and beverages for participant's sustenance. After the completion of the conference, the conversion phase of the import-conversion-export model, members and staff are then exported back to their home lives and places of employment. Other elements are also exported from the conference like payments for services rendered or reports, articles, and books. This notion of the group relations conference as an import-conversion-export model based on Rice's open system theory will become pivotal during the analysis of this dissertation's findings in chapter eight.

As discussed in chapter two, a pivotal element of open system theory is attention to the primary task. By linking this notion of primary task to the study 
of leadership, Rice (1965) defined the primary task of the group relations conference:

To provide those who attend with opportunities to learn about leadership. Leadership involves sensitivity to the feeling and attitudes of others, ability to understand what is happening in a group at the unconscious as well as conscious level, and skill in acting in ways that contribute to, rather than hinder, task performance. But increased sensitivity and understanding are means, not ends, and the end is the production of more effective leaders and followers. (p. 5)

Challenges of the group relations conference design. The challenge to organizational members is the acquisition of this skill. Therefore conferences are designed to provide experiential learning events that enable members to learn these skills through direct experience. These group relations conferences give their members the opportunity to examine their own responses to authority and the act of authorizing, as well as the responses of others, in addition to examining the feelings that become mobilized as a result. For example, members experience the pressures of filling leadership roles, and learn what it feels like to both lead and follow in a relatively safe environment.

Members also experience the conflicts that may arise in themselves and others when participating in a group and experimenting in leadership roles. Based on a combination of the open systems framework and psychoanalytic theories which interpret the projections, fantasies, and transference that occurs 
in groups, group dynamics can be effectively explored within the group relations conference design. "What the members make of the role, authority and person of the consultant, and what he in turn experiences of their projections on to him, constitute primary data for the elucidation of group processes" (Miller, 1993, p. 21).

As the group relations conference progresses, participants are continuously challenged to accomplish the primary task of the event: To study the group's behavior. As an example of this challenge, Rice (1965) wrote:

The definition of the task of the conference as the study of its own behavior, and the absence of structure save for that of the staff, force members either to set up an 'organization' for themselves or to abandon the task. It is in the attempt to set up 'organizations' and in the taking of roles in them that members have the opportunity to experience for themselves the forces that are brought to bear on them when they take roles requiring leadership, and the forces they bring to bear on others who demand their following. (p. 25)

The influence of conference staff. Even from the earliest days, staff at the Tavistock conferences originated from a wide range of professions and countries, and included racial and gender diversity. Therefore the Tavistock approach was, from the start, interdisciplinary. Some of the staff, for instance, were anthropologists like Rice and Miller from the Tavistock Institute, yet other staff 
members were from the prison system, government, educational institutions, churches, consulting organizations, as well as the mental health professions. Yet, even though the group relations conference theories and design were sound, there were still obstacles to success. Miller (1989) recalled, "Reputable though these bodies were, experiential learning of the Bethel type was still a novelty in Britain, and psychoanalysts somewhat suspect. Co-sponsorship by a university was seen as important in adding credibility" (p. 3). Therefore, the Tavistock Institute sought co-sponsorship with the University of Leicester through connections with Professor A. J. Allway, Head of the Department of Adult Education there.

In addition, an executive committee was formed consisting of Allway and Rice, along with Professor W. Tibble, Head of the School of Education, University of Leicester, and Pierre Turquet of the Tavistock Institute and the Tavistock Clinic. Through this collaboration, and the joint sponsorship of the University of Leicester and the Tavistock Institute, the first Leicester Conference was launched in 1957.

Purpose of the Leicester Conference. Trist and Sofer (1959) described the experimental nature and purpose of this event:

It was to meet the need for a course of training harnessing new knowledge and understanding about groups, but rooted in British as well as American experience, that the first inter-professional Training 
Conference in Group Relations, to be held at Leicester, was planned as a pilot experiment. (p. 11)

The Tavistock Institute four year report (1956-60) described the philosophies behind this early group relations conference:

From the time of its earliest origins in officer selection, resettlement and therapeutic community work during the war years, the Institute has devoted considerable attention to the problem of communicating an understanding of group processes and ways of applying it...In practical affairs today the individual has, more than ever before, to achieve his aspirations with and through other people in the complex settings of organizational and professional life. He, therefore, needs a greater awareness of the way he behaves with others, and of the social and psychological processes within and between the groups which make up organizations. (p. 11)

This allusion to the importance of understanding both an individual's interaction with others and the social and psychological processes within and between groups demonstrated the influence of psychoanalytic frameworks and intellectual foundations described in chapter two. Further evidence of the influence of psychoanalytic theory and practice on the Tavistock Institute's working principles is found in its articulation of its own ethical principles described in the words of the Tavistock Institute four year report (1956-1960) "as the medical ethic with its principle of professional confidentiality" (p. 3). 
The group relations conference design stabilizes. After a brief evolutionary period between 1957 and the early 1960s, the design of the Leicester Conference began to stabilize and the format became more predictable. Miller (1989) recalled:

The essentials of the approach, including its theoretical underpinnings, were largely established by the mid-1960s. Since then, the 'Leicester Model' has provided the basis for numerous other conferences, some run by the [Tavistock Institute] and very many more by other institutions, in Britain and a dozen different countries around the world. In most cases these were developed with the active support of the Tavistock Institute. (p. 1)

Although the structure of the conference has remained largely unchanged, this is not to infer that the experience of a group relations conference is in any way, ever the same. The dynamics among every membership and staff group vary; consequently, no two conference experiences are ever alike. Yet certain conference events have become hallmarks of the Tavistock model's Leicester Conference design. Some of these hallmarks, gleaned from a review of thirty-two Leicester Conference brochures ${ }^{4}$, include the following:

1. Every conference member is assigned to a small study group, which is made up of approximately nine to twelve individuals from all walks of life. The task of this small group is to study its own behavior as it unfolds, in the

\footnotetext{
${ }^{4} 1963$ to 2002, excluding 1977 and 1986 to 1989.
} 
here and now. A consultant is assigned to assist the group at its task by helping the group examine its own behavior.

2. Not part of the original conference design, the large study group was added to the conference structure in the late 1960 s based largely on the work of Turquet (E. J. Miller, personal communication, October 29, 2001). All conference members now attend the large study group which usually consists of the entire conference membership. The task of the large study group is to study behaviors that might occur in a crowd or in meetings that consist of more people than can easily form face-to-face inter-personal relationships. It is not uncommon for sub-groups to form or split, anti-groups to emerge, and fantasies or myths to be played out. Three to four consultants are normally assigned to assist the group at its task of examining its behavior.

3. Another event not included in the first conference design, which was successfully added in 1959 largely through the work of Bridger, was the inter-group event. During the inter-group event, members are free to form their own groups in order to study behaviors within and between groups. Consultants are available upon request.

4. Near the end of the conference, all members are assigned to application groups made up of five to ten people from similar or complementary backgrounds. The goal of the application group is for members to reflect on their conference experience in order to consider how their learning can be applied to 
similar roles outside. A consultant is assigned to assist individuals in their interpretations and application of their new knowledge.

After having experienced the events of a conference, it is up to the individual to decide upon their own authority which conference experiences and learning is valuable to them. Therefore, Miller (1983) observed:

What he [sic] learns, therefore, is unique to him. He cannot be told what he 'ought to have learned': indeed, that phrase itself is an expression of dependence on authority. Other people, including the consultant, may offer their views of a situation, but only the individual member is in a position to understand, in light of the role he has, the relationship between what is happening around him and what is happening inside him; hence it is on his own authority that he accepts what is valid for him and rejects what is not. (p. 22)

These four structural features of the Leicester Conference, (small study group, large study group, inter-group, and application group) were built upon the three intellectual foundations of the Tavistock model (described in chapter two): open systems theory, primary task, and boundary management. If open systems theory brought attention to the significance of boundary management as a leadership function within organizations, then the group relations conference provided a temporary institution in which to explore how organizations managed that boundary in order to survive. Therefore, the appeal of the Leicester Conference design was that it provided a means to accomplish 
the study of leadership and authority as it occurred in the here-and-now of organizational life.

Trist: Director of the first Leicester Conference. The first Leicester Conference was directed by Eric Trist of the Tavistock Institute. Born in 1909, Trist was a clinical psychologist at St. Andrews University in Scottand. Prior to World War II, he received a fellowship to spend two years abroad in America and, as a result, walked picket lines for the Hunger and Strike Committee as a means to study the Great Depression in the United States. During World War II, he was instrumental in establishing the War Office Selection Boards, and worked with Bion, Rickman, Bridger, and the rest of the invisible college, discussed previously.

After the war, "he was one of the principal founding members of the Institute in 1946 and had a deep influence on its work, development and international reputation until-and, indeed, long after-he left in 1966 to pursue his second, highly productive career in North America" (Trist in-memorial brochure, November 4, 1993, p. ii). After leaving the Tavistock Institute for this "second career," Trist taught his socio-technical system at the Wharton School of the University of Pennsylvania in Philadelphia and then at York University in Toronto. Trist died in Carmel, California on June 4, 1993.

In preparation for the first Leicester Conference, the organizing committee had successfully recruited forty-five participants, of which over one third were from a wide array of local industries and community organizations. The other 
members came from universities and other educational organizations, the prison system, probation service, local authorities, and voluntary organizations. Six months after the conference, Twenty-six of these members attended a 2-day follow-up meeting and the responses to this meeting seemed to justify holding a second conference the next year. A Leicester Conference of similar design has now occurred every year, sometimes twice per year, since 1957.

Refiections and Refinements. The 1960 s were a time of reflection about application and refinement of technique for the Tavistock model and the design of the group relations conference. Although other people such as Allaway, Bridger, Daniels, Gosling, Herrick, Hutton, Lawrence, Menzies Lyth, Miller, Reed, Turquet, and Woodhouse were influential, Rice was the central figure in the solidification of the group relations conference format and the development of the Tavistock model during this time period (Leicester Conference Brochures, 1963-1970). In 1962, Rice was authorized by the Tavistock Institute to take over the leadership of the group relations conferences. Miller (1989) recalled:

The reasons were largely pragmatic: the conferences had been losing more money than the Institute could afford, and Rice was willing to try to make them financially viable...However, Rice's major contribution to the conferences was not economic but technical and conceptual. The period of his direction saw at least four significant developments in design. (p. 5) These four developments included the addition of the large study group as well as two similar types of inter-group events--one of which evolved into what is 
now known as the institutional event. The last development was to eliminate the lecture format in favor of placing more emphasis on assisting members to find application for their new knowledge through application and review groups.

In addition to Rice's refinements of the Leicester Conference design that year, 1962 proved to be a year of reflection and restructuring for the Tavistock Institute as a whole. Bolstered by their initial success with group relations training and the Leicester Conference, the Tavistock Institute sought to investigate further areas for application by convening an international meeting in Lausanne, Switzerland. The purpose of this meeting was "to exchange information, to test the need to bring into existence an overall European organization concerned with this field of work and to discuss its relationship with the National Training Laboratories for Group Development in Washington" (Tavistock Institute Annual Report, 1961-1962, p. 7). The overarching objective for this activity was twofold: first, to continue research with " 'unstructured groups' in human relations training inside organizations" and second, "to reexamine the basis of this type of work in relation to recent developments in organizational and open system theory" (Tavistock Institute Annual Report, 1961-1962, p. 7).

The results of this meeting were never published, but the Tavistock Institute continued to refine and reflect upon ways to broaden the application of its work to organizations and work life, nevertheless. It accomplished this by focusing on earlier studies done at the Tavistock Institute which concluded that 
"human needs, satisfactions and interests could be met in the work situation without sacrificing economic goals, and that alienation in work need not necessarily be a direct consequence of attempts to increase economic efficiency" (Tavistock Institute Annual Report, 1965-66, p. 6). Based on these new theories about the inter-dependence of human and technical factors in the workplace, a socio-technical approach emerged "entailing the recognition that the technological and human aspects of work systems are complementary and interdependent, and that one is not reducible to the other" (Tavistock Institute Annual Report, 1965-66, p. 6). This philosophy became a keystone in the Tavistock tradition.

Gordon Lawrence, a former Tavistock Institute researcher and Leicester Conference Director, recalled the excitement of these new ideas, the group relations conferences, and how he thought that this new Tavistock model was a way to get to "the truth of organizations...A glimpse of the shadow world of organizations...The feeling was that you were at the edge, you were always at the sharp end of learning and this was particularly demonstrated by Pierre Turquet" (Lawrence Interview, 2002, p. 6-7). Lawrence reflected further: They were quite extraordinary conferences. But remember conferences were only a small part of the work that we did. And I think that one was fascinated by conferences because the problems that you were having on the outside could be brought into the conference and could be, if not directly talked about, illumined through the work that you were doing and 
visa versa. Whatever you leamed at the conference could be taken out again. And that movement between the two was always very important...I think it translated quite easily into the whole idea of how people defend against the anxieties of the workplace. And this idea of defense which Isabel [Menzies Lyth] kept importing and developing was, I think, the crux of [the Tavistock model] at that time. (Lawrence Interview, 2002, p. 5-6). The Centre for Applied Social Research (CASR)

In 1965 the Tavistock Institute was once again reorganized, this time into five subunits, in order to better meet its institutional vision and the needs of its clients. The five subunits were: The Human Resources Centre, the Centre for Applied Social Research (CASR), the Committee on Family Psychiatry and Community Health, the Family Discussion Bureau, and the Institute for Operational Research (Tavistock Institute Annual Report, 1965-66).

The Centre for Applied Social Research (CASR) was founded as the center of the Tavistock Institute's group relations training, consulting, and research services. Rice was selected as chairman, supported by an all-star staff which included Gosling, Menzies Lyth, Miller, Sofer, and Turquet (Tavistock Institute Annual Report, 1965-66, p. 13). As evidence of the Tavistock Institute and CASR's dedication to continuous refinement, one of this department's stated goals was to remain

always alert to the need to improve the quality of our professional work, to sharpen and develop our concepts, and to cast a larger proportion of 
our research findings in the forms in which they can be published or

taught. (Tavistock Institute Annual Report, 1965-66, p. 13)

Another goal was to continue to find application for CASR's group relations theories in organizational life.

A growing reputation for the CASR. As word of the CASR's organizational successes spread, it found itself in the unique position of having more opportunities for work than its current staffing levels could sustain, thereby allowing the organization to be more selective about its projects. The days of struggling for funding back in the post-war period were over, at least temporarily, and CASR hired a number of new staff members to join its organization in order to assist with the long-term contracts it was signing (Tavistock Institute Annual Report, 1965-66, p. 46).

Examples of these new consultancy projects included a diverse range of clients such as the Ministry of Transportation, the London Fire Brigade, the Ministry of Health, British European Airways, the engineering department of a major motor manufacturer, and religious organizations, to name just a few. In addition, other group relations events were now being offered, for instance, the study of gender relations at work and specially tailored programs designed to address industrial concerns of specific sponsors. Further expanding the application of the Tavistock model, Miller "directed a one-week conference for the Graduate Programme at the Manchester Business school" as a visiting professor (Tavistock Institute Annual Report, 1970-71, p. 5). 


\section{A rapid dissemination of group relations conferences. As previously} discussed, the 1960 s was a time refinement, refiection, and expansion as the Tavistock Institute and the CASR's theories and practices were becoming popular and their name widespread. Miller recalled:

The late 60 s onwards saw rapid dissemination of group relations conferences: new institutions to run them were set up in many countries. In some (for example Grubb Institute in UK, AKRI in USA, OFEK in Israel) the Tavistock Group Relations Programme [sic] had an active role in staff training and development, initially through providing Tavistock Directors and enrolling potential local staff in Leicester Training Groups. Elsewhere, local institutions emerged without our direct involvement, though in some cases potential staff had Leicester experience. Overtime, all these institutions have developed in their own way. From some of them, people have come to Leicester in membership, training group or staff roles and that helps to maintain some consistency in the models used. In other cases it is difficult to know what is being done in the name of group relations. Obviously I don't and shouldn't have any control over thisthough I admit that at times I've wished I had! What I have done over the last 15 years is to try to define the "Leicester Model". That makes comparisons possible. (E. J. Miller, personal correspondence, September $27,2001)$ 
Although the entire decade of the 1960 s was highly successful for the Tavistock Institute, the peak year, in terms of number of participants in group relations training programs, occurred in $1969^{5}$ when 716 peoples attended Tavistock group relations events. Of this, 55\% (393) of the participants were from industry and commerce and $20 \%$ (139) from medical, social, or other professional fields.

In response to this overwhelming public interest in group events, the 1970s saw an expansion in the availability of a variety of group events both in England and in America ${ }^{6}$. In 1971, the Tavistock Institute began offering two 14day residential Leicester Conferences, one in the spring ${ }^{7}$ and one in the fall, as well as other non-residential conferences, and weekly small study group events at their London facility (Tavistock Institute Annual Report, 1970-71, p. 4).

By 1973, enrollment had stabilized with 552 annual participants of which $38 \%$ (212) were now coming from medical, social, and professional fields and $34 \%$ (192) from educational institutions including universities with only a small percentage of participants originating from industry and commerce-obviously a significant change in member demographics over just four years time.

Although Miller and his colleagues at the CASR were pleased with the popularity of its group relations program, the 1970-71 Tavistock Institute Annual

\footnotetext{
${ }^{5}$ Interestingly, the following year membership dropped $42 \%$ to 414 participants of which $42 \%$ were from the medical, social, and professional fields. This drop in enrollment and change in demographics could be attributed to Rice's death late in 1969 and the subsequent turnover in leadership of the Leicester Conference and the CASR.

${ }^{6}$ The details of the transference of the Tavistock method to the United States will be discussed in subsequent chapters.

7 Referred to as the Easter Conference.
} 
Report noted some concerns about the unbridled spread of their methods in the United States: "A more intractable problem is a growing number of conferences which carry the label of the 'Tavistock model' but which are organized by bodies that have no affiliation either to the A. K. Rice Institute or to CASR" (p. 5).

A format change to the Leicester Conference design. In 1969, Miller directed the Leicester Conference for the first time with Rice as his Associate Director. In one of the few format changes to the conference structure, Miller and Rice offered a different program that year. Conference participants applied for membership in one of two groups: one group, for experienced group relations members, was called the " $B^{8 n}$ group; the other group, for first time attendees, was now referred to as the " $A$ " group. The Tavistock Institute Annual Report (1970-71) reported how this change came to occur:

Although these conferences are conceived as essentially educational institutions from which members go back to and apply what they have learned to their work-roles in diverse organizations, a growing minority of members are attending primarily for training, in that they seek to become qualified to run group events of their own. This shift in the character of the conferences is being closely watched and we have adjusted to it in part by continuing to offer at the Easter [Leicester] conference special provision for members with previous experience. (p. 4)

\footnotetext{
${ }^{8}$ To qualify for "B" group status, an individual must have either significant group relations experience or previously attended a Leicester Conference.

9 "The " $A$ " group was formerty referred to as the working conference membership.
} 
During this era, the Leicester Conference's focus appeared to be predominantly on the study of leadership, authority, and organizations. The conference membership format remained largely unchanged, alternating between one large working conference one year and a split membership consisting of an "A" and "B" group the next (Leicester Conference Brochures, 1970-1980).

Although considerable technical developments have occurred over the years and there have also been shifts in emphasis in response to changing social values, in three fundamental respects, the 'Leicester Conferences' have remained unchanged: the focus is on the relatedness of individual to group and organization; the method relies basically on learning through experience in 'the here and now'; and the stance is educational. (Leicester Conference Brochures, 1979, p. 1)

Although the Leicester Conference design has remained largely unchanged over the past 45 years, except for minor variations such as those noted above, different individuals have had a significant impact on the experience of a group relations conference. Two frequently mentioned names as examples of those having such an impact were Pierre Turquet and Eric Miller.

Pierre Turquet. After Rice's death in 1969, Miller and Turquet alternated the directorship of the Leicester Conference until Turquet's untimely death in an automobile accident in $1976^{10}$. Many informants described with great admiration

\footnotetext{
${ }^{10}$ In 1976 Lawrence joined the rotation, first directing the Leicester Conference in 1978, then alternating with Miller until Lawrence's resignation from the Tavistock Institute in 1982.
} 
the impact that Turquet had on their learning and the group relations movement, and the tremendous sense of sadness and loss they felt at his death (Carr Interview, 2002; Lawrence Interview, 2002; Menzies Lyth Interview, 2002; Miller Interview, 2002). Lawrence recalled:

I think the gift that [Turquet] had was that he had a French father and his mother was a professor at London university. Pierre was a psychiatrist and I think he served with distinction in the war. And he was totally committed to the idea of group. He was very instrumental in the developing the general practice of groups which were run by the clinic at the time. How would I summarize Pierre? I think that you knew that Pierre had read much European literature and, for example, you know you would go to Oxford, and Pierre would buy yet again another copy of Lear. Another copy of this--his library was full of duplicates. He was a remarkable man...What Pierre could do...you sort of felt him to be thinking in the large group and you felt him to be thinking in the institutional event. He was thinking all the time. (Lawrence Interview, 2002, p. 9)

Menzies Lyth also recalled Turquet and his influence over developments in the group relations movement at the time:

[Turquet] was a very large man, he was probably even bigger than Bion. He was very gifted and did have a lot of very innovative ideas... He was very influential because he attended a terrific number of Leicester Conferences. He was a real stand-by, he did a lot of the development of 
the large group work, because he was quite into psychosis as well and psychosis is absolutely alive in the large group...I think Turquet and Bion and Trist and Harold Bridger and me, probably others-Tim Dartington-have that feeling. We understood about how a person in a group could apparently lose his self, all together, and change in the most incredible ways because of other members. And I personally rather try to specialize in the subtleties of why that's done. Because it can sound like magic--and it isn't. (Menzies Lyth, 2002, p. 34-35)

Another often recognized leader in the group relations movement in the United Kingdom was Eric Miller.

Eric Miller. Born in High Wycombe in the United Kingdom in 1924, Miller's education was interrupted when he volunteered for military service in World War II serving in Britain, India, and Burma with the Royal Indian Artillery. After the war, he attended Cambridge University earning his doctorate in anthropology. Miller spent many of the ensuing years outside of England including traveling in Northern Thailand and conducting research on the caste system in Kerala, India. His social science philosophies became influenced by the group relations movement in the United States when he spent a year at Harvard in the 1950s. In 1956, Miller accepted a two-year assignment at the Calico Mills in Ahmedabad, India where he no doubt exchanged ideas with Rice who had begun making innovative transformations to the mill's organizational system there. 
These were foundational experiments using the socio-technical system, described in chapter two.

In 1958, Miller returned to England and joined the staff of the Tavistock Institute. Directing his first Leicester conference in 1969, with Rice as his Associate Director, Miller went on to Direct over 15 more Leicester Conferences and dozens of other conferences as well as participating in a host of other group relations events throughout the world. Upon Rice's untimely death in 1969, Miller was chosen to replace Rice as chairman of the CASR. Miller has remained a central figure in the group relations movenient for over 45 years.

What is particularly noteworthy about Eric's contribution is that his time at the Institute spanned several 'generations' of these scholars; that he survived the schisms and disagreements that were occasionally, but inevitably, part of the Institute's intense, close-knit community; and that he was able to exercise clear leadership for and behalf of the Tavistock, often amidst colleagues who were themselves powerful and ambitious leaders. It is thus hard to over-estimate the significance of Eric's role in sustaining and strengthening the Tavistock Institute during his many years there. (Stein, 2002, p. 12)

Miller died from complications of lung cancer on April 5, 2002 in London. He will be remembered as "an astute thinker, writer and action researcher...the quintessential Leicester Conference man: to many, he was Leicester, a man who 
combined gravitas with a dry sense of humour [sic] and a razor sharp mind" (Stein, 2002, p. 13).

Two pressing issues in the 1970s. Under Miller's leadership the CASR continued to evolve in the early 1970 s identifying two pressing organizational issues. First, they determined that they were predominantly responding to the needs of clients and working in areas that they were asked to investigate--not directing their own future. "We came to the view that we wanted to extend our areas of work to include research into current social dilemmas, such as those posed by disabling conflict and poverty" (Tavistock Institute Annual Report, 1969-70, p. 4-5).

Second, the CASR noted that their current system "did not provide sufficient opportunities for young people to join us and to learn" (Tavistock Institute Annual Report, 1969-70, p. 5). Instead, the current structure encouraged consultants 'to shed junior staff and to live in a world bounded by clients. Our consultants were in danger of a future that implicitly involved simply growing old together with no obvious successors" (Tavistock Institute Annual Report, 1969-70, p. 5).

In response to these two challenges, the CASR restructured its organization. Yet even with this restructuring, the CASR remained committed to its original values "to maintain considerable emphasis on consultancy and social science practice directed to facilitating social change. This is a distinct part of our orientation" (Tavistock Institute Annual Report, 1969-70, p. 5). 
Miller described how, after Rice's death in 1969, he was selected to replace Rice as the Director the Group Relations Training Programme within CASR and as the Director of the Leicester Conference. He claimed that he was selected for this position, over Turquet, because of his organizational experience and education in anthropology. Miller confided that he believed Turquet to be more qualified for the Director position, but that it was uniformly held by group relations people in England, that having a non-clinician in this role was essential (Miller Interview, 2002). Miller stated:

[Pierre Turquet] and I inherited the Tavistock Group Relations Programme when Rice died. He was the more qualified, but Rice was insistent that it was inappropriate to have a psychiatrist or analyst in the Director role because such a person was likely to have more difficulty in holding on to group-as-a-whole dynamic. The membership would tend to set up individual causalities to mobilize the Director to his therapeutic role. I have certainly seen this happen with Turquet and others. (E. J. Miller, personal correspondence, 2002)

Based on these quotes, it becomes apparent that the early developers of the Tavistock model were well aware of the potential systemic conflicts that might arise by overemphasizing the therapeutic side of the group relations experience. In this respect, they were continuing in the tradition of multidisciplinary staffing that Bion, and others, had pioneered at Northfield. Although it is easy to see the potential for therapeutic value, Rice and his cohort 
designed conferences with a specific organizational application orientation based on the system psychodynamics model described in chapter three. Yet, as we will see in subsequent chapters, when this Tavistock method was exported to America, it seemed to lose both its multidisciplinary and its application orientation in favor of emphasizing the therapeutic side of the group relations experience that Miller and Rice guarded against. To use terms from open system theory, it became a closed system (Rice, 1965). This concept will be further explored in chapter eight.

Dedining interest in the group relations movement. By the late 1970s, enrollment in group relations events was in serious dedine. In 1977, only 269 people attended CASR group training events. In response to the waning interest, 1980 was the last year that CASR offered two residential Leicester Conferences. There was a similar drop in interest in group events in the United States during this time period which will be discussed later in this dissertation. Since 1980 , the Tavistock Institute has continued to offer one annual Leicester Conference as well as a diverse series of other group relations events.

In 1979 Miller, the Leicester Conference Director, offered the first Training Group in addition to the usual "A" group or working conference format. The purpose of the training group was to provide "advanced training in applying the methods of these conferences whether in similar events or other contexts" (Leicester Conference Brochures, 1979, p. 2). After that year, the Leicester Conference format alternated between an " $A$ " and " $B$ " membership one year and 
a working conference with training group the next. This continued until 2001 when Director Tim Dartington offered an "A," "B," and Training Group format for the first time.

While Miller remained intimately involved in the group relations movement in the 1980s and 1990s, he was ever aware of the need to plan for succession and rotated a number of new faces into the directorate of the Leicester Conference. These included Obholzer, Carr, Dartington, Sher, and Khaleeleewho in 1995 became the first woman to direct the Leicester Conference.

\section{Exportation of the Tavistock Model}

As Miller described earlier, there was a rapid dissemination of the Tavistock model and group relations conferences throughout the world in the 1960 s (E. J. Miller, personal correspondence, September 27, 2001). The next chapters of this dissertation will examine the circumstances of the transference of the Tavistock model to the United States and the emergence of the A. K. Rice Institute (AKRI) and its methods of working with groups. Chapter four will discuss the cultural context in which this transference was accomplished; chapter five will highlight the influential people; chapter six will discuss the influential organizational structures; and chapter seven will detail some of the changes that took place over time and critical incidents that sparked those changes. 
Chapter IV: Tavistock Transferred-Stories of the Group Relations Movement in America: The Cultural Context (Including the Story of an Indigenous Group Relations Model)

\section{Introduction}

This chapter-and the three subsequent chapters-tell the story-or to be more precise, a number of different stories-about what happened when the Tavistock model was transplanted to the United States and was institutionalized within the A. K. Rice Institute (AKRI) that was created for this purpose. This chapter provides exposition for the three stories that follow. It explores the cultural context of the United States and why that culture was predisposed to welcome the Tavistock approach when it was imported to the United States in 1965.

This chapter also describes an indigenous group relations tradition, introduced by the National Training Laboratories Institute for Applied Behavioral Science (NTL), which developed prior to the importation of the Tavistock model to the United States. This indigenous model's approach is often considered to be radically distinct from the Tavistock model. Yet, in the previous chapter evidence of early cross-pollination was provided. In subsequent chapters these two models, the NTL and Tavistock models, will be examined further. The findings suggest that while there are some early similarities, there are also significant differences between these two models. In addition, I will argue that the AKRI 
tradition, which emerged in the United States in the 1960 s with roots in the Tavistock Institute's theories and methods, also differed in significant ways from both the indigenous NTL model and the imported Tavistock model.

Before these issues can be addressed, however, the various versions of the "Tavistock transferred" story will be told in chapters six, seven, and eight. As a preface to these chapters, which tell the Tavistock transferred story from different vantage points, the cultural context of the post-World War II era in America and the indigenous group relations model that sprang up in this context will now be discussed.

\section{Post-War Culture in the United States}

In England, the proximity of war to everyday life meant there were thousands of civilian casualties and private homes bombed; this created a highly stressful environment for the general population that was not present in the United States. Although there was rationing and self sacrifice in the United States during the war, and thousands of Americans were killed in battle in Europe, America, after the war, was a much different place than post-war England. One major difference was that, compared to England, the United States had few wardamaged structures to attend to. Therefore, as Europe turned its attention to rebuilding demolished cities and towns, the United States was able to concentrate on expanding its industries. With virtually no competition, as well as a ready-made customer base in destitute Europe and Asia, the United States economy thrived (Roszak, 1995). 
By 1945, in fact, the United States was well on its way to being the world's only state-of-the-art technological establishment. New industries such as electronics, chemicals, plastics, and aerospace were created and required a new generation of highly skilled workers to support them (Roszak, 1995). And since inflation was negligible, the American dollar was actually buying more goods. Gitlin (1987) wrote, "Natural resources seemed plentiful, their supplies stable; and only small think-tanks and obscure writers worried about whether they might ever prove exhaustible" (p. 13).

This time of plenty was what Roszak (1995) called the age of affuence in the United States. Consumerism was at an all-time high: Many Americans drove big gas-guzzling cars out to seemingly identical homes in the newly created suburbs in order to eat TV dinners while watching quiz shows via a new medium called television. Disgusted by what appeared to be self-indulgent behavior, warweary Europeans looked on with both envy and resentment at those Americans who were now acting like "pigs in heaven" (Roszak, 1995, p. xvi).

Of course there was another side to the story of the "age of affluence"; this was played out on the streets of Harlem and in the backwoods of Mississippi where this new found prosperity did not reach and inequities in the status quo persisted.

Movies, music, and literature both reflected and propelled the morphing culture of the fifties and sixties. The influential messages spread by these media created a powerful force that fueled the formation of a number of different 
movements in the United States, such as the students', civil rights, women's rights, and anti-war movements. Another movement of sorts was formed on the fringe of the literary world to guard against what they perceived to be the "deathly pallor of middleclass culture" (Gitlin, 1987, p. 47). Scorning American society, conventional schooling, and Christianity, a group of young intellectuals, called beats, caught the attention of many a youth. Almost exclusively young, White and male, this group had a "lust for freedom, individuality and a bohemian lifestyle" (www.beatfest2002.com). Even though by the early 1960s many of the original beats had moved on, their message had been picked up by a new group of young enthusiasts from high school kids in the suburbs to part-time bohemians, and still has reverberations in literature and music today.

In part, due to this beat attitude as well as to the rise in consumerism, the empowerment movements, and the influence of movies, music, and literature that, in the midst of pervasive prosperity in the United States, some members of the younger generation began experiencing a sort of identity crisis. According to Roszak (1995), this new generation of young, educated, idealists

had already decided that Beatnik poets and Greenwich Village folksingers were better role models than fathers who had sold their souls to General Motors or mothers who racked their brains all day to bake a better biscuit...Here then was a contradiction that left-wing ideologues of the past had never foreseen...In post scarcity America, rebellion was breaking out where it was least expected: amid younger members of the bourgeois 
elite whose interests the military-industrial complex purported to serve. Taking full advantage of the security permitted by the general affluence, this generation began to demand levels of freedom, self-expression, and enjoyment that suggested they saw life as something more than getting and spending. Worse, they demanded an idealism that life rarely affords in adulthood. (p. xov)

These demands by the younger generation infuriated an establishment that did not take lightly insinuations that their leadership was faulty or that their lifestyle was not the utopia they believed it to be. Few times in history have ever witnessed debates about such fundamental values held before an entire nation. It seemed that the American ethos itself was being called into question.

The confrontation between a critically thinking younger generation, hardened through experience in a myriad of political and social movements, and an apparently close minded establishment, prone to harboring secrets, resulted in pervasive distrust of authority. By the mid-1960s, in fact, the theme question authority became a battle $\mathrm{cry}$ as different movements coalesced into one poorly coordinated, disenfranchised, anti-establishment group. Thus, by the time that the Tavistock model, with its foundation in the study of authority, was exported to the United States in 1965, the cultural ground was already richly fertile and prepared for the growth of this approach on American soil. 


\section{An Indigenous Group Relations Model: Lewin and the NTL}

The ground, in fact, was so fertile that an indigenous approach to working experientially with groups had already sprung up in the United States during the post-war period. Organizationally this approach took the form of the National Training Laboratories Institute for Applied Behavioral Science (NTL). The NTL's conceptual roots can be found in the theories of sociologist, Kurt Lewin, a theorist who, as noted in the previous chapter, had a significant impact on the thinking of members of the Tavistock Institute in England. The remainder of this chapter focuses first on Lewin, then on the NTL, the organization that Lewin's thinking inspired, and finally on the NTL's influence in the American cultural context.

Lewin and his work. After fleeing Nazi Germany for the United States in 1932, Lewin settled into a teaching position at Iowa State University in applied behavioral science. During World War I, he had observed first hand the potential that humanity had for good and evil, and firmly believed that the social sciences could, and must, be used to maximize human good. His harrowing wartime experiences, in fact, resulted in a life-long commitment to using science to integrate democratic values in society. Freedman (1999) wrote: "When WWII ended, the full extent of the Holocaust was revealed in horrific detail. Lewin was convinced that the democratization of America and its institutions was the only viable means of preventing a recurrence" (p. 127). 
Two decades earlier, Lakin (1976) made a similar assessment of Lewin's thinking when he wrote:

It is perhaps no accident that the human relations training laboratory began in the wake of World War II--a war against fascism--and that other forms of experiential groups received a great impetus at the same time. The idea of democratic participation in a pluralistic society with contending pushes and pulls was anchored, at one end, in the ideal of free individuals competing in a free society and, at the other, in acknowledged responsibilities to community, job, and family. (p. 53)

It seems that Lewin, among others, was struggling with the very definition of a democratic society--and the boundaries of freedom within it. These concepts become foundational in the development of the $N T L$ model.

The precursor and, to some extent, the prototype for the NTL's human laboratory and the Tavistock group relations conference, was a 1946 conference that Lewin, then the Director of Massachusetts Institute of Technology's (MIT) Research Center for Group Dynamics, was asked to create ${ }^{1}$. The conference's aim was to assist in training leaders to deal with inter-group tensions in their home communities. The organizing committee's minutes (Feb. 27, 1946) noted that the task of the conference was:

\footnotetext{
1 This conference was sponsored by the Connecticut State Department of Education, the Connecticut State Inter-Racial Commission, the Connecticut Valley Office of the National Conference of Christians and Jews, and the Commission on Community Inter-Relations of the American Jewish Conference.
} 
Eliciting cooperation and trying to educate people in a clear understanding of how people of different races, colors, and creeds can live and work together, and how best we can achieve harmony. (cited in Freedman, 1996, p. 343)

Lewin agreed to organize the conference, undoubtedly, in part, because he was committed to the democratic nature of the conference goals. Furthermore, the need for greater racial understanding was obvious in the aftermath of World War II as Black Americans returned home from the war feeling entitled to compete for better jobs and educational opportunities (Freedman, 1996).

Lewin also undoubtedly accepted the Connecticut Commission's invitation because it provided an opportunity to conduct research on behalf of the Research Center for Group Dynamics, his research center located then at MIT, and later moved to the University of Michigan, Ann Arbor (Bradford, Gibb, \& Benne, 1964; Freedman, 1996). Lewin and his staff, in fact, intended to study and document the process by which conference participants dealt with the controversial issues presented throughout the event.

This research element played a significant part in the first conference. It also was a key element in the design of the NTL, later founded after Lewin's untimely death in 1947 by Ronald Lippitt, one of Lewin's previous graduate students, along with two of Lippitt's friends: Kenneth Benne and Leland Bradford (Back, 1972; Freedman, 1996; Lakin, 1976; NTL Institute Website, 2001). In 1996, for example, Freedman observed: 
Contemporary historical revisionists have recently blurred this [emphasis on research]. I maintain that $\mathrm{NTL}$ was founded to develop and study [italics added] methods for preserving and enhancing democracy in our American society and its institutions. (p. 344)

Thus, Lewin approached the 1946 conference with two goals: to help people learn how to live together harmoniously by embracing democratic values and to treat the conference as an opportunity for action research. Lewin devised a training program consisting of three learning groups, each containing a leader and an observer whose task was to record the interactions among the group participants. Lewin asked Lippitt to lead one group and invited Benne and Bradford to lead the other two. What happened at the workshop would become legendary in the field of group relations (Back, 1972; Bradford, Gibb, \& Benne, 1964; Freedman, 1996).

Three of the conference participants asked to attend the evening staff meeting which was usually devoted to staff reports of the day's events. Much to the chagrin of the staff, Lewin agreed to this unorthodox request. As the staff reported to the group, one of the female participants disagreed with a male staff member's interpretation of her behavior that day. A male participant agreed with her assertion and a lively discussion ensued about behaviors and interpretations. Word of the session spread, and by the next night, more than half of the sixty participants attended the evening staff meeting. By the last evening of the conference most, if not all, participants were attending these sessions, which 
often lasted well into the night. This new concept of learning in the moment, respecting peoples' different interpretations of events, and providing feedback became a cornerstone of the NTL model, and, as was discussed in the previous chapter, was shared with other group relations organizations like the Tavistock Institute (Back, 1972; NTL Institute Website, 2001).

Back (1972) hypothesized how the changing cultural context, and a growing group consciousness, in the United States made this particular Connecticut workshop the impetus for an entire group relations movement:

The workshop was designed precisely for that part of the population most susceptible to this new movement. The trainees included people engaged in interracial work, professionals, people involved in education and community work--all were people who were dissatisfied with themselves, their effectiveness in dealing with an important problem, and their relationship to the dominant issues of society. In other times, people in a similar predicament might have sought spiritual comfort, ideological inspiration, or confirmation of their weaknesses; but here they were looking for help in the form of improving their techniques of dealing with other people and through the growth of group consciousness. (p. 47) It was clear to all involved in this new training program that something exciting had been discovered about ways in which adults learn. Lewin's hypothesis that adults learn more effectively through experiences shared in training group events rather than traditional seminars was judged correct by 
conference research. The thesis seemed especially applicable to learning situations geared to modifying behavior. As we have seen in the previous chapter, this hypothesis was one that Rice $(1965$, p. 26) came to share and also used to develop the model for the Tavistock group relations conferences.

In 1947, the first NTL human laboratory occurred in part to further develop and to test Lewin's ideas. At this event the Basic Skills Training Group or T-Group was born ${ }^{2}$.

T-Group and the laboratory setting. The first human laboratory was conducted at Gould Academy in Bethel Maine in the summer of 1947. The Bethel location was selected in part because of Lewin's belief that intense personal learning experiences should be conducted on a "cultural island" where participants felt safe to try-out different approaches (Bradford, 1967, p. 138). The goal of this event was to experiment with new methods for re-educating human behavior and social relationships. The educational process that was at the core of these initial and subsequent NTL workshops was called sensitivity training and was transmitted to the participants via small groups of people meeting in TGroups (Freedman, 1999, p. 127-8).

The basic structure of the NTL human laboratory, which was originally three weeks in length, has now been slimmed down to just six and a half days,

\footnotetext{
${ }^{2}$ This first workshop was a joint venture between the National Education Association (NEA), the Research Center for Group Dynamics at MIT and the NTL. It was, in part, through the legitimacy gained through the connection with the NEA and the fruitful research collaboration with the MIT that NTL survived these earty years. Small yearly grants from the Camegie Corporation kept the NTL afloat through the fledgling years of the late 1940s. Then in 1950, Bradford (1967) recalled "a large grant from the Carnegie Corporation gave more assurance of continuity and made possible the establishment of a year-round office and program for NTL to be located within the National Education Association" (p. 141).
} 
consisted of T-Groups in the morning and an A-Group in the afternoon. The TGroup emphasized interpersonal and intra-personal learning. The A-Group, or Action Group, emphasized "skill training and social change" (Bradford, 1967, p. 141).

Bradford, Gibb, and Benne (1964) described the sort of pedagogy employed at the NTL workshops which, as discussed in chapter four, became one of the design elements that was cross-pollinated with the Tavistock Institute's group relations conference when it emerged in England ten years later:

The major method of learning employed is one in which participants are helped to diagnose and experiment with their own behavior and relationships in a specially designed environment. Participants are both experimenters and subjects in joint learning activities. Staff members or trainers serve as guides in the institutionalization of experimental and collaborative approaches to learning in the laboratory community. They also guide the transfer of these approaches outside the laboratory. ( $p$. vii) This pedagogy of learning from one's own behavior in a specially designed environment through the assistance of a guide, rather than a traditional teacher, is pivotal. It is the fundamental teaching strategy upon which all experiential group events are based-whether conducted at an NTL, Tavistock, or A. K. Rice Institute (AKRI) event. 
Comparing the pedagogies of the NR and Tavistock models. Although both the NTL and Tavistock models are based on a similar experiential learning pedagogy--investigating the group as a "microcosm of the total society" (Klein and Astrachan, 1971, p. 660), studying behavior as it occurs in the here-andnow, and allowing latitude for an individualized interpretation of the learning experience--there are also distinctly different areas emphasized within these similar processes. For example, Klein and Astrachan (1971) observed that the NTL's "training groups are used to help their members learn about group dynamics and about their own presentation of self to others through direct participation" (p. 663). Conversely, Klein and Astrachan noted that the Tavistock's

study group approach emphasizes a focus on the group; it deals little with the dynamics of individuals. It assumes that when members speak they usually speak for the group or some part of the group, and it conceptualizes most of the group's behavior as a function of its relationship with the authority figure. (p. 665)

More specifically, the NTL model's human laboratory focuses on modifying an individual's directly observable behaviors and attitudes through a variety of feedback exercises. In contrast, the Tavistock model's group relations conference focuses on understanding the covert and unconscious group behaviors, especially in relationship to authority figures, within the temporary social institution of the 
conference structure (Klein and Astrachan, 1971; Neumann et al., 2000). Table 1

further amplifies the differences between these two models.

Table 1: Comparing the NTL and Tavistock Models of Group Relations ${ }^{3}$

\begin{tabular}{|l|l|l|}
\hline Model & $\begin{array}{l}\text { National Training } \\
\text { Laboratories (NTL) }\end{array}$ & $\begin{array}{l}\text { Tavistock Institute of Human } \\
\text { Relations (TIHR) }\end{array}$ \\
\hline Origin & USA & UK \\
\hline Date: $1^{\text {st Event }}$ & 1947 & 1957 \\
\hline Early Influencers & $\begin{array}{l}\text { Benne, Bradford, Lewin, } \\
\text { Lippitt. }\end{array}$ & $\begin{array}{l}\text { Bion, Bridger, Menzies Lyth, } \\
\text { Miller, Rice, Trist, Turquet. }\end{array}$ \\
\hline Orientation & Education & Application \\
\hline Main emphasis & $\begin{array}{l}\text { Interpersonal effectiveness } \\
\text { within group process. }\end{array}$ & $\begin{array}{l}\text { Group as a whole within wider } \\
\text { social system. }\end{array}$ \\
\hline Focus & $\begin{array}{l}\text { Learning how attitudinal and } \\
\text { behavioral change of } \\
\text { individuals results in } \\
\text { effective progress within } \\
\text { group. }\end{array}$ & $\begin{array}{l}\text { Understanding psychoanalytic } \\
\text { dynamics within group as } \\
\text { members relate to authority } \\
\text { figures embedded within } \\
\text { larger social institution. }\end{array}$ \\
\hline Objectives & $\begin{array}{l}\text { Individual growth, } \\
\text { interpersonal competence, } \\
\text { behavioral change through } \\
\text { experimentation. }\end{array}$ & $\begin{array}{l}\text { Interpretation and } \\
\text { understanding of } \\
\text { organizational life and } \\
\text { authority in specific } \\
\text { relationship to Director and } \\
\text { consultancy staff. }\end{array}$ \\
\hline Application & $\begin{array}{l}\text { Organizational development } \\
\text { Socio-technical systems/Open } \\
\text { Systems Theory }\end{array}$ \\
\hline $\begin{array}{l}\text { Individual } \\
\text { behavior }\end{array}$ & $\begin{array}{l}\text { Individual behavior is the } \\
\text { responsibility of that } \\
\text { individual; individual } \\
\text { expected to speak for self; } \\
\text { own up to his/her feelings. }\end{array}$ & $\begin{array}{l}\text { Concentrates on individual } \\
\text { only in so far as he/she is } \\
\text { manifesting something on } \\
\text { behalf of the entire group. }\end{array}$ \\
\hline Staff role & $\begin{array}{l}\text { "Trainer" role-models good } \\
\text { honber behavior through }\end{array}$ & $\begin{array}{l}\text { "Consultant" adheres strictly to } \\
\text { studying group's behavior in } \\
\text { the here-and-now. }\end{array}$ \\
\hline
\end{tabular}

\footnotetext{
3 Adapted from Neumann, Holvino, and Braxton, 2000, p. 11; using ideas from Bion, 1961;
}

Freedman, 1999; Klein and Astrachan, 1971; Rice, 1965; Trist and Sofer, 1959 


\begin{tabular}{|l|l|l|}
\hline Representation & $\begin{array}{l}\text { Forming, storming, norming, } \\
\text { performing; feedback; } \\
\text { inclusion, control, affection. }\end{array}$ & $\begin{array}{l}\text { Pairing, fight-flight, } \\
\text { dependency; projections; } \\
\text { transference and counter- } \\
\text { transference; open systems. }\end{array}$ \\
\hline $\begin{array}{l}\text { Leadership and } \\
\text { power }\end{array}$ & $\begin{array}{l}\text { Concerned with internal } \\
\text { struggle, provision for } \\
\text { support and nurturance of } \\
\text { followers }\end{array}$ & $\begin{array}{l}\text { Boundary management; } \\
\text { potential for mutual } \\
\text { dependency and hostility } \\
\text { between leader and follower. }\end{array}$ \\
\hline
\end{tabular}

NT's golden age. Freedman (1999) called the 1960s NTL's "Golden Age" because there was a steady increase in enrollment in its programs and widespread popularity of its philosophies and ideals. "The growth of NTL in the sixties was phenomenal. Income between 1963 and 1968 had multiplied by five, contracts by nine, and the NTL network had nearly doubled" (www.ntl.org.).

Many famous and influential people attended NTL events at its facility in Bethel, Maine. For instance, Douglas McGregor, originator of the philosophies of Theory $X$ and Theory $Y$, attended an NTL event. Harold Bridger, co-founder of the Tavistock Institute, first came to Bethel in 1957 and has returned virtually every year since to bring his version of the Tavistock's socio-technical systems theory ${ }^{4}$. Abraham Maslow, originator of Maslow's Hierarchy of Needs, also spent time in Bethel during this period. Finally, Carl Rogers, one of the early influencers of the widely proliferated Encounter Groups in the 1960 s and 70s, was an early NTL enthusiast (Freedman, 1999).

From the "golden age" to the dedine of NTL. It is important to examine briefly the NTL's organizational history and development because, as we will see

\footnotetext{
${ }^{4}$ Socio-technical systems theory was discussed in chapter three.
} 
later, the two group relations organizations in the United States, NTL and AKRI, have at times mirrored as well as diverged from each other developmentally. For instance, we will see later in this dissertation that, like NTL, AKRI was experiencing tremendous popularity and growth during the 1960s. It will also become clear that AKRI continued to prosper well into the 1970s-a period of decline for NTL. Causes for this disparity will be examined.

Here, it will be sufficient to state that, during the 1970 s, NTL was beginning an era that would be characterized by "moral, ethical, and financial crisis within the NTL" (Freedman, 1999, p. 133). The NTL became in some ways subverted by the very egalitarian philosophies it claimed to support: the civil rights', women's, anti-establishment, anti-war and pro-peace movements. In the early 1970s, in fact, NTL imploded. Porter, current NTL President, recalled, "Part of that implosion had to do with people feeling that the organization was dominated by White males and [it was time] to bring in more women and people of color" (Porter Interview, 2002, p. 7). As we shall see, the story of the transference of the Tavistock model to America has had a similar plotline, although, the organizational crisis in the Tavistock transferred story occurred more than a decade later than it occurred in the $\mathrm{NTL}^{5}$.

In addition to these social challenges, there were other problems of a more financial nature that plagued the NTL during this period of decline. First, with a glutted membership of well over $500, N \pi$ had essentially trained itself out

\footnotetext{
${ }^{5}$ Coincidentally, both organizations experienced their respective organizational "implosions" approximately 20 years after their initial incorporation date: 1951 to 1970 for the NTL and 1970 to 1990 for the AKRI.
} 
of business. Independent trainers, former members who were taught their skills by the NTL, now competed with and often won out over NTL for the lucrative contracts that the parent organization so desperately needed in order to survive. Porter recalled:

There had been this rapid expansion and growth and there were field offices in five or six different locations around the country. And it never really operated as a business because it was just this thing, this association that people came to, and then there was a realization that you had all this expense...by the 70s we had trained so many people to do the same thing that we did--they were out doing it for the business' that would have automatically come to NTL. (Porter Interview, 2002, p. 7). There were other financial challenges as well: The NTL's training facility in Bethel required extensive renovations, the Department of Defense had cancelled a major training contract, and the proposed NTL university was determined to be too costly and was abruptly cancelled. In addition, the proposed name of this new university, the University of Man, did not sit well with female members of the organization. "Paradoxically, NTL was facing changes and difficulties in its own organization that it had helped other organizations to solve" (www.ntl.org).

In addition to the NTL facing internal personnel conflicts and financial challenges, the development of the new field of organizational development (OD)-a field that was rooted in NTL thinking and methods--in the 1970 s created other challenges for the faltering organization. Freedman (1999) observed that 
one of the causes of NTL's decline was their "core value" to "give what was learned away to people who could use the knowledge. There was no sense of proprietary information, and copyrights were not used" (p. 129). Although on the surface this cooperativistic philosophy seems similar to the free-flowing nature of good will pervasive in the tie-dyed sixties, by the seventies such a philosophy was a huge financial liability. Porter discussed these early decisions and the financial impact on her organization today:

There is an economic struggle at NTL because we have never acted like a business, we never trademarked anything we did. We started with the philosophy that education was to be given away. Well, now there are other companies that are taking our stuff and are making a million dollars off of it and we created it...We've always operated for 57 years, on an economic shoe-string and it was just enough to pay the bills. We've had a love hate relationship with money in the organization, because I think we always thought that money was just an evil medium but we needed it just to get by. We've never had large reserves, so when you live on a shoestring and something causes you to break that shoestring then you're sort of in trouble. (Diane Porter Interview, 2002, p. 24-25)

Encounter groups. Yet, the problem was not just financial. The explosive popularity of NTL's training events in the United States in the 1950s and 1960s, and NTL's lack of copyright for their material, also set the stage for replications of their work, authorized and unauthorized. This replication became so 
widespread in America in the sixties that it became known a full-fledged movement, the personal growth or human potential movement. Groups within this movement, generically called encounter groups, traced their origins to the theories of Lewin, the methods of the NTL model, and the concept of sensitivity training developed by NTL in the 1950 s, capitalizing on the fame and success of these earlier ideas and organizations. Yet, encounter groups lacked the structure, focus, and application that previously discussed group relations models had.

Some of the greatest criticisms of encounter groups were the questionable expertise of group trainers, the psychological danger of some exercises, and a lack of standardization of training goals. For example, a wide variety of nonverbal exercises were often used in encounter sessions consisting of almost any imaginable scenario--some included the deprivation of sleep or bathroom facilities or forced interactions among naked group members--all as a way to explore social taboos. Another criticism of encounter group workshops was their enthusiastic, yet unsubstantiated, claims of success which encounter group experts such as Howard (1970) and Rogers (1970) freely admit.

Yet during the height of its popularity, this human potential movement was a heady representation of the changing American culture, and was often referred to-albeit sometimes satirically--in movies such as The Diary of a Mad Housewife and Bob and Carol and Ted and Alice, television programs such as Dragnet, The Courtship of Eddie's Father, and The Phil Donahue Show, and popular magazines such as Time, Vogue, Redbook, and Psychology Today. A 
number of best selling books were also written about the human potential movement during this time. Please Touch by Jane Howard (1970) and Cart Rogers on Encounter Groups by Carl Rogers (1970) are two of the most popular (Schimke, 1972).

Few of these encounter groups remain in existence today. Many of their themes, however, can be found in mainstream self-help programs like Alcoholics Anonymous, 12-Step programs, or even daytime talk shows like Oprah.

University programs. In addition to encounter groups replicating the NTL's work, a number of colleges were able to operationalize the NTL's earlier idea of a university program oriented around their theories and model of working with groups. Freedman (1999) wrote:

For example, George Williams College, Benedictine College, Pepperdine University, Fielding Institute, and the Union Graduate School-began master's degree programs in OD and human resource management. A few doctoral programs also emerged, most notably that of Case-Western Reserve University. Today there are over 20 universities in the US alone that offer graduate degrees in OD. (p. 135)

The NTL was not directly involved with, nor did it receive any financial reimbursement from, these lucrative university programs that built upon NTL ideas.

Eventually intellectual ties were severed as well. As Freedman (1999) noted: 
By 1977, NTL no longer held a leadership position in the field of OD. Its primary organizational effort focused on avoiding extinction. In addition, 'professional' NTL members who had been serving as business managers at the central office were replaced by naive but enthusiastic professional administrative staff. NTL's focus became one of maximizing revenues and reducing costs. (p. 136)

Required restructuring. In order to save its faltering organization, a massive restructuring was required on many levels at NTL. First, "all of its 500 Fellows, Members, and Associates were 'fired' " (Freedman, 1999, p. 135). Then only about 75 of those people were rehired, this time under a new cohort system designed to ensure better representation of women and people of color. In addition, these new members volunteered to donate two weeks of unpaid service to the organization over the next two years. NTL also stopped its once popular but now no longer lucrative publishing business, focusing now only on publishing its Joumal of Applied Behavioral Science and an occasional book. It also closed the six regional field offices that were located around the United States in favor of developing one national office ${ }^{6}$. Finally, the Board was reconstructed to included one-third White males, one-third women, and one-third minorities.

In 1975, Elsie Cross, the first woman and first person of color to join the Board, was elected as Chair of the Board and Edith Seashore became the first

\footnotetext{
${ }^{6}$ This elimination of local centers will also be discussed, in chapter seven, in relationship to restructuring efforts made by the A. K. Rice Institute (AKRI) in 2001.
} 
woman President of NTL (www.ntl.org). Freedman (1999) noted that a high price was paid to accomplish this restructuring:

Around this time, NTL lost a lot of its creative talent either because they were excluded from re-entry to the organization, or because for various reasons they declined the invitation to re-enter. For example, Warren Bennis, Marvin Weisbord, Chris Argyris, Harvey Hornstein, Warren Burke, and Barry Oshry were NTL members before 1975 but were no longer members after 1976. (p. 136)

Although this tumultuous restructuring was disruptive, and many talented former NTL members were alienated, it does seem that these systemic changes were required for the very survival of the organization. And while the changes may not have been ideal, they did seem to stabilize the faltering organization. By 1979, NTL had partnered with American University and developed a jointly sponsored master's program in order to finally begin to capitalize on the success and popularity of its own ideas in a university environment. And by the close of the tempestuous seventies, NTL was able to pay its past debts and its training laboratories were once again thriving. In this respect this period of the history of NTL demonstrated its operation as what Rice (1965) called an open system. Yet, as we will see in the next section even an open system remains threatened by its environment; the risk of entropy is constant.

NTZ's chance for recovery. After surviving its restructuring phase of the mid-1970s, a trimmer NTL was primed for full recovery as the end of the cold- 
war period in the 1980 s ushered in a more competitive global marketplace eagerly attempting to harness the advantages of the rapid technological innovations bursting forth at this time. Businesses in dire need of NTL's assistance in their struggle to restructure, downsize, and reengineer their organizations in order to compete in this new global marketplace might have provided an opportunity for the NTL to capitalize on. Yet, the proliferation of NTL's work never occurred. Freedman (1999) wrote:

The major activity at NTL during this decade was the repackaging of workshops into certificate programs in diversity management, OD consultation, laboratory-based or experiential education, and the like...what could have been a remarkable opportunity for NTL to reestablish itself was ignored or neglected. (p. 137)

"What went wrong?" we might ask. Holvino, an experienced NTL and AKRI scholar, provided one answer. She observed that continuing to repackage once successful workshops into a product and then, once the market was saturated, refocusing the themes of these same workshops into a train-thetrainer product, undermined NTL's success. By concentrating on providing these products, the NTL stopped experimenting, researching, and pushing the boundaries of group relations as the organization had done in previous decades. Holvino recalled:

I do think [NTL] has shifted from its original work which was a lot more focused on learning, was a lot more focused on research, learning about 
groups, experimenting with modes of working with groups...Pressured by the need to make money to survive in the context of a very [competitive] market environment, where profit is what makes sense, in that context $\mathrm{NTL}$ had to consolidate its learning into a product. And began to sell the product and the product is now Human Interaction Labs. And when that didn't bring enough people then we developed other products to sell. We invented, for example, how to teach people how to be diversity consultants...So I think we got stuck in a form of T-Group that is maybe from the 70 s or 60 s or something. There is no on going learning and research pushing the boundaries of what we are doing. (Holvino Interview, 2002, p. 22-23)

When asked to compare the causes of NTL's shift in ideals over the years from a research and experimental approach towards a more product oriented approach, Holvino pointed out:

We need to put all this in the context of the social environment in which we are. Those were also the days when there were big grants for research and for learning. Now learning is totally tied to the corporate environment. Even universities depend now on corporate monies to do their research. So I think it is unfair to say that it is an NTL problem I think it's a problem of who's doing the learning in a US capitalistic context today, who can afford to do learning? (Holvino Interview, 2002, p. 24) 
This question of "who can afford to do learning?" becomes a reoccurring theme within the group relations movement in the United States and, as we will see later in this dissertation, the AKRI struggled with this concept as well.

Where does NTL's future lie? The 1980s and 1990s were a time of tremendous potential for the theories and philosophies of the NTL as organizations struggled to meet the demands of a changing world and more global marketplace. Yet, NTL did not capitalize on that potential. Instead practitioners trained by NTL established their own companies, making millions of dollars meeting this market demand by copying NTL's methods and even using NTL's never-copyrighted training materials. Meanwhile, NTL focused on tightening its bottom line costs and developing a replicable product to sell-apparently losing sight of its foundational ethos. As Freedman (1999) pointed out:

During the early 1990s, NTL was faced with an identity crisis that continues today: is the Institute to continue to evolve into a moralistic, anti-oppression advocate for its own aggressive version of social justice? Or is NTL an Institute that conducts research in the applied behavioral sciences, then publishes and uses the results to create and deliver experiential, andragogical training programs that provide participants with concepts, strategies, methods, and personal skills needed to enhance democratic processes? Can it be both? (p. 137) 
The answers to these questions, and more, are still being sought within NTL today. In 1998 Diane Porter, an experienced and savy business woman, was hired as Director and President of the NTL. She is the first non-practitioner ever to hold this position and brings a different, more business-oriented perspective to the job. Porter recalled that when she was hired, there "was a feeling that the organization wanted to move outside itself rather than to stay so inwardly focused and pick its President from one of its existing members" (Porter Interview, 2002, p. 2).

One of the main challenges Porter and the NTL are still wrestling with is the question of organizational purpose ${ }^{7}$. Porter stated:

The big issue is: Do we do our programs for our own benefit, and the people who pay to come to them just happen to be necessary bystanders to help pay for this experience? Who do we serve? Do we serve our clients, or do we serve ourselves? And I think we are still wrestling with that question today. (Porter Interview, 2002, p. 4)

Organizational reassessment is never easy, especially for the generation closest to the organizations founding, perhaps in part, because reassessment can feel like rejection. Such questions about organizational purpose were replete within the Tavistock Institute's history, as we saw in chapter four-although they were noticeably absent in the history of AKRI--as we will see in the following chapters.

\footnotetext{
${ }^{7}$ This struggle over organizational purpose will also be discussed in chapter seven with regards to the AKRI.
} 
For many of the older generation who were involved in the group relations movement since the golden days when NTL was at the height of its popularity, these changes represented a sad turn of events as NTL's influence waned. Freedman (1999) noted:

For many reasons, including financial exigencies, NTL seems to have abandoned its pre-eminent position and moved to the less influential fringes of OD. Functional leadership in the $O D$ field has been assumed by various associations, universities, and consulting firms. For most younger or newer OD educators and practitioners, NTL seems to be perceived as a quaint anachronism that has some historical significance. Painfully, for me, many of these folks do not even recognize NTL's name. (p. 138)

\section{Conclusion}

By the time that the Tavistock model of group relations was imported to the United States in 1965, American culture had already prepared Americans to question authority. Furthermore, many Americans were attracted to the notion of examining group behavior and experiential learning thanks to the foundational work of the NTL and the proliferation of encounter groups. As a result, many people were already primed to embrace the imported Tavistock model and its methods of questioning authority. In fact, by the late 1960 s, the group relations movement had become so widespread in the United States, that "1968 was described in the New York Times as 'The Year of the Group' " (Klein \& Astrachan, 1971, p. 662). It is this combination of political, social, and cultural factors, in 
part, which helped to set the stage for the subsequent popularity of the AKRI and its group relations conferences. Further details of this fascinating story-as well as the AKRI story of decline which was both different from and similar to the NTL decline story--will be provided in the following chapters. 
Chapter V Tavistock Transferred-Stories of the Group Relations Movement in America: The "Great Mother" Story

\section{Introduction}

The story of any organization can be told in many ways. This chapter, and the subsequent two chapters, contain three different stories of the A. K. Rice Institute (AKRI). Each story focuses on different aspects of this institution.

This chapter discusses the life and influence of the person often referred to as the "the mother of group relations in America," Margaret Jeffrey Rioch (Carr Interview, 2002; Gould Interview, 2002; Miller Interview, 2002; Shapiro Interview, 2002; White Interview, 2002). Although "great person" theories of leadership have been called into question in recent years, AKRI cannot be understood without learning about Rioch, her role in founding this organization, and her contributions-for better and for worse-to the organization's culture, structure, and politics.

\section{Rioch's Personal and Professional Background}

The story of Rioch's life is a fascinating one and quite unusual for a woman of her generation. Rioch was born in 1907 in Paterson, New Jersey. After the death of her father the following year, she moved with her mother to live 
with her grandmother, whose own husband had also died at a young age, and her mother's sister. Rioch was the only child in this household of three women, all of whom were teachers, and none of whom ever remarried. Rioch (1996) recalled:

As a child and as a young girl, it seemed to me very natural that a woman should have a profession. In fact it would seem to be unnatural for a woman not to have a profession of significance and importance to her. Marriage, on the other hand, did not seem so natural. (p. 5) Although this was the depression era, Rioch, who had attended high school in Ridgewood, New Jersey, attended Wellesley College and received her doctorate from Bryn Mawr College in 1933 where she studied philology, literature, and philosophy. After graduation, her first job was teaching German at Wilson College. She eventually became Associate Professor of German at Wellesley College where she met her future husband, David McKenzie Rioch, M.D. who was a Professor of Neuroanatomy at Harvard Medical School in Boston. The two married and moved to St. Louis, Missouri, where David Rioch became the first Chair and Professor of Neuropsychiatry at the Washington University School of Medicine (Rioch, 1996; www.continents.com). Rioch (1996) wrote the following about this move:

We moved from Boston to St. Louis. It never occurred to me to raise any questions about this, although it meant for me giving up a job and a promising career. Today a woman would probably at least question 
whether or not to leave Boston...I soon found out that Washington University in St. Louis had a policy...for the purpose of protecting against nepotism...that meant that there was no hope of my getting a job there as long as my husband was employed in the medical school. (p. 7) Although initially disillusioned by these obstacles, Rioch seemed to make the best of her situation and, over time, she realized that her real interest lay in psychology. "Fortunately marriage gave me leisure and financial security enough to pursue graduate work in psychology," (Rioch, 1996, p. 7) she wrote. In 1943, she received her Master of Arts Degree from Washington University in Psychology. Her first area of interest and research after graduation became the Rorschach test which was just gaining notoriety in the United States at the time. Through this work, Rioch quickly realized that her interests lay more in qualitative, rather than quantitative, research methods and ultimately she found herself drawn towards clinical work and psychotherapy (Rioch, 1996; www.continents.com).

After five years in St. Louis, David Rioch decided to return to the east coast and took a position at the Chestnut Lodge Sanitarium in Rockville, Maryland. Rioch (1996) remembered:

Again without questioning I went along and found my own niche in the Community Mental Hygiene Clinic in Rocksville and, later, as psychologist at Chestnut Lodge, where I was the only psychologist ever permitted to do therapy in that very medically, psychoanalytically-oriented hospital...My 
psychotherapy has a psychoanalytic orientation, and, of course, I have been psychoanalyzed myself over several years. My major teachers were Harry Stack Sullivan and Frieda Fromm-Reichmann. (p. 8)

During this time period, Rioch also started to explore the relationship between psychotherapy and religion, including exploring the influence of Zen Buddhist teachings. She trained in Paris with Dr. Hubert Benoit, and collaborated with Professors Alan Watts, Daisetz Suzuki, and Martin Buber in this area (Rioch, 1996; www.continents.com).

One of Rioch's most famous projects was conducted in collaboration with Charmain Elkes at the National Institute of Mental Health in 1960-62 and was entitled A Pilot Project in Training Mental Health Counselors. Rioch trained middle-aged mothers whose children were grown and out of the house in psychotherapy to act as mental health counselors. The purpose was twofold: first to help meet the demands for community-based, low cost mental health services; and second, to provide older women with meaningful second careers. Rioch (1996) wrote:

When the children no longer need them, they were left feeling unused, unneeded, empty. I knew from my personal acquaintances that many of these women were intelligent, perceptive, and potentially very good therapists. The second problem...was that there was a great need at that time for low-cost psychotherapy. My idea was that for many intelligent women whose husbands were at the height of financially successful 
careers-doctors, lawyers, etc. - the financial rewards were not very important. (p. 10)

Although by today's standards Rioch's thoughts could be considered sexist, racist, and upper class, these comments should be considered in their historical context, when many women did not have careers and often happily relied on their husband's income.

In some ways this research proved to be pivotal as the idea of using paraprofessiona/mental health workers spread in the United States, both easing the burden on clinicians as well as broadening opportunities for many less well represented groups to gain entry into medical fields. This idea of using trained, yet non-medical, professionals in their therapeutic communities, of course, can be traced back to the Northfield Hospital during World War II, and the Tavistock Institute of Human Relations (Tavistock Institute) in post-war England. Rioch's attraction to this concept of paraprofessionals, and therapeutic communities, could be another reason that she was so quickly attracted to the Tavistock model and quickly became dedicated to the task of successfully importing it to America.

\section{The Tavistock Model Goes To America}

The story of Rioch's attempt to bring the Tavistock model of group relations to American soil begins in 1963 when she first went to the Tavistock Institute's Leicester Conference at the suggestion of an English friend, C. Sofer (AKRI History video, 1995). Rioch, a clinical psychologist and psychoanalyst, along with her colleague, Morris Parloff from the National Institute of Mental 
Health (NIMH), traveled to London to participate as members in this world renowned group relations conference. This was the seventh Leicester Conference and was directed by Rice with Turquet, among others, on staff. Rioch (1996) wrote of her impressions of Rice:

Since my college days there is no one I regard so much as my teacher, mentor, and in many ways a role model. I admired particularly the discipline with which he held to any task he took on, but particularly that of conference director. (p. 11)

The 56 year old Rioch was so taken with both group relations, and Rice himself, that, at the end of that conference, Rioch approached Rice and Turquet about the possibility of conducting a group relations conference in the United States in the near future. After a discussion, the three agreed it might be better to conduct another group relations conference for Americans in England as a trial the following summer and so they set about to arrange it (Rioch, 1996). Upon returning to the United States, Rioch conducted some personal research by attending an National Training Laboratory (NTL) event in Bethel, Maine; her goal was to ensure that these novel British group relations conferences were not already being conducted in some other form in America. Of her NTL human laboratory experience, Rioch (1996) wrote:

The whole attitude, the philosophy, the principles, and what one could learn, seemed to me to be quite different from what I had experienced in 
England so that I felt sure I would be bringing a new injection into the American bloodstream. (p. 12)

Although Rioch did not specifically describe the ways in which she experienced the NTL model differently than her previous encounter with the Tavistock model, there are commonly recognized distinctions between the two models that she may have observed. For instance, the NTL model "focuses on interpersonal effectiveness in the context of group process," while the Tavistock model "emphasizes the group as a whole embedded in a wider social system" (Neumann, Holvino, and Braxton, 2000, p. 1). More specifically, the NTL model's human laboratory focuses on modifying an individual's directly observable behaviors and attitudes through a variety of feedback exercises. In contrast, the Tavistock model's group relations conference, reflecting the intellectual foundation of psychoanalysis discussed in chapter two, focuses on understanding the covert and unconscious group behaviors, especially in relationship to authority figures, within the temporary social institution of the conference structure (Klein and Astrachan, 1971; Neumann et al., 2000).

Perhaps Rioch recognized some of these differences, because she concluded that the Tavistock method was indeed "a new injection" and in the summer of 1964 Rioch and twenty five Americans, mostly from mental health fields, journeyed to London. It was there that they were joined by twenty five Europeans, many of whom were Tavistock Institute clients from the business world, at a group relations conference. Although not much has been written 
about this historical event, it must have been a success because, in June 1965 , the first American group relations conference was held at Mount Holyoke College in South Hadley, Massachusetts.

\section{The Mother of Group Relations in America}

As noted in the chapter five, the instant success of the Tavistock model in the United States, like the popularity of the indigenous NTL model-can be, in one sense, attributed to a social climate inclined to question authority. This cultural attitude slowly developed in the post-World War II years until it became a ubiquitous theme in the 1960 s when Rioch brought Rice and his Tavistock method to America. The explosive growth of the group relations movement and the rapid development of the AKRI was also due, however, to Rioch's personal connections to famous and influential people, as well as her convincing powers of persuasion.

As discussed earlier, Rioch was a creative, highly educated, driven, career woman, with powerful connections decades before these were common characteristics for women (though she was also fondly remembered to have had a traditionally feminine side as well (Gould Interview, 2002; Klein Interview, 2002)). These traits were perhaps nurtured by Rioch's employment experiences; as detailed previously she worked her entire life in male dominated professions such as universities, hospitals, and clinics and seemed to have thrived in that competitive arena in a way that could be considered uncommon for a woman of her generation. 
Gould, an early AKRI leader and Rioch friend, summed up a unique aspect to her character: "Margaret was always thought to be a man's woman and not a woman's woman" (Gould Interview, 2002). By this, Gould meant Rioch seemed to prefer male company almost exclusively to female companionship both personally and professionally. Although in her biography Rioch does mention a woman friend, Edith Helman, as a companion from her early teaching days in Boston before her marriage, most of her connections are clearly with men (Rioch, 1996, p.6). Once again, Gould provided some insight:

Margaret, basically, professionally, grew up in a man's world and...she was a woman who liked men, dearly. She was friendly enough towards women, she wasn't hostile toward them. But it was clearly the men in her life that excited her. I mean that obviously in the broadest sense. (Gould Interview, 2002, p. 20)

As already noted, Rioch was uniformly regarded as "the mother of group relations in America" (Carr Interview, 2002; Gould Interview, 2002; Miller Interview, 2002; Shapiro Interview, 2002; White Interview, 2002), not only because of her powerful influence in importing the Tavistock method from England, but also because of her passionate, and sometimes controlling, drive to see this new experiential learning method succeed in the United States. Klein, an early AKRI leader and Rioch friend, described her personality and her involvement with group relations in the following way: 
[Rioch was] dynamic, very goal focused, driven, this was her baby, she really pushed for it, was tremendously involved in it, pushed the envelope a lot. Made things happen, was very assertive, and could get people to do things. She introduced me to people from all over and if I was hesitant about a paper of mine she'd say 'Do it, do it'...she was very diligent and she was really focused and this approach wouldn't have taken off as well without her. (Klein Interview, 2002, p. 10)

Although pivotal in the early growth of the fledgling AKRI, Rioch was clearly a complicated woman. Shapiro, a third generation AKRI leader, described his experience with her leadership:

[Rioch was] a formidable woman! She was a tough old bird. She was incredibly smart--passionately involved in this work, [yet] a difficult person. A woman of definite opinions...if there was something about you that offended her, and she was easily offended, you were off her list. And it was hard to get back. She was difficult. (Shapiro Interview, 2002, p. 3)

In addition to Shapiro's observation about one of Rioch's idiosyncrasies in the quote above, Klein, offered another insight into Rioch's leadership: Rioch "developed a number of younger men who were coming up and sort of taking over, becoming the next generation. So women felt somewhat left out" (Klein Interview, 2002, p. 10).

Patterns of exclusion. It seems somewhat shocking, yet ultimately not surprising, that a strong, assertive woman like Rioch, who herself had apparently 
struggled to succeed in a male dominated profession, would create an organization that would essentially foster an exclusionary climate. Yet, a review of 36 years of AKRI history supports the claim that women were predominantly excluded from organizational leadership roles on the AKRI Board of Directors, consultancy roles as conference staff, and conference leadership roles as directors.

For example, between the years 1966 and 1970, Rioch was the only woman to serve on the staff of the AKRI National Conference. In 1970, one woman, Rachel A. Robinson, joined Rioch and the six male members on the conference staff. In 1969, when the AKRI Board of Directors was established, Rioch was one of two women, the other being Elisabeth Solomon, appointed to the board with six men. This trend to have one, perhaps two, women in leadership roles continued for the first 15 years of AKRI's existence.

Some informants have responded that this lack of representation of women on National Conference staff was merely a reflection of the lack of diversity in our culture at that time. In other words, if Rioch wanted to get powerful and influential people to support her fledgling organization in order to ensure its success, by definition she had to recruit men because men were the ones in these high ranking positions. Klein observed that the men Rioch selected were in a position to vouch for something which then made it possible for younger people to join...and that attracted a lot of people, both men and women. But it was the senior males in those places. It's possible that it 
could have started more equally but then it wouldn't have reflected our culture. (Klein Interview, 2002, p. 27)

But women were not the only people who felt "somewhat left out." Another, perhaps less visibly distinct group on the periphery of the AKRI leadership circle consisted of people from organizations not affiliated with mental health fields. For example, the entire American staff of the first four AKRI National Conferences (1965-1968) were exclusively clinicians or people with mental health backgrounds. The only exceptions were the two Englishmen from Tavistock, Rice and Miller, both anthropologists by training. In 1969, Kenn Rogers, a Professor of Business Administration and Organizational Behavior at the American University, became the first American non-healthcare person to serve on staff at the AKRI National Conference.

It was not until 1986-21 years after the first American conference-when Earl T. Braxton directed the AKRI National Conference that a non-clinician was the Director of this event (E. T. Braxton, personal correspondence, June 20, 2002). In fact, since its inception, only $32 \%$ (12 of 37) of the AKRI National Conference Directors were from non-clinical backgrounds (excluding Rice's early guidance in this capacity). This trend of exclusively using clinicians on staff dissipated slightly in the 1990 s, but 60 to $70 \%$ of AKRI National Conference staff still continue to come from mental health professions. In addition, Braxton was the only person of color to ever direct this event (E. T. Braxton, personal correspondence, June 17,2002 ). 
The Queen and her Princes. I argue that the exclusionary practices alluded to above were not just a refiection of the times. In fact, the exclusionary culture that developed can be traced back to the predilections and practices of Margaret Rioch. As Rioch began to organize her fledgling organization, a certain trend began to emerge in the people she chose to join her inner circle of leadership. This inner circle tended to be, for the most part, White, male, often Jewish, and typically clinicians. They became known as Rioch's Princes. It is unclear exactly how and when this colloquialism started. Perhaps because Rioch had imported the Tavistock group relations tradition from England she became known as the Queen, which, therefore, made her court of protégés the Princes. Yet this colloquialism earned an international fascination as Menzies Lyth, now retired from the Tavistock Institute, easily and jokingly remembered "Margaret, and all her young men as well" when they visited London in the sixties and seventies (Menzies Lyth Interview, 2002, p. 27).

Gould unabashedly described his memory of this phenomenon: "Margaret had her, basically her couturier of favorites--her court, her inner circle. Clearly, by the way, Garrett O'Connor was her number one Prince. I was the number two Prince" (Gould Interview, 2002, p.18).

Miller, retired Director of Tavistock Institute, remembered it somewhat differently: "Roger [Shapiro], Larry [Gould] and Garrett [O'Connor], possibly in that order, were the three crown Princes, waiting for the laying-on-of-hands by 
Queen Margaret...I have no recollection of a Princess" (E. J. Miller, personal correspondence, February 11, 2002).

Klein recalled the list of Princes in yet a different way:

Roger Shapiro, who was a little older than the other Princes, but he really spent a lot of time with Margaret, I can remember he was always there. And then I guess Garrett O'Connor, Larry Gould, myself, maybe there were some other people. (Klein Interview, 2002, p. 12-13)

Although which males could claim lineage to a Princely title remains up for interpretation, one detail that every informant definitely agreed upon was that Rioch had no Princesses. Gould recalled, "There were no Princesses. Margaret never had a Princess. Until the day she died she never had a Princess" (Gould Interview, 2002, p. 19).

How did one obtain access to Rioch's inner court and the coveted Princely title? Klein candidly observed:

I think there was some combination that we were all hard working, pretty aggressive, pushy, somewhat flamboyant...Why else did [Rioch] choose us? Other than those things, I think she saw promise and she liked being surrounded by young, bright, good looking men. (Klein Interview, 2002, p. 14-15).

White, an early AKRI leader of the second generation, remembered it in a slightly different way. She discussed how the Princely phenomenon was in some ways ignited by the group relations conference experience itself and suggested 
that one could be brought into the AKRI castle by a Prince, yet that person might not be welcomed into Queen Rioch's inner court. White recalled:

All these people at these big conferences wanted to get into this little tiny tight circle of well held, united, divine...chosen ones...So now the problem with 'Mother,' was that she had her twelve, and I think there may have been twelve. And each of them may have had one or two. I was one of Larry's [Gould]. [Rioch] didn't like this second tier out there because the guys, rightly so, figured they needed to bring some women in--because Margaret was the only woman. So Margaret had these step-daughters that she did not like at all. (White Interview, 2002, p. 8)

Shapiro had a somewhat different interpretation of the Prince role and how it functioned in the organization:

It gets attributed to charisma or to a relationship with Margaret or some other fantasy. But, really what it has to do with is those people who made significant contributions to the thinking, either in terms of their intellectual capacity or their forcefulness or their organizational skills. In an organization that is built around group dynamics, the issue of differentiation and envy is powerful. Every time anybody differentiated themselves, every time, either through their capacities or their skills...it would invoke competitiveness and envy, and murder. (Shapiro Interview, 2002, p. 6) 
There is an alternative interpretation than the one offered by Shapiro, of course. The alternative emphasizes the dysfunctionality of an inner circle of chosen people. The early leaders of AKRI were certainly aware of the negative repercussions of having an inner circle and the impact of this sort of organizational structure on the dynamics of a group. It is curious, therefore, that this phenomenon would not only be tolerated, but apparently nurtured, through Rioch's leadership and the subsequent leadership of following generations. The complexity of this phenomenon will be explored in the next chapter which tells the story of the AKRI from an organizational perspective.

Rioch's role after Rice's death. Rice's untimely death on November 12, 1969 was a devastating blow to the shocked inner circle of AKRI leaders. In part blinded by their quick rise in popularity during the anti-establishment era of the late 1960s, the inner circle appeared to have been living in a fantasy that their leader would live forever. The now incorporated name-sake, the A. K. Rice Institute, picked up the pieces as best it could.

The first Holyoke Conference after Rice's death seemed to be extremely challenging for those that knew Rice and especially painful for Rioch. The inside cover of the 1970 Holyoke Conference brochure simply stated "Notice: The Board of Directors of the Mount Holyoke Group Relations Conference announces with deep regret the death of Dr. A. Kenneth Rice on November 12, 1969. Dr. Margaret J. Rioch will be director of the 1970 Conference. Dr. William Hausman 
will be associate director" (Group Relations brochure, 1970, p. 1). Rioch (1993) wrote of this experience:

In those days, chiefly because of the difficulties in communicating between England and America, we tended to be very forehanded about brochures. The one for the next June was already prepared and at the printer in November with A. K. Rice listed as Director. For the past several years I had been Associate Director. The whole staff too was already in place, having been approved by the Director and Associate Director. Although we of the American staff knew Ken had not been in good health in the summer, we had not known that his ailment was so serious, indeed fatal. (p. 233)

As a result of these staffing changes, Rioch opened the conference stating simply "Ladies and Gentlemen, this conference was to have been directed by Kenneth Rice. As you no doubt know, he died last fall and I am directing in his place with the agreement of the staff" (Rioch, 1993, p. 234). And she then proceeded to introduce the staff which included Flint, Gould, Hausman, Klein, Miller, O'Connor, Rogers, and R. Shapiro.

Gould recalled that after Rioch directed that 1970 Holyoke Conference, she told him that "she didn't want to be the Director and she wasn't Ken [Rice]" (Gould Interview, 2002, p. 20). Rioch never directed the AKRI National Conference again. She says of that decision, that the 1970 Holyoke Conference "had been more than enough emotional strain for awhile" (Rioch, 1993, p. 234). 
Klein suggested that the problem was not that Rioch could not measure up to the director role. He recalled Rioch's transformation into the role of Conference Director:

I was at Amherst where [Rioch] really took over and Rice was still there.

This was probably the year before he died...[Rioch] was the Director but Rice was there so we really experienced her as the Associate Director. But she really became the Director and then the next year Directed. Her leadership became more powerful. (Klein Interview, 2002, p. 15)

Although Rioch might have been a bit reluctant after her 1970 experience to actually direct the National Conference again, she did serve as a staff member at the 1973, 1976, 1977, and 1978 AKRI National Conferences and continued to direct on a local conference level. In addition, Rioch had previously participated on the staff of the Tavistock Institute's Leicester Conference in 1966, 1968, 1969, and then for the last time in 1973. In addition to Rioch's national and international group relations work, Gould remembered her nurturing support for the regional group relations conferences done on behalf of the national AKRI at what were referred to as local AKRI centers.

[Rioch] very actively took up Ken [Rice's] philosophy of stimulating the development of the centers. So she participated in, or directed, many of the local conferences of the centers as they formed to help them get off the ground. (Gould Interview, 2002, p. 15) 
As the seventies progressed, Rioch and her Princes found the political and cultural climate fertile ground for their methods, and public interest in their conferences skyrocketed. Dozens of group relations conferences were being conducted every year in the 1970 s and in all parts of the country. It was the golden days of the AKRI.

Toward the end of the 1970 s, Rioch was aging and her inner circle was slowly losing its influence over their organization. Successful converts to the AKRI methodology had begun to infiltrate the institute and were struggling, unsuccessfully, for admittance into the inner leadership sanctum. Although there was a noticeable change in ethos towards people of color serving on staff', positions in the directorate of the AKRI National Conference or Board of Directors were still off limits to those lacking a Princely title. Even as subsequent generations came in, entry to the Queen's inner court was still restricted to mostly White, male, Jewish clinicians. For some, the only way to change the AKRI's organizational culture seemed to have been to seize it. White recalled:

The [AKRI] Centers got more formalized when the third generation, fourth generation people who were supporting the conferences, who were willing to do the work of pulling together their organization, began to have more influence. And there was a coup in terms of the overall leadership of the organization, and the west coast kind of took over from Washington where Margaret was seated...Kay West...She is the one who did it...it took

\footnotetext{
This point will be further explored in chapter seven.
} 
a queen to undue the queen...And she was a well-to-do, she's passed away now, she was a well-to-do woman. And she had a sense of entitlement, righteousness, and authority. So she could resist Margaret's attempts to make her 'feel like a dog.' Which is how Margaret managed to keep everyone else in line, she just made you feel like a dog. ...actually we got along fine, she has an affinity for Black people...But she was going to hold on to this thing until she died. And so therefore it got snatched...And some of the inner folks just stopped doing the work, they just drifted away. The thing got too polluted. (White Interview, 2002, p.

Failure to prepare for an heir. Unlike the Tavistock Institute, as discussed in chapter four, there was a distinct lack of preparation for the future on the part of early AKRI leadership. This lack of attention to succession seems ironic because Rioch seemed so impressed with the concept, writing in 1993, "More than anyone I have ever know or known about, Ken Rice prepared for succession...One of the important lessons that Ken Rice by his own example taught about leadership was how to give it up" (p. 234). Yet many informants claimed that this was precisely one of Rioch's most glaring leadership deficiencies resulting in wide repercussions for the AKRI (Carr, 2002; White, 2002; Lawrence, 2002). Carr, a Rioch friend and former Leicester Conference Director, recalled:

[Rioch] obviously inspired considerable devotion among a lot of people. And I think she got herself, as we all do I suppose in a way, into the 
position of being the sort of ancient leader who is just sort of there and there and there. With the next generation pushing quite hard to do things and as a result doing things differently. (Carr interview, 2002, p. 15) Carr inferred that because there was no gradual succession or transference of ideologies over time, the next generation felt a need to define themselves almost defiantly as different from the previous generation.

White's supported this idea and recalled Rioch's lack of attention to transition which ultimately led to a coup in terms of the overall leadership of AKRI as Kay West and GREX, the west coast center, seized control from the Washington-Baltimore center and an aging Rioch. White remembered Rioch's reluctance to transition: "Margaret [Rioch] was also very, very old and sort of losing her sharpness and if she had had some [insight into] the way she held her authority, she might have set up a transition to another authority" (White Interview, 2002, p. 9-10).

These insights are helpful in understanding how the reluctance on the part of AKRI leadership to recognize a need for succession, coupled with the AKRI membership's desire for increased involvement, created an undertow within the organization. By the time Kay West "snatched" the seat of AKRI leadership from Washington, much damage had already been done to the psyche of the organization. And as White mentioned, many of the old inner circle "just stopped doing the work," though remained portentously in the organization's periphery. 
As these different organizational challenges occurred in the late 1980s, Rioch remained vigilant and involved. More than one informant recalled that few changes were made without the "laying on of the hands" by Queen Rioch even into the 1990s (E. Braxton, personal conversation, June 26, 2002; Miller, 2002; White, 2002). Rioch continued her clinical practice, group relations work, and teaching as a professor of psychology at the American University until 1991 when the early stages of Alzheimer's disease forced her into semi-retirement. The author of over fifty publications on group relations and psychotherapy, Rioch remained active until 1993 when the advancement of the disease forced her into permanent retirement. She died of a heart attack in her home in Chevy Chase, Maryland on November 25, 1996 at the age of 89 (Rioch, 1996;

www.continents.com). Upon the settlement of her estate, it was found that Rioch had left her once fledgling organization, the AKRI, a lump sum of $\$ 100,000$ ( $N$. Stevens, personal communication, June 15, 2002).

Although news of this wonderful endowment was no doubt exciting for this struggling organization, to this day the AKRI leadership has not developed a plan for its use. Some Board members suggested that the entire lump sum be used to develop one significant item or used as seed money. Others think that, if doled out judiciously over the years, this money could keep the organization going for decades. Meanwhile, without a united vision, the money sits being slowly whittled away by day to day operational costs ( $N$. Stevens, personal communication, June 15, 2002). 
The next chapter will explore the complex results of some of the concepts outlined in this chapter-concepts such as patterns of exclusion, lack of attention to succession, and charismatic leadership styles-on the organizational structures of AKRI. 
Chapter VI: Tavistock Transferred-Stories of the Group Relations Movement in America: The Organizational Structures Story

\section{Introduction}

The story told in chapter five focused primarily on one individual, Margaret Rioch, and the role that she played in transporting the group relations model developed in England by the Tavistock Institute of Human Relations (Tavistock Institute) to the United States. The focus of this chapter is on the resultant organizational structures and cultural norms that emerged when the group relations methods developed by the Tavistock Institute were exported to the United States and began to be utilized by a new organization, the A. K. Rice Institute (AKRI), that was created for this purpose.

The stories told in this and the previous chapter overlap, of course. As has already been indicated, Rioch's preferences and predilections had organizational implications. Here these organizational implications are brought to the foreground. For instance, in chapter five it was noted that the AKRI emerged in the $1970 s^{1}$ as an organization with (a) little formal infrastructure, (b) leadership norms based on patterns of exclusion represented by an in-group (the Princes) and an out-group (everyone else), and (c) a predominantly charismatic

\footnotetext{
${ }^{1}$ After the loss of Rice's influence due to his death in 1969.
} 
leadership style inattentive to succession. This chapter continues this story, describing how these three elements helped shape four organizational factors that distinguish the AKRI from the Tavistock tradition, which it claimed as its lineage. Over time these organizational factors contributed to the development of a quite different approach to group relations work in the United States.

The four organizational factors that this chapter discusses frame the AKRI organizational structure even today. These factors describe (a) an organization that is largely an "organization-in-the-mind" that relies primarily on an oral tradition rather than written records, (b) an organization that appears to have as its sole purpose the holding of group relations conferences, (c) an organization that attempts to be both centralized and decentralized and ends up being a loose confederation of organizations rather than an institute with a distinct and clearly defined primary purpose, and (d) an organization that appears to be one whose limited structural elements mirror many of its exclusionary cultural norms.

\section{An "Organization-In-The-Mind" With an Oral Tradition}

AKRI-in-the mind. The AKRI is a unique organization because, unlike the Tavistock Institute or the NTL, or most organizations for that matter, the AKRI largely exists in people's minds. By that I mean that the AKRI lacks any physical structure or locale-there is no institute or office space one can visit; no journal for members to read or publish in; and no group of full-time employees to engage with. 
Furthermore, unlike the Tavistock Institute or the NT, which as evidenced previously in this dissertation have detailed written histories, the AKRI appears to have made little effort to document its history. This observation is made based not only on the scarcity of published accounts of AKRI history ${ }^{2}$ but also because few primary sources other than conference brochures were available for historical analysis. The absence of historical records made it evident that the history of AKRI over the past 37 years has existed almost exclusively as an oral tradition ${ }^{3}$.

An oral tradition. Vansina (1961) observed that organizations which rely on oral traditions foster a climate fertile for the development and circulation of "rumors, myths, sagas, legends, anecdotes, proverbs, and folk-songs" (p. 5). Therefore it is not surprising that, given the absence of a written AKRI history, an informal oral tradition based on myths and legends emerged in its place. In some ways such myths and legends, like that of Queen Rioch's inner court, shaped the history of the AKRI.

Therefore, AKRI was and continues to be, to a large extent, an organization that exists in the minds of members rather than an organization of written policies and procedures and of formal infrastructures and organizational entities. Furthermore, the minimal structures and entities that were created were not helpful in bringing coherence and a clearly defined shared purpose to AKRI. Indeed, one of the only apparent organizational purposes was to organize group

\footnotetext{
2 Five joumal articles.

${ }^{3}$ Idea developed through conversations with Mary Rafferty and Marian Uriquella.
} 
relations conferences. This aspect of the AKRI organizational story will now be presented.

Group Relations Conferences as Organizational Structure

Although the AKRI conference brochures continually referred to its roots "in the tradition developed by the Centre for Applied Social Research of the Tavistock Institute of Human Relations of London" (Group Relations brochure, 1969, p. 1) and the AKRI was, in fact, named for a key Tavistock Institute leader, A. K. Rice, from the start the AKRI was a very different sort of organization than the Tavistock Institute described in chapter three. The AKRI, for example, seemed to be expressly formed to organize group relations conferences, not to do the community-based social science work that the Tavistock Institute aspired to do. Furthermore, for many years, the task of putting on a conference provided the only real structure ${ }^{4}$ the AKRI had.

An organization initially structured around an annual conference. The first American conference was held at Mount Holyoke College in 1965 and was jointly sponsored by the Tavistock Institute through the support of Rice, the Washington School of Psychiatry (WSP) through the support of Rioch, and the Department of Psychiatry at Yale University School of Medicine through the support of Fritz Redlich, chairman. Rice directed this first conference and brought Pierre Turquet, his friend and colleague who was a psychoanalyst from the

\footnotetext{
4Although a Board of Directors was established in 1969 and scientific meetings were held every few years beginning in 1976 (see Appendix B), these factors in no way substantially altered the AKRI organizational structure.
} 
Tavistock Clinic, and John Sutherland, the Director of the Tavistock Clinic, to serve on staff.

Over the next four years, Rice served as Director, with Rioch as his Associate Director, of what would soon be more commonly referred to as the annual Holyoke Conference. During those years, the conference continued to be jointly sponsored by the Tavistock Institute, the WSP, and the Department of Psychiatry at Yale University. The conference format closely resembled the Tavistock model in its structure of small group, large group, inter-group, and application group events and the primary task of studying the dynamics of authority and leadership in an experiential fashion (Group Relations Brochure, 1966-1969; Rice, 1965).

What was missing from the AKRI in these early years was an organizational infrastructure, such as that of the Tavistock Institute or the National Training Laboratories (NTL), which would support its group relations work and provide a purpose for its existence in the organizational world. Yet since many Americans were already attracted to the notion of examining group behavior and experiential learning from the work of the NTL and encounter groups, the instant popularity of AKRI's conferences masked the need for an organizational purpose and infrastructure that could sustain the organization and provide long-term viability and growth for the fledgling institute.

\section{Lack of Application Orientation}


Although it is clear that the early leaders of the group relations movement in America based the development of the AKRI on the imported philosophies of the Tavistock model, Sher observed that at some point shortly after Rice's death in 1969, the Tavistock Institute and the AKRI's philosophies and connections began to diverge:

Margaret Rioch came to one of the Leicester Conferences and got excited about them and established something at the Washington School of Psychiatry. A K. Rice was a helper for her there. But I think at some point after that, it seemed to me the thing moved off in two directions. You've got in Britain, A. K. Rice developing a laboratory to study groups and organizations with direct application value...Whereas in the states, you have group relations as a phenomenon developing...And that I think gave a particular character to the American group relations movement and it's been distinct from the British character. I am more in favor of the application of group relation's theory, thinking, and learning to actual real life organizations. (Sher Interview, 2002, p. 32)

Sher makes a critical observation: His claim is that the American group relations movement, based in the AKRI, differed from group relations in the United Kingdom because the group relations work being done in America lacked "application of group relations theory, thinking, and learning to actual real life organizations" (Sher Interview, 2002, p. 32). 
Once again, this lack of application orientation can be traced back to the AKRI systemic framework and its lack of interdisciplinary ethos and, ultimately, to an organizational structure that would have provided these things. I argue that if the leadership of the group relations movement in the United States had been drawn from the diverse work settings advertised in the conference brochures, then AKRI might have been more apt to find application for its group relations work in a wider array of organizational life. Instead, the group relations movement in America developed a sort of therapeutic orientation, through the use of dinicians, rather than the Tavistock Institute's application orientation, through an interdisciplinary focus.

Krantz (1993) provided support for this hypothesis by discussing how the application oriented consulting work became separated from the group relations conference when the Tavistock tradition came to America:

Conference work and Consulting are split apart [in the US] and housed in separate enterprises, activities institutionally bounded from one another. This difference illustrates what I feel is an important split that underlies our formation as an organization [i.e. AKRI]. When aspects of the Tavistock tradition were brought across the Atlantic, the Conference work split off from what we might call the organizational, or socio-technical work. Conference work was lodged in the AKRI, primarily composed of clinicians. The organizational, or socio-technical work was lodged in 
various management schools including UCLA, Wharton, York and others. (p. 239)

Group relations ladder. Sher further described how this lack of application orientation, along with the membership organization structure, led to frictions within the AKRI. He observed that the AKRI structure and lack of application orientation caused a virtual group relations ladder to emerge, encouraging people to dimb within the AKRI organization, rather than apply the work to outside organizations. It stands to reason that if there was no application for the group relations work outside of conferences, then the focus for group relations work became solely dimbing the ladder of the group relations power structure. Sher described this phenomenon:

So you've got in Britain, A. K. Rice developing a laboratory to study groups and organizations with direct application value. And I suspect we might be able to say that people were at that stage, would not have been interested in climbing a group relations ladder [in Britain]... I'm not in favor of developing group relations as a professional career. I mean once it becomes institutionalized and professionalized and socialized, one is going to get all of the problems that I think you are encountering in America [in the AKRI]. The politics, the internal politics of organizations. (Sher Interview, 2002, p. 32)

Given Sher's observation, it is clear that, after Rice's death, the group relations movement in America started to professionalize and the development of 
applications for group relations work seemed to become secondary to the competition over being selected to work on conference staff. The group relations conference became its own ladder to success. Even if not financially lucrative, it was a ladder to power within the AKRI organization and the individual conference structures. Klein supported this hypothesis:

The problem with the [AKRI] is that a lot of people join it because all they want is to be consultants at conferences. That is only one small aspect of what you can use this knowledge for. You can use it to be more effective as an Executive Coach, an Organizational Consultant, I don't mean at a training event but in real organizations that aren't temporary, you can use it in an administrative role or a management role. (Klein Interview, 2002, p. 9)

While this drift away from the Tavistock Institute ethos started thirty years ago, it remains an undercurrent in the AKRI even today. Sher observed:

When I was in the States last year at AKRI...I didn't hear anything about people's work and it occurred to me that people do their work in other organizations...They don't do it at AKRI and all I heard was more and more rarefied comments about group phenomenon. But it was unrelated to bricks and mortar. (Sher Interview, 2002, p. 33)

In the previous section, both Krantz (1993) and Sher (2002) presented compelling arguments about this same point. Krantz discussed how the consulting, or application orientation of group relations work became split off 
when the Tavistock model was imported into the United States and then located in various management schools around the country. Sher also supported the notion of a split, observing a lack of focus by the AKRI on the "bricks and mortar" of organizational life. These concrete examples provided by well respected experts are further data to support the hypothesis that the AKRI has modified the more application oriented Tavistock model in which it was rooted to produce a hybrid, more therapeutically oriented model of group relations, and that the AKRI's organizational structure was built almost exclusively around the task of putting on group relations conferences. Furthermore, one of the AKRI's decisions about structures - the decision to have regional centers-resulted in AKRI also becoming, to a large extent, a rather loosely organized confederation. This story in the AKRI organizational tale will now be told.

\section{Centralization, Decentralization, and the Resultant Confederation}

In addition to the examples provided above that distinguished the AKRI from its lineage in the Tavistock Institute, another factor began to emerge within the AKRI structure. Evidence supports the claim that, as early as 1966, the AKRI began emerging as an organization that attempted to be both centralized and decentralized and ended up being a loose confederation of organizations, called centers, rather than an institute with a distinct and clearly defined primary 
purpose. The history and impact of these organizational centers will now be presented.

AKRI centers. The development of regional AKRI centers around the United States was an essential part of the vision of the AKRI organizational structure from the earliest days. The first AKRI center (see Appendix C) was the Washington-Baltimore Center, founded by Margaret Rioch, Roger Shapiro and Garrett O'Connor circa 1966; it remains in existence today. In 1969, three new centers were formed: The Topeka Center founded by Roy Menninger, which no longer exists; the Minnesota Center founded by William Hausman, that lasted until 1975 when it dissolved; and the West-Coast Center GREX, Latin for group, that was founded by Lars Lofgren, Arthur Coleman, Lowell Cooper, and Richard Shadoan, and is one of the eight centers still in existence today (AKRI, 1995; AKRI, 2002).

In addition to the Washington-Baltimore Center and GREX, the WestCoast Center, the other six centers still in existence today are: The Boston Center, named the Center for the Study of Groups and Social Systems (CGSS) founded circa 1982 by Leigh Estabrook, Edward Shapiro, Sten Lofgren, and Mary Wright; the Chicago Center called the Chicago Center for the Study of Groups and Organizations (CCSGO) founded circa 1990 by Solomon Cytrynbaum and Robert Lipgar; the Mid-West Center founded circa 1977 by Edward Klein; the New York Center founded circa 1982 by Harold Bernard, Ken Eisold, Leslie Freedman, Lawrence Jacobson, Avi Nutkevitch; the Philadelphia Center entitled 
the Philadelphia Center for Organizational Dynamics (PCOD) founded by Rose

Miller circa 1994; and the Texas Center founded circa 1971 by Glenn Cambor and Manuel Ramirez (AKRI, 1995; AKRI, 2002).

Other AKRI centers no longer in existence include: The Yale-New Haven Center named the Center for the Education of Groups and Organizations (CEGO), founded by Jim Miller, Edward Klein and Nancy French; the North Central Center founded by William Hausman, Marian Hall, Jim Gustafson, and John Maurel circa 1969 and lasting until 1978; another west-coast center called Study Center for Organizational Leadership and Authority (SCOLA) established circa 1973 and disbanded circa 1979 was founded by Garrett O’Connor, Lars Lofgren, Kay West, Charla Hayden and Zoltan Gross; another New York Center entitled the Institute for the Applied Study of Social Systems (IASOSS), founded circa 1971 by Larry Gould, Jay Seaman, and Dave Singer, lasted until circa 1978; and the Central States Center founder by Louesa Danks, Elizabeth Heimburger, Bob Baxter, and Tim Dolan circa 1974 and unincorporated December 31, 1999 (Group Relations Brochure, 1975-1979;1984;1991; 1995; AKRI, 1995; AKRI, 2002).

This "federated organization of centers, each one having a representative to a National Board of Directors" (Gould Interview, 2002, p. 10) could have been borrowed from the early NTL organizational structure which also initially had separate centers', described in chapter four. Gould (2000) wrote:

\footnotetext{
7 The NTL retained this structure until the mid-seventies when they dissolved the centers into one nationally run organization in order to stream line expenses, and has continued with a centralized structure to this day.
} 
The rationale for this development was quite straightforward. The ordinary centrifugal forces of career development were dispersing trained staff around the country and, as noted, several groups had already formed and were working independently. The federal structure had as its rationale, therefore, the development of a collaborative network of local institutions - both to embrace those already formed, as well as providing for new ones to come into existence, and link up. (p. 50)

Gould recalled how he, Rioch, Hausman, and some others developed the basic organizational structure for the AKRI, in part, as a response to the fact that group relations people were moving away from the east coast, taking new jobs in other parts of the country:

While the bulk of the people doing group relations work was in the northeast corridor from Washington to Boston, with New Haven in between, a Diaspora started to develop as people involved in group relations work took jobs in other parts of the country... What simply then happened over the years, is that as critical masses of people developed in other parts of the country, they made application for center-hood. (Gould Interview, 2002, p. 10-11)

Although Gould (2000) claimed that the purpose of the centers was "straightforward," evidence revealed that there are various interpretations of why the centers were established and what function they were expected to serve. For instance, the 1976 National Conference brochure stated the AKRI "is now 
constituted by eight centers in the United States, each one of which conducts programs of its own" (Group Relations, 1976, p. 2). This description would lead one to believe that the centers were autonomous to conduct their own work in order to further the "educational and consultative work" (Group Relations, 1976, p. 2) of the organization. Yet in reality, the centers seemed to focus exclusively on organizing local conferences rather than on developing any other educational programs or supporting consultative work.

Klein gave a somewhat different twist to Gould's storyline about centers being, in part, a response to group relations aficionados spreading out across the country. He noted:

One of the reasons...for the centers was to give people work so that they could work at local weekend conferences with the hope that they'd accrue enough hours so that they could be on the National [Conference] staff where the big boys and girls were. (Klein Interview, 2002, p. 9)

White provided a different, more metaphorical interpretation:

Margaret Rioch brought the work to the States. She formed what in effect was a kind of Church. And people who pray to this Church were from all over everywhere...And that original group of men and women, mostly men, around her was simply spreading the word...they wanted to make mama proud...and she was proud. And she...just bestowed the greatest warmth and love and affection on these folks. And they, that inner circle, they felt extremely special, like they were extremely special people, on a 
mission. On a kind of religious odyssey...they were in the business of conversion. (White Interview, 2002, p. 7-11)

Shapiro, much like Gould, took a more pragmatic stance:

It is just too complicated, given people's lives, to travel [to conferences].

You can build an organization and develop local interests and develop

local conferences. And expand the work. (Shapiro Interview, 2002, p. 3-4)

Gould recalled how he and his colleagues in New York wanted the

autonomy to do local conferences without having to pursue sponsorship from the Washington School of Psychiatry or the Tavistock Institute:

Actually the New York Center, largely at my urging, and this has to do with my own personality and character, said we need to do local events and why should we have to talk to the Washington School of Psychiatry or to the Tavistock, if we want to do local events. Let's form a New York Center and we called it IASOSS...I remember talking to Eric Miller about it, thinking that he was going to give me a hard time and actually he was quite encouraging, he said 'of course'. Subsequently it became very clear that in general the ideology of the Tavistock with regard to spreading this work was basically to help the groups develop to the point that they can take on the work themselves and develop their own institutions. (Gould Interview, 2002, p. 10-11)

Regardless of which of these four informants' opinions is most accurate, one factor remains central to each: one of the main, if not the only, purpose of the 
centers was simply to conduct group relations conferences on a local level. The consultancy emphasis of the Tavistock model in England was no where to be found.

Federated versus confederated structure. Although Gould (2000) described the AKRI center structure as "federated," (p. 50) a system based on a strong centralized government, evidence supports the idea that the AKRI center structure actually emerged as a confederate system, a system based on a weak central government and powerful affiliated units. In other words, most of the power and influence within the AKRI was seized by the local centers leaving the national organization relatively powerless. An excellent example of this phenomenon can be found by examining the history of the Center for the Education of Groups and Organizations (CEGO), which was the AKRI's Yale-New Haven Center.

CEGO: A case in point. The story of CEGO's struggles and transformation can be used to illustrate understand the paradoxical nature of the relationship between AKRI national and its regional centers--dearly illustrating the confederate nature of the AKRI structure. CEGO's history can also be used as an example for more pragmatic reasons: Much has been written about it, its successful operations, its subsequent break with AKRI, and its transformation from AKRI center to self sufficient organization. This proliferation of written records is unusual for the AKRI. 
CEGO was a very active and highly successful AKRI center. Klein, who was one of the founders of CEGO in 1969 as well as the Director of Group Training in the Yale Psychiatry Department between 1967 and 1975, estimated that in an average year during that time he directed twelve to fifteen weekend group relations conferences at Yale (Klein Interview, 2002). Group relations conferences were in high demand, in part, because many universities required psychiatry students to have substantial experience in group relations training as part of their residency programs. In addition to the psychiatry residents, Klein discussed how other graduate students from psychology, administrative sciences, epidemiology, public health, and other disciplines also attended his events.

Calling it "the hay-day of the community mental health movement" (Klein Interview, 2002, p. 3), Klein described how he and his colleagues at Yale, and in CEGO, continued to expand and apply their work in innovative new ways. For example, CEGO used group relations methods in drug dependency programs in various ghetto areas around New Haven and in mediating between Black Panthers and local Police Rookies in a community training program. Because of CEGO's application of group relations methods to the amelioration of wider social problems, it appears in some ways, closer to the Tavistock Institute's methods of application oriented, interdisciplinary group relations work, than to AKRI's methods and its almost exclusive focus on holding group relations conferences.

Klein was also involved in the development of a Social Community Psychiatry Training Program which embraced psychiatry as a form of social 
activism with a special emphasis on communities (Klein Interview, 2002). Klein recalled the premise behind the notion of social community psychiatry and how it dovetailed nicely with the Tavistock methods:

You couldn't put everyone in the ghetto on the couch; you couldn't do psychoanalysis which was the preferred high priced treatment at the time. So Social Community Psychiatry would involve people learning about systems and groups and how to be effective that way. What better way, than to learn something experientially at a Tavistock conference? (Klein Interview, 2002, p. 2)

After only a few years as an AKRI center, the highly successful CEGO began questioning the purpose of its affiliation with the AKRI national organization. Cytrynbaum (1993) described his memory of the critical incidents leading to CEGO's split from AKRI in the early 1970's:

Jim Miller and Nancy French, our representatives to the AKRI Board reported that AKRI was planning to impose a substantial tax on Centers that were involved in sponsoring residential conferences...The feeling was that we were going to be taxed excessively for our success in carrying on residential work. In addition, there was some feeling on the part of a number of CEGO members that we were not fairly and appropriately represented on the AKRI Board. CEGO had a number of minority and female members and the feeling was that AKRI was not taking our 
organizational and professional interests seriously...the battle cry 'no taxation without representation' was expressed. (p. 33)

Seeing little reason to remain affiliated with the AKRI and its exclusionary tendencies, CEGO seceded from the AKRI infrastructure to continue its successful group relations work on its own.

\section{An Organization with Exclusionary Cultural Norms}

So far in this chapter we have seen how the AKRI's organizational structure, or lack thereof, has limited the focus and application of the organization's group relations work. We have also seen how this phenomenon was evidence of AKRI's divergence from its roots in the Tavistock tradition. The following section will address how Rioch's preferences and predilections, and the AKRI's limited formal infrastructure, created, or at least accentuated, many of the organizations exclusionary cultural norms. In particular, the organizational implications of themes introduced in chapter five-in particular, the themes of (a) leadership norms based on patterns of exclusion, and (b) a predominantly charismatic leadership style inattentive to succession-will be explored.

Leadership norms based on patterns of exclusion. As was previously discussed, the emergence of a Princely inner circle of predominantly White, male, Jewish clinicians within the AKRI reinforced distinctions, both real and imaginary, between those who had access to information and power within the organization and those who did not. Carr explained the American shift away from the 
Tavistock Institute's interdisciplinary ethos as a move toward a more psychoanalytic focus:

The American basis of this work was much more psychoanalytic and psychoanalysts, psychiatrist, psychologists---that whole world was much more present both in the staff and membership than it was in England. In Great Britain it was always much more spread among industry, government, church, psychology. It was all part of a field, a set of fields...In America...the whole thing was brought over by Margaret to the American Institute of Psychiatry in Washington...and because of the plethora of psychoanalysts and therapists and all the rest of it in the US, I don't think that it ever quite broke out of that origin. (Carr Interview, 2002, p. 14)

The question that remains is: Why should it matter whether group relations events utilize only clinicians or a diverse range of professions on conference staff? Aside from the lack of application orientation discussed above, and the fact that perhaps the conference brochure should more clearly represent the actual staff and member's areas of expertise, does having only health care professionals on staff really affect the conference experience? Carr had some ideas on this:

When you have a conference of members and staff who are largely in the psycho-therapeutic world, then you have to be very particularly wary of collusion into that world. When you've got a variety of worlds on both 
staff and members you've got a better chance of something being picked up for what it is in the conference, not outside [of the conference]. I won't say that it is superior or better but it's just different and slightly more invigorating, I think. (Carr Interview, 2002, p. 20-21)

This discussion of "collusion into a therapeutic world," reemphasized the connections between group relations theory and psychoanalysis. Given the extent to which group relations theories are intertwined with psychoanalytic theories, one might infer that the more one knows about psychoanalytic theory the better staff member one could be. Carr disagreed:

The whole model itself is based upon psychoanalytic thinking but it is not based on being psychoanalyzed and being involved in psychoanalysis. I think that there was a time when it was felt, I'm not so sure if that was true in America, but it was felt that in order to be a staff member you needed to have been psychoanalyzed. I don't think that has ever been held too strongly in Great Britain and it certainly would be, I think, untrue today, well it is certainly untrue today. I mean I've not been psychoanalyzed and I've directed two Leicester Conferences and a lot of other conferences. (Carr Interview, 2002, p. 22)

Yet, Gould disagreed with Carr's perspective, emphasizing his opinion about the importance of returning to stricter psychoanalytic interpretations in conferences. Gould suggested: 
We've probably strayed a bit too far from the psychoanalytic roots, that the conferences are probably less about authority even though it continues to be in the title...In my generation...it was distinctly more psychoanalytic, distinctly more about unconscious processes, distinctly more about transference. If you read Experiences In Groups, Bion talks mostly, I think, about the groups' relationship with him and what kind of picture the group has of him and how it uses him. To me that is still the model about how one positions himself within the conference. There are lots of other dynamics that go on that are interesting in groups...giving feedback...that's just not what we are about. (Gould Interview, 2002, p. 27)

Given this, Gould not only believed it is important to return to stricter psychoanalytic interpretations about the group's unconscious processes, but he also emphasized the need for group relations scholars to re-examine the psychoanalytic theories that underpin the group relations models. Gould recalled his early involvement in the group relations movement in the 1970s:

We were much more steeped in the psychoanalytic world in every possible way, including knowing the literature. I don't think that there is anybody of my generation that didn't know the literature reasonably well...these days, again my hypothesis,...is that there is a considerable lack of knowledge and conversant with these books, articles, and ideas except in a very superficial way...I never think most people in the AKRI these days 
really understand basic assumption life terribly well...for example Bion says at the beginning of Experiences In Groups, the extent to which many of his ideas spring from and can not be understood fully without understanding Klein's notions of the paranoid schizoid and depressive position...My generation, roughly, broadly speaking, those were things that people thought about, worried about, talked about. I don't think that is part of the conversations any more in the AKRI. I think probably almost nobody has really read Klein or read Klein deeply. (Gould Interview, 2002, p. 27-28)

Yet, Cytrynbaum (1993) daimed it is exactly this fixation on these early theorists and their work, such as Bion's (1961) Experiences In Groups, that has in some ways negated the possible influence of more recent research which builds upon these early theorists' ideas:

It is surprising to me that for many Tavistock theoreticians and practitioners, Bion's Experiences In Groups remains the dominant viewpoint with respect to the understanding of small group processes and development...It is again surprising to me that a body of systemic research and theory accumulated over the last twenty-five years on small groups has had so little impact on theory and practice of small group consultation in the Tavistock Tradition. Specifically I am referring to the work originally identified with the SocRel tradition at Harvard, and later including a whole host of systemic and rigorous, observational, empirical 
and clinical studies within an ego-psychological framework (certainly reflecting the Kleinian influence) which indicate that group processes and development are much more complicated and sophisticated than Bion had originally articulated. (p. 41)

As a leadership scholar, Monroe brings another perspective to the debate about conference staff being from clinical backgrounds and the requirement for psychological theory:

I'm not sure that there is one best way...Different staff members bring different strengths with them. I think there is a role and a place for people that have done a lot of work in psychology. They bring an awful lot to the staff. People who have been really immersed in organizational life also bring a very important perspective. And I'm not sure there is one best way to prepare for the work, for conference work, and certainly for organizational consulting--which I still want to hold on to. That is a really key piece of this work, not conferences. It is what conferences are geared for...improving people's ability to exercise leadership and authority in group settings, organizational settings, all kinds of groups. (Monroe Interview, 2002, p. 30-31)

White embraced all of these philosophies described above in her vision of the future of group relations:

My picture of the ideal future is that we self consciously continue to offer the orthodox group relations opportunities-AKRI conferences, Leicester 
Conferences--just as they have always been. So there is a part of me that fights for orthodoxy; and fights for looking down at the floor; and fights for the rigid boundaries and all that because that tool is exquisite to those that it is exquisite for...But figuring out how to get it into the mainstream is a move beyond sending people to conferences...Until recently we were frightened, I think, of the notion that there'd be an unconscious world occurring that we were not controlling. I think it is much more in the mainstream now. People use common parlance around all these ideas: transference, projections, unconscious...I think that psychoanalysis has done its job. It has gotten all that kind of material into the mainstream consciousness. So now that that is more true than it used to be, maybe we can be less stymied by our way of thinking about application. (White Interview, 2002, p. 23-25)

Like Gould, White has respect for the orthodoxy of the Tavistock tradition, yet like Carr, Cytrynbaum, Monroe, and Sher, she yearns for the elusive application piece in mainstream consciousness. As a modern day compromise, White suggests the retention of the more psychoanalytic traditions, for those to whom it appeals, yet she also urges a continued search for new applications for group relations theories and practices.

Other patterns of exclusion. In addition to the lack of interdisciplinary representation, other patterns of exclusion continued to be evident in the AKRI. Holvino observed how studying and understanding "difference" is integral to the 
study of authority, one of the specific goals of both the AKRI and the Tavistock traditions:

You put people...that represent different nationalities or races or genders in a staff, not because you are necessarily politically correct but because you do get different dynamics around authority. I think that's a way to study [authority] and it's not the same to have a white man in an authority position than to have a Black woman...I think the issues we are trying to study are differences around the same theme that we have been trying to study all along. (Holvino Interview, 2002, p. 16-18)

Holvino also expressed concern about other emerging exclusions within the AKRI. She described how there is a concern among some AKRI members that the organization is in danger of becoming an elitist organization focusing only on "White people's stuff":

If we want to be relevant and make this useful [it has]...to make sense to Latinas or Blacks-I don't want this to seen as White people stuff. So we have to do that by bringing people that are of those groups and we have to do that by pushing for things that are relevant to those groups. (Holvino Interview, 2002, p. 15)

Regardless of whether women, people of color, or non-clinicians were intentionally excluded, culturally left out, or simply overlooked, one cannot ignore the structural implications of exclusion within the AKRI organizational system. Lack of Attention to Succession in a Charismatic Leadership Structure 
Another way in which the AKRI cultural ethos distinguished its organizational design from the Tavistock tradition was its lack of attention to leadership succession. Some informants alluded to the influence of a charismatic leadership style which emerged within AKRI's early leadership group as a reason for this tunnel vision (Holvino, 2002; Lawrence, 2002; Monroe, 2002; Shapiro, 2002; White, 2002). As we will see, charismatic leadership-though valuable at times-is a type of leadership which is largely unconcerned with succession. As Jones (1993) put it:

The working of charisma reinforces belief in the leader by effecting an internal transformation among believers. The accomplishment of tasks by the charismatic ruler, although taking place on the terrain of the mundane, is disconnected from any rationale-technical, means-ends, or survival concerns. (p. 128)

It is this lack of concern for the survival of the organization that will be explored further in this section.

Piazza (1995) defined charisma as:

A unique personal power conceived of as belonging to those exceptional individuals capable of securing the allegiance of large numbers of people. It is a special quality of leadership that involves the ability to capture the popular imagination and to inspire the unswerving allegiance and devotion of large groups. (p. 1) 
Inferring that this type of leadership was perhaps faulty or inefficient, the new AKRI leaders of the nineties described in 1995 being in the "painful transition from what some have characterized as a transition from charismatic leadership to a more collaborative organization" (AKRI History video, 1995). Yet, Piazza (1995) observed that there are benefits to charisma and a place, though perhaps time-limited, for charismatic leadership especially in the formative stages of organizations. Lofgren (1993) agreed and noted:

Contrary to the emerging notion that charismatic leadership may have pathological influences on group life, I suggest that the presence of charismatic influences can be a normative stage, and may have beneficial effects in the life of many groups, especially those groups that are in formative stages...A recent example of this kind of beneficial influence of charisma is the very important inspirational and organizing influence exerted by Margaret Rioch and others in the Group Relations organization (the A. K. Rice Institute) in this country. (p. 139-141)

Further supporting and expanding on this idea, Piazza (1995) proposed that:

Charismatic leadership may have very important influences that may be particularly beneficial in assisting new movements and organizations to survive and flourish. Charisma may provide inspiration that can have enormously stimulating, organizing and containing influences within a group and on the kinds and quality of work that can be attempted and accomplished. (p. 9) 
Cytrynbaum (1993) also agreed that charismatic leadership does have its place, yet described some of the repercussions of this mode of operation:

Charismatic leadership may be crucial in terms of the development and maintenance of any innovative paradigm. But it is a two edged sword...the orthodoxy which very often tends to accompany such central charismatic leadership, may end up producing an exclusionary culture which deprives the movement of input from other critical sectors. (italics added; p. 4041).

An exclusionary culture appears to be exactly what developed within the AKRI. The same charismatic leadership, provided by Rioch and her protégées, that rocketed AKRI and the group relations movement to the forefront in the 1960 s and 1970s, ultimately created a dependent culture that stagnated the organization in the 1980s, resulting in an implosion in 1990, which will be examined in the next chapter. As future generations of AKRI leaders attempted to replace Rioch and her inner circle of Princes, it became clear to some people that this old model of charismatic leadership was antiquated and needed revision. Holvino recalled the environment as AKRI struggled with this challenge: In AKRI there had been something about charismatic leaders, charismatic consultants, as a framework for doing the work. And if a person is not charismatic then they shouldn't be Director, or they cannot be Director of a conference if they don't have this persona that is totally riveting. I think that has been difficult to change...I think that it's a struggle with 
leadership...some of us talk about changing leadership to be less charismatic, less heroic, but I think we still look for saviors and for charismatic leaders that will do the work and will be fantastic. (Holvino Interview, 2002, p.34-36)

Other group relations scholars, like Shapiro, are less optimistic about separating charisma from leadership:

I don't know what it means if you try to eliminate charisma. If charisma is seen as bad, if the narcissism of leadership is seen as bad, and you try to eliminate it, what are you eliminating along with it? That's the enduring question. (Shapiro Interview, 2002, p. 15)

Lofgren (1993) recognized that this task, to transition successfully beyond the once required charismatic leadership model to a more mature form of authority, remains a significant leadership challenge, one that endangers the very survival of the organization. Yet, she noted that it is important to remember that not only has the charismatic leader been functioning "on developmentally less differentiated levels. The group members have been collusively existing in these 'primitive' spaces as well" (Lofgren, 1993, p. 142).

Once followers of the charismatic leader begin to realize their participation in this process, negative reactions often surface. Piazza (1995) noted:

Followers become anxious about who has been in control, whether they have been manipulated, and what goals have been pursued...Full recognition of how much authority group members have abdicated 
(presumably against their wills) to charismatic leaders can too predictably result in intense reactions of envy and hatred in the previously docile and admiring group members. (p. 9)

Piazza (1995) further advised that in order to break out of this cycle, the group must engage in an honest appraisal of its past behavior and its collusion in the charismatic leadership dynamic so that it may then begin to function on more sensitive and sophisticated levels. Although this is a painful process, "to move on to a more mature functioning requires both appreciation of, and separation from, the group's past" (Piazza, 1995, p. 9).

\section{Conclusion}

This chapter examined the organizational elements that emerged when the Tavistock model was imported to the United States and identified key elements within the AKRI as evidence of its drift away from the Tavistock Institute ethos. This analysis concluded that the AKRI emerged largely as an "organization-in-the-mind." Initially, the requirements and demands of organizing group relations conferences provided the only real structure and purpose the organization had. Eventually an organizational infrastructure emerged consisting of a relatively weak national organization with a confederation of stronger regional centers, although its operations continued to focus predominantly on group relations conferences. These structural elements mirrored its exclusionary cultural norms. 
Before these matters can be discussed further, however, one more version of the "Tavistock Transferred" story must be presented. The next chapter will further expand upon themes developed here by considering the changing AKRI, changing times, changing faces, and the changing group relations movement in America in the 1980s, 1990s, and early 2000s. It will be demonstrated in a later chapter (chapter eight), that this combination of structural factors and cultural norms worked in concert with other factors to undermine the AKRI's ability to focus on what should have been its primary task and function in a manner consistent with the Tavistock tradition in England. This lack of focus on the primary task, it will be argued, resulted in an organizational structure that Rice $(1958 ; 1963 ; 1965)$ would have defined as a closed system. 
Chapter VII: Tavistock Transferred-Stories of the Group Relations Movement in America: The Story of Change

\section{Introduction}

This chapter presents a third telling of the Tavistock-in-America tale. The first version of the story focused on Margaret Rioch, the woman who brought the Tavistock model to the United States and founded the A. K. Rice Institute (AKRI), and her protégées. Among other things, this story emphasized how a charismatic personality shaped the way that the Tavistock model was implemented differently in America than it had been in Britain. The second telling of the tale, in chapter six, brought institutional/structural and organizational/cultural factors front and center, emphasizing again how the AKRI's work has diverged from its roots in the Tavistock tradition. This third version of the Tavistock-in-America tale is constructed around the theme of change. Its focus is on a changing AKRI, changing times, changing faces, and the changing group relations movement in America in the 1980s, 1990s, and early 2000 s.

\section{Changing AKRI}

The previous two chapters have identified seven organizational factors that emerged in the AKRI. These factors described an organization that had: (a) little formal infrastructure, (b) leadership norms based on patterns of exclusion, 
(c) a predominantly charismatic leadership style inattentive to succession, (d) operated largely as "organization-in-the-mind," (e) as its sole purpose the holding of group relations conferences, $(f)$ an organizational structure that made it a loose confederation of centers, and $(g)$ exdusionary cultural norms.

It is my contention that these seven organizational factors contributed to the AKRI's functioning, at times, like a closed system ${ }^{1}$. Yet, there is evidence to support that, before his death in 1969, Rice had attempted to push the closed AKRI system in an open direction. It was an effort, at best, that was only temporarily successful. Examples of this push towards an open system include Rice's leadership at the 1969 AKRI National Conference, which will be discussed in the following section. This story will illustrate how Rice attempted to open up the closed AKRI system, urging the AKRI leadership to observe how an organization, in this case the temporary organization of a group relations conference, can relate to its physical and social environments, and shift to a new internal steady state when changes in its environment require internal changes within the organizational system (Miller, 1979; Rice, 1958; 1963; 1965). Yet unfortunately, few substantive changes to AKRI's organizational structure were made and it was unable to sustain this open state without Rice's influence.

Redefining institutional sensibilities and commitments. After four years of sponsoring group relations conferences, the AKRI was challenged in 1969 by the first in a series of struggles over organizational purpose. Social environmental

\footnotetext{
'A mechanically self sufficient organization neither importing nor exporting across the boundaries of the organization.
} 
pressures of the times, such as changing cultural attitudes about race and gender, were alive in all facets of American life, and were exerting pressure on the AKRI as well. As a result, the 1969 AKRI National Conference became a pivotal event that year, requiring AKRI leadership to reflect upon its "institutional sensibilities and commitments" (Gould, 2000, p. 44). This conference was held at Mount Holyoke College on June 7 to 20, 1969 and included, once again, Rice as Director and Rioch as Associate Director, as well as Arden A. Flint, Marvin H. Geller, Laurence J. Gould, William Hausman, Edward B. Klein, Eric J. Miller, Garrett J. O'Connor, Ken Rogers, Roger L. Shapiro on staff (Group Relations Brochure, 1969, p. 7).

It is important to note that, in keeping with the traditions of that time, there were no people of color or women, save Rioch herself, included in the conference leadership and all staff members (except Rice) were from the field of mental health.

In a sense of foreshadowing, the conference brochure described the purpose of the conference: "This will be a Working Conference to explore the dynamics of power and responsibility [italics added] with opportunities for learning about interpersonal and intergroup problems of leading, following and participating" (Group Relations Brochure, 1969, p. 1). It is important to point out the irony in that statement of purpose when read in the context of who hadand who did not have-formal authority at that conference. How could a conference that had as its roots the exploration of the dynamics of power and 
responsibility tolerate the fact that every person holding a position of formal authority was a White male clinician except one White woman, Rioch? This irony would not be lost on the membership during the course of the event and, predictably, would surface during the institutional event, an event where members were free to form their own groups in order to examine conference dynamics. Gould (2000) recalled:

In 1969, the last conference Ken [Rice] was to direct before he died, the Institutional Event once again became the focus of powerful, current social dynamics-race relations and racial equality. In that year there were a substantial number of black colleagues in the membership including Rhetaugh Dumas, Ophie Franklin, Rachel Robinson, Leland Hall and Claude Thomas. (p. 45)

As the institutional event unfolded, these very issues about the dynamics of power and responsibility moved center stage and were combined with racial elements that had been imported into the conference from the wider social environment. It became clear to Rice that the issues about race that were surfacing "were so important and compelling that they could not be constructively dealt with within the boundaries of the conference-that is, interpretively-and as such, a focus on these issues made the task of learning all but impossible" (Gould, 2000, p. 45). Rice devised a plan in private, which he shared with the conference staff later that night at the evening meal. Gould (2000) noted: 
He had decided to meet with the black [sic] members alone, outside the working session boundaries of the conference, to engage them in an exploration of their relatedness to the conference institution, both in the here and now, and in the future. (p. 45)

This search to define the relatedness of an issue to the conference institution and the environment is the very definition of an open system. Rice was employing the techniques central to the Tavistock tradition and attempting to role model leadership in an open system.

Yet, Rice's Holyoke conference staff was livid as they struggled to understand their feelings of outrage and betrayal by their leader (and future namesake of their organization-Rice). They believed his actions had gone against everything he had ever taught them. Gould (2000) recalled:

How, we demanded, could he even consider doing that? And why couldn't we join him in such a meeting if he did? And how about the impact on the rest of the conference membership? And didn't this violate everything that he taught us about primary task and boundaries, and sticking to them? And wouldn't doing this destroy the conference? And so on, and so on and so on. (p. 45)

Rice calmly listened to his staff's objections, and patiently tried to explain his thought process and reasoning, but to no avail. His staff would not listen to reason and Rice grew increasingly irritated. Finally, Rice explained: First, this issue of race was more important, and had broader implications, than any one 
conference ever could; second, "alienating and insulting the black membership by only responding to their quite real concerns interpretively [italics added], would have long lasting and destructive consequences for the future of group relations work in America" (Gould, 2000, p. 45); third, none of the White staff members were asked to join him because they had not shown themselves to be "sufficiently clear-headed" (Gould, 2000, p. 45) about these racial issues to be of any use in the dialogue.

As a result of the dialogue between Rice and the Black membership, it was decided to arrange an extended meeting in the near future to further examine these issues and it was subsequently held on September 21 and 22 , 1969 at the Washington School of Psychiatry. Every Black member of this initial conference group, except one, attended the September meeting in addition to Rice, Klein, and other White members of the Washington School of Psychiatry. After Rice's meeting on race, virtually every non-White attendee subsequently took up a staff role at an AKRI conference and recruited other people of color to join the group relations movement. Gould (2000) recalled:

These included Rose Miller, Earl Braxton, John Johnson, Jan Ruffin, and somewhat later, Leroy Wells. Once again, at another critical moment, Ken's work with this group played, to my mind, a pivotal role in shaping to this day, AKRI's institutional sensibilities and commitments. (p. 46) As Gould noted, Rice provided exemplary leadership, and in particular, I contend, modeled how to engage in an open organizational system. Yet others within 
AKRI leadership and the group relations movement in America at the time seemed less aware of these dynamics.

Organizational implications. It is clear from the story above that Rice understood the implications of exclusion, the dynamics of power, and its potential impact on the future of the AKRI and the group relations movement. One might even infer that Rice recognized that the primary task was not the conference itself but addressing whatever major issues about power and authority it had stoked. For instance, by respecting the seriousness of the Black members concerns and the potentially far reaching implications on the future of the group relations movement in America, Rice facilitated movement away from a closed system examining "White people's stuff" towards an open system that valued a diverse membership and its relatedness to its physical and social environments. As was the conference's goal that year, Rice exemplified how to explore the dynamics of power and responsibility in a way that sustained an open AKRI organizational structure—at least temporarily. Yet after his death, there is clear evidence that the AKRI was unable to sustain this open structure and returned to its closed state.

This idea will be discussed in detail, and analyzed with regard to the present study's three research questions, in chapter eight. The following section will examine how other societal pressures exerted their influences over the AKRI and also increased tensions within the group relations movement in the United States. 


\section{Changing Times}

1980s: A time of political and cultural change. There were four distinct changes in the 1980 s wich led to tensions in the group relations movement in the United States and set the stage for critical incidents which occurred within the AKRI in the 1990s. Some of these changes were external to the AKRI; others were internal factors exacerbated by environmental influences. Regardless, these four forces all worked in concert to affect the organization and its membership.

The first factor was the political and economic changes which occurred in the 1980 s in the United States. For instance, the leadership of President Ronald Reagan ushered in a more fiscally conservative, less community-centered view of governmental responsibility. Along with Reagan's political conservativism came a widespread economic recession that had broad implications in many areas of society.

The group relations movement was not immune to the far reaching impact of these political and economic changes. Cytrynbaum (1993) noted a rather mundane yet significant impact of these changes: "By the early 1980 s the oil crisis and the dramatic increase in the cost of airfares essentially made residential conference work away from home with a significant number of imported staff impossible" (p. 39). Therefore, the significance of having a strong local following was amplified, further strengthening the power and importance of local AKRI centers. 
The second change was a waning public interest in political activism, social programs, community outreach, and movements of all kinds. As a result, the group relations movement suffered a decline in support and popularity among the general public and the once overflowing group relations conferences were becoming sparsely attended.

The third factor was the changing ethos of psychiatry as a whole. During this era there was a general shift away from the use of groups as a method of treatment towards more pharmaceutical solutions to psychological problems. Cytrynbaum (1993) observed, "Psychiatry had [begun] its mission to return to the womb of mother medicine so apparent today" (p. 34). As a result, interest in social psychiatry and its application in communities, represented so well by the work of CEGO, ${ }^{2}$ was waning. And working experientially with groups was no longer the prominent requirement for psychiatric residency that it once was. Therefore, the motivation to attend a group relations conference for a large part of AKRI's constituency was effectively eliminated.

The fourth change was, in large part, internal to the AKRI. Just as the NTL experienced a period of social implosion around its 20 year anniversary ${ }^{3}$, the AKRI also was being challenged by internal turmoil at its 20 year mark. Organizational tensions intensified by the social, political, and economic challenges of the times, along with the structural ones discussed in chapter six ${ }^{4}$,

\footnotetext{
2 Described in chapter six.

${ }^{3}$ Described in chapter four.

${ }^{4}$ Such as patterns of exclusion, lack of attention to leadership succession, and the ramifications of a charismatic leadership style.
} 
were slowly reaching an apex within the AKRI. These challenges set the stage for a number of critical incidents that occurred in the AKRI, coming to a head in 1990.

Although the exact details of the 1990 AKRI National Conference are convoluted and have been distorted by hearsay, one fact remains clear: deep and lasting reverberations were felt by all AKRI members at the time. The aftermath of this event continues to haunt the organization to this day. This critical incident was a coup of sorts, where the traditional AKRI leadership was overthrown by a new wave of leadership with a different philosophy about group relations work. Described as a catactysmic event, it was a time of "painful transition from, what some have characterized as, charismatic leadership to a more collaborative organization" (AKRI History video, 1995). These critical incidents will be discussed later in this chapter. Before these incidents can be recounted, however, some exposition is required. Changing Faces

In addition to the external and internal changes affecting the success of the group relations movement, discussed above, a changed American culture with more inclusive attitudes towards women and minorities in leadership positions emerged in the 1980 s to which AKRI was forced to respond. As described in chapter six, many new faces were seen at group relations events demanding access to, and influence over, the AKRI organization. Yet, these new faces were not Princely, by Rioch's definition. 
Inclusion of these people ushered in a new era. Previously unexplored questions, such as how to judge a staff member's competency to consult or to direct a conference, were raised. Those who were new to the group relations movement took these questions as insinuations of incompetency and claimed that it was yet another not-so-subtle form of discrimination. Holvino observed: The competency stuff arises when people that are not White and are not male begin to arrive into the organization. Then suddenly we have to do competencies. This just happens too much. It's not just about competencies; it has this whole other layer of control. Of controlling who is in and who is out in a different way. (Holvino Interview, 2002, p. 38) As a result, the 1990 AKRI National Conference proved to be the time and place for the ethos of Rioch's princely court to collide with the philosophies of this changing era.

Selecting a "Princely" face as Conference Director. The story begins in 1989 with the selection of Edward Shapiro, a psychoanalyst and Director of the famous Aston-Riggs Clinic in Stockbridge Massachusetts, as the AKRI National Conference Director for the usual three year stint. His selection for this position was made through the usual channels at that time. After attending two conferences as a member in the mid 1970's, Shapiro began "working on staffs at the Washington-Baltimore Center" (Shapiro Interview, 2002, p. 2), then directing local conferences, and, in 1980, was asked to join the staff of the National Conference for the first time. In 1988, Shapiro was the Associate Conference 
Director under the tutelage of Earl Braxton as Director and in 1989 Shapiro directed his first AKRI National Conference. Viewed early on as an up-andcoming Prince by Rioch and her inner court, Shapiro's competency to consult or direct was never challenged.

The influence of a different conference structure. Before the 1990 AKRI National Conference even began, it was already different from previous conferences in many subtle, yet influential, ways. These differences worked in conjunction with other influences both institutionally, within the AKRI, and at the conference itself, to create this watershed event.

First, the membership was divided into two groups, a Working Group and a Training Group. Although this was a common format for the Tavistock Institute's Leicester Conferences, this was the first AKRI National Conference to include a Training Group since the 1966 National Conference under the directorship of Rice. The Conference Director, Shapiro, described how he became interested in this unique Training Group design:

I decided, with consolation with the [AKRI] Board of Directors, to have a Training Group. That was the first Training Group in America in the National Conference [since 1966]. And I asked Wesley [Carr], who directed the Training Group at Leicester, to bring it, to bring the design and work with me around developing it. Now, that also made me a bit more vulnerable because I had never directed a conference with a 
Training Group in it. So that was innovation time, innovation trying to be imported from England. (Shapiro Interview, 2002, p. 16)

This unique conference structure with which most of the staff, including the Director, had little experience, became a very important influence within the conference.

Second, the title of this conference was "Authority, Leadership, and Interdependence in Organizational Life" with the concept of interdependence added as an element to study for the first time at a National Conference. By introducing this concept of interdependence into the conference environment, the Director and staff appeared to be encouraging an examination of the nature of mutually dependent relationships within organizations and, specifically in this case, conference life. Another important inference to be drawn from the label of interdependence could be the relationship, or lack thereof, between authority and leadership in a mutually dependent relationship. This became an important dynamic as the conference unfolded.

Third, the conference staff and the various roles staff members were to play also were significantly different from previous AKRI National Conferences. Shapiro was the Conference Institution Director as well as Director of the Working Conference. Serving as Conference Associate Director and Director of the Training Group was Wesley Carr, at the time Dean of Bristol Cathedral in England. Although Carr had considerable conference experience and had previously directed the Leicester Conference and its Training Group, he was the 
first Englishman since Rice to serve in the directorate of the AKRI National Conference. The rest of the conference staff included Marian D. Hall, Charla Hayden, Elizabeth B. Knight, James Krantz, John T. Lundgren, Janice E. Ruffin, and Leroy Wells Jr.

Fourth, Robert F. Baxter, was curiously listed under both Administrative Associate and Consultant Staff (Group Relations, 1990, p. 8), in addition to being noted as the current President of the AKRI Board of Directors (p. 11). This lack of clarity in Baxter's role, as listed in the conference brochure, appears to be foreshadowing of later conference occurrences. In addition, of the nine staff members, six were from health care professions while the other three were either from the clergy, organizational consulting, or the university.

Although the data above may seem trivial, one cannot begin to understand what happened at the 1990 AKRI National Conference without understanding the following three points: (a) That the conference membership was uniquely structured to include a Training Group; (b) that the conference staff's backgrounds and roles were unique; and (c) that the area of conference study--namely interdependence-was unusual. There is one more point that should be emphasized before the story of this watershed event can be told: Although the conference Director was experienced, he was under stress from outside influences. Shapiro, the Conference Director admitted, "I was in the middle of a divorce and my life was in some disarray" (Shapiro Interview, 2002, p. 15). 


\section{A Watershed Event: 1990 AKRI National Conference}

Regardless of the influence of these structural elements, the nine day AKRI National Conference seemed to begin in the usual manner with an opening plenary at 12:45 pm on June $16^{\text {th }}, 1990$. Over the following days, the Working Conference attended large and small study groups, inter-group, and institutional events while the training group met in separate very small study groups and training events. The Training Group and the Working Conference met together during plenaries throughout the institutional event, and over the last few days of the conference during review and application groups when select Training Group members consulted to the Working Conference.

Yet in the ensuing days a series of critical events occurred: First, the conference boundary became damaged; second, a split emerged in the conference staff and membership; third, a conference member had a psychotic episode; fourth, issues around competency to consult were brought to the forefront; and fifth, role boundaries became blurred. Each of these five critical incidents will be discussed in detail below.

A damaged boundary system. Over the first few days of the conference a number of critical incidents occurred, causing deep reverberations within the staff and the conference as a whole. To use Rice's open systems terminology, these critical incidents damaged both the internal and external boundary system of the conference. By the fifth day of the conference, when the institutional event took place, the boundary system was so extensively damaged that the 
conference structure appeared to be irretrievable. Carr, the Associate Director, recalled what happened:

The conference, in my judgment, began to get out of hand because the Director as we discovered was speaking across the boundary of the external...He said he was doing this. And as a result what was happening was because, in my view, the outer boundary was being broken quite regularly, the inner boundary was un-holdable. Because people couldn't hold inner boundaries unless the outer boundary is utterly secure. And in my judgment, it certainly wasn't. At some point in the institutional event it reached a point where it became dear to me that this was happening. (Carr Interview, 2002, p. 26-27)

When Carr referred to the Director "speaking across the boundary of the external", he meant that Shapiro was having personal conversations with someone outside of the conference and then injecting that information back into the conference.

Carr described how he became aware of this phenomenon:

In two ways really, first of all because you begin to wonder where the Director is coming from because if he has processed [conference events] with some one else outside then there's outside data and... the whole notion of the outsider sees more of the game, comes in. You know if I tell you something about a conference that you've not been at, and you know anything about it, you can almost certainly point out something to me 
which I would not have seen. But on the other hand what's your authority for saying it. The answer is you have virtually none whatsoever, and therefore it can't be important to me as Director--it shouldn't be. Now if that was going on with the Director and then later on he actually said that he was speaking to someone who 'she said such and such,' at which point I had to say this boundary is so badly blown, that we have a very dangerous conference on our hands. And somehow or other it has to be sealed. (Carr Interview, 2002, p. 26-27)

Feeling a responsibility as Associate Director, Carr began to take matters into his own hands as the week progressed. He confronted the Director with his concerns about the permeability of the conference boundary and asked Shapiro to stop these private conversations, but Shapiro refused.

Carr felt he had few choices left at his disposal to try to get the conference boundaries under control:

I couldn't then with integrity continue to be Associate Director because I was excluded from this cross-boundary activity. And I couldn't hold the total boundary of the conference without the Director. And since the Director was a very good personal friend of mine it was a most interesting fight than for most people...I resigned as Associate Director but not as Director of the Training Group and, well, we just did the rest of the conference like that. (Carr Interview, 2002, p. 26-27). 
Although Shapiro confessed to having outside distractions and marital problems during the course of the conference, he remembered the boundary management issues differently than Carr did:

Wesley [Carr] resigned as the Associate Director and, he'll have to tell you what his reasons were for that, it was very difficult that he did. Some of the reasons had to do with the fact that he and I had written this book and we were, since I was dependant on him in the conference in relation to the Training Group, we were in a kind of seamless pair dynamically. So I think one of the things on his mind was to interrupt that pair so that things could be more visible, so he stayed as Director of the Training Group. I was angry at his resigning. He made that decision on his own. And I contemplated firing him as Director of the Training Group, but decided not to. (Shapiro interview, 2002, p. 15-18)

Shapiro also recalled an AKRI organizational dynamic that he felt permeated the conference boundary and played itself out in what felt to him like a disruptive dynamic within the conference itself:

I was on the [AKRI] National Board for a number of years before [the 1990 Conference] and the organizational dynamic was about transition in leadership, particularly in terms of bringing in female leadership. I was on to that and trying to work with that, with the National Board. And there were lots of difficult organizational dynamics around gender transition in leadership...for example early on in the [1990] conference the female staff 
members had their own meeting which they wouldn't, the data of which, they wouldn't bring back into the conference and I couldn't get a hold of what the dynamic was, as Director. (Shapiro Interview, 2002, p. 15) As the conference progressed, complications around boundary management and access to critical information continued to be a significant issue within the staff group.

A split emerged in the conference staff and membership. As a result of Carr's resignation as Associate Director, a split emerged within the conference staff and membership. As Director of the Training Group, Carr continued with one part of the staff and membership under his leadership while Shapiro directed the other part of the staff and membership as Working Conference Director.

It was fairly divisive in the staff. The training group went its merry way, also divided. So it was quite a splitting conference. And I suspect that some of the splitting went into the institution, the sponsoring institution. (Carr Interview, 2002, p. 26-27).

This notion of the conference splitting and reverberating back into the sponsoring institution is an important point which will be explored in the analysis of the AKRI in chapter eight.

Psychotic member. Another unfortunate, yet critical event that occurred during the 1990 AKRI National Conference was that a member of the Working Conference had a psychotic episode, apparently losing touch with reality and acting out. Shapiro remembered: 
The member that went psychotic, had been psychotic before, so he was psychotic coming in [to the conference]...One of the issues that ideally has changed is that when I started directing I eliminated the clause on the application that you had to sign that you were in good mental health ${ }^{5}$.

Because it didn't make any sense to me. (Shapiro interview, 2002, p. 24)

Monroe was a member of the Training Group and a consultant to the application group where some of the member's psychotic episodes occurred. She recalled her experience:

For me it was very significant because I was a member of the Training Group...When we had completed so much training we were sent to consult to the application groups. And I had a particularly difficult application group. I mean actually...someone really had a psychotic episode. For me there was an awful lot of learning about what I was actually able to hold and contain that became very significant. (Monroe Interview, 2002, p. 23-

Curiously, the psychotic member was not removed from the conference but was allowed to continue participating in conference events. It was perhaps this

\footnotetext{
${ }^{5}$ Prior to this conference, each participant needed to procure a reference letter as part of the AKRI National Conference application which attested to their mental stability. The 1979 conference brochure read:

In addition to the completed application, each applicant must also provide a written recommendation from someone who can vouch for the applicant's personal integrity, stability and capacity to participate in an intensive learning experience such as this. (Group Relations, 1979, p. 8)
}

This requirement of a written letter of recommendation to accompany the conference application continued sporadically over the years, though it was not a requirement for either the 1989, 1990, or 1991 conference application. Perhaps in response to this incident, in 1992 the letter of reference returned as part of the application process and has been a requirement ever since (Group Relations, 1989-1992). 
decision, in part at least, that was the root of so much consternation both during and after the conference as the AKRI Board of Directors wrestled with their fear of litigation and their evaluation of conference events.

Training group competency to consult. As previously discussed, the notion of including a Training Group at an AKRI National Conference was in itself an unusual concept. Although it was often done biannually at the Tavistock Institute's Leicester Conference, a Training Group had not been included in the AKRI National Conference since 1966. Carr described his experience as the Training Group Director and the challenging role that the members of the Training Group often played within the conference:

I ran the Training Group as the Associate Director on the basis of training groups which we had run at Leicester for many years, in which the Training Group members are both members and, at the end, acting consultants, if you like. So there's a very important role, but a very difficult one. Nobody's ever pretended it's easy. But it is a very good way of learning about being a consultant, because you can't hide away as a consultant because you are always being dragged back as a member. You can't be a pure member because you are always being pushed away as a consultant. So you get a very strong sense of being used. And the training group sits within the conference for some functions but very much as a sub-conference with its own learning and with its training program, as opposed to experiential learning. (Carr Interview, 2002, p. 26) 
Couple this training change with the fact that few staff members, including the Director, had experience working with a Training Group, and it seems to have added a unique element to conference dynamics even before the event began.

In addition to these challenges, questions surrounding competency to consult, which had begun to emerge within the AKRI in the 1980s, became a hotly contested issue at the 1990 conference when staff were tasked to operationalize what had previously only been debated topics. One side of the debate supports the notion that competencies could be implemented as a way to standardize job requirements in order to be more inclusive and counter the illusion of elitism which emerged during the early Princely years, discussed in chapter six. Another side of the debate argued, as Holvino did in the quoted material presented earlier in this chapter, that competencies were never an issue until a growing number of women and minorities became members of the AKRI and pushed for a larger leadership role within the organization in the 1980s.

Shapiro recalled how the debate about competencies became injected into the 1990 AKRI National Conference in the first place:

What the staff decided to do, in that conference, was to institute something that had been a thorn in the side of the [AKRI] organization forever. And that was public evaluation of competence. Because we decided we would choose out of the Training Group, based on written criteria, who would consult...And that was wild. When you start instituting public criteria for differentiation in competence and you hire people on the 
basis of public criteria as oppose to secret dynamics-people don't like that. People get hurt, they get angry and it produced a very powerful dynamic in the conference. (Shapiro Interview, 2002, p. 17-18)

When pushed to discuss exactly what the evaluation criteria were, Shapiro recalled:

We said these are the criteria by which staff are chosen to consult. There were half a dozen, I don't know what they were. There were half a dozen criteria. And people who didn't meet those criteria weren't chosen. It was just a minor thing in the whole conference but it had larger institutional implications for the AKRI. Because of the whole question about how you choose consultants. Do you do it based on the basis of the old boy network or do you do it on the basis of some public statement about what the issues were? So it was a very powerful, developmental institutional dynamic. (Shapiro Interview, 2002, p. 17-18)

Regardless, the debate around competencies became a public reality during the 1990 AKRI National Conference when some individuals from the Training Group were not chosen to consult to the application groups in the final two days of the conference. Carr described his role in this dilemma as Training Group Director:

[The] Director of the Training Group has to commend to the Director of the Conference the trainees for acting consultant appointment [to the application groups]. And Charla [Hayden] and I very sadly came to the 
conclusion that two of them simply couldn't get their heads and their feelings sufficiently around things to be recommended for this. So we had a divisive division in the Training Group, which is fairly unusual in my experience. Whereby I forget how many, say ten went off to be consultants and two were not and they were left with Charla and I consulting to them according to contract but of course to no effect at all. And so we had quite a stressful time and the trainees had a stressful time, far more stressful a time than they will ever have as consultants. (Carr Interview, 2002, p. 25-32)

As a result of this somewhat unsuccessful attempt to develop a way to institute public criteria to certify group relations competence, tensions were further exacerbated and the rift within the AKRI around the issues of competency widened.

Role boundaries became blurred. Another confounding element that came to light as the conference unfolded, was how the AKRI Board President, who was also serving as conference administrator, was mobilized out of this conference administrative role and into action in his role as Board President. Shapiro explained:

The other thing was that the President of the organization, I hired as the Administrator. I did that, after a lot of discussion with the National Board in part because we were trying to develop ourselves administratively, as an organization. And I thought it would be useful for the President to have 
that experience while he was President in that role. And he thought so too. And he came in. But it tumed out to be a terrible mistake. When things got tense, he got pushed into the role of President and not the role of Administrator. And then there became tension because a group of staff coalesced around him. And it was terrible. (Shapiro Interview, 2002, p. 9)

Carr recalled this phenomenon as well:

There was a sense that a new guard with a little bit of the old guard was there [at the conference]. There was a very odd thing in that one of the senior people in the AKRI was the administrator. And again it was an interesting experiment, but I think maybe too many experiments in one conference. (Carr Interview, 2002, p. 30)

By the statement, "too many experiments in one conference," Carr is referring to the confounding combination of elements emphasized earlier in this chapter: (1) that the conference was uniquely structured; (2) that the conference staffs' backgrounds and roles were unique; (3) that the area of conference study-namely interdependence-was unusual; and finally, (4) the conference Director was under stress from outside influences.

\section{A Changing Group Relations Movement}

After the 1990 National Conference. As discussed previously, tensions had been mounting within the AKRI before the 1990 AKRI National Conference. For example, debate around divisive issues such as the exclusion of women and minorities from leadership positions, the overpowering and exclusionary influence 
of charismatic leadership, and the predominance of mental health professionals in leadership roles, had been contributing to discord within the AKRI for the previous two decades. Yet these factors were just some of the elements that led to the 1990 AKRI National Conference becoming a watershed event which the Director himself described as "fraught" with difficulties right from the beginning. Other elements included the inclusion of a Training Group with public competencies, the pivotal role that Carr, Training Group Director, played because of Shapiro and his staff's lack of experience with Training Groups, the AKRI Board President serving as conference administrator, and the way the National Conference staff was appointed by their respective centers rather than selected and authorized by the Director, all significantly affected the conference dynamics. These conference elements combined with the AKRI's heightened organizational tensions to create a recipe for social implosion in the 1990 s.

Yet, as Shapiro pointed out, "There had been disastrous conferences before" (Shapiro Interview, 2002, p.24). Why did this conference become such a watershed event? Shapiro described his experience after the conference:

In the aftermath of that [1990 National] Conference, the Board of Directors, in my view, lost their way. And sent an inquiry to the membership asking them to evaluate the performance of the Director...To ask the membership to assess the performance of a staff...and to reconstruct a conference from fantasies and projections of members, in terms of the work of the Director, is very difficult to do. So I experienced 
it as, one, irrational, two, anti-task, and three, an attack. And then I was invited to come to the National Board Meeting for a conference review and I was told that it was going to be an assessment of my performance...So I decided not to go because it felt to me like a witch-hunt. And I sent my conference report to everybody instead...There was a splintering of the organization, a number of the former Directors wrote a petition suggesting that this was irrational and needed a setting to review it. I offered to meet with the Board with a consultant, but they didn't want to have a consultant. So they fired me. That is they fired me as Conference Director. So I didn't have a third conference. (Shapiro interview, 2002, p. 8-13)

It is unclear on precisely what grounds Shapiro was "fired." Some informants alluded to a mishandling of the psychotic episode; others claimed it was a retaliation against the charismatic leadership model, represented by Shapiro. When pushed on the reason for his dismissal, Shapiro was unsure: I don't really know. I think that they fired me because I didn't show up [to the Board Meeting]...They never really have given me a cause...Directors could be fired at will. I had a three year contract, they just decided not to renew it. They didn't have to give any cause and they didn't. (Shapiro interview, 2002, p. 15)

Carr described the conference's powerful dynamics, psychotic episodes, and the influence of the AKRI structure over the conference event: 
It was a very powerful conference. And of course occasionally these happen with very powerful dynamics and just occasionally at Leicester some one might be hospitalized or something. It has happened. But I think people got unduly nervous over that conference...My impression was afterwards that they put the [Director] far too much of a sort of trial, when it became very legalistic and moralistic and they should have just let it go. I mean part of the problem again with the AKRI setup, again compared with ours--but I don't want to make the comparison too strong-[is that] all of the members go back usually to some sort of area where there's an institute waiting for them to join--Boston, Texas, whatever it is, GREX. Whereas in England, they just go--and we never see them again or very rarely. And I think that because the members and the staff all go back to these local institutions, institutes, there was a sort of persecution afterwards which I think was inappropriate. (Carr Interview, 2002, p. 34-35)

Carr's observation seems to link with Sher's point, in chapter six, that the nature of the AKRI organizational structure caused a virtual group relations ladder to emerge where the focus for group relations work became solely climbing the ladder of the group relations power structure, and in this case annihilating the competition. Sher further emphasized:

I'm not in favor of developing group relations as a professional career. I mean once it becomes institutionalized and professionalized and 
socialized, one is going to get all of the problems that I think you are encountering in America [in the AKRI]. The politics, the internal politics of organizations. (Sher Interview, 2002, p. 32)

Providing further evidence of the influence of internal politics on the challenge of establishing conference boundaries, Carr emphasized the potential for confusion when staff appointments are made for the National Conference by the AKRI's centers:

[1990] was a turning point of some sort for the National Conference. The problem with the National Conference it seems to me is that it has a status because it is national. But in actual fact, because the staff members are appointed essentially by the area institutions, you've got a very difficult problem about establishing the coherence of the staff and the outer boundary of the conference. Where does it belong? And on this occasion it was breaking up very seriously with correspondingly dangerously effects on the members. (Carr Interview, 2002, p. 28) Yet with all of its challenges, Carr observed that, for many of the participants, this conference was still an extraordinary learning opportunity:

After the conference, it fell out into sort of 3 groups: the very, very young and new, who enjoyed it enormously and said 'wow we must do this again"; the middle group who said 'we must hold everything together some way or another;; and the old group who said these new people are not conforming to the model'. (Carr Interview, 2002, p. 32) 
Although the power of this unique leaming experience no doubt intrigued and attracted some new AKRI members, the handling of the post-conference investigation and subsequent firing of Shapiro as Director alienated many more. For example a former Rioch Prince, Gould, vocally resigned his AKRI membership in protest. Others, like White, simply lost interest in the organization and drifted away. By the mid-nineties, AKRI was a troubled organization searching for a new organizational vision.

Hindsight. Informants seemed to agree that 1990 was a year of critical change for the AKRI and the group relations movement in the United States. What remains contested and unclear, even today, is what we should be taking away from those events in 1990. Monroe offered one interpretation:

Ed Shapiro represented a certain kind of authority and a certain mode of directing that was overthrown. That's my sense organizationally. And after that you found a whole new generation of Directors and people willing to take on the directing role that I think couldn't when the directorship was seen as the work of some one that looked and acted like an Ed Shapiro. (Monroe Interview, 2002, p. 23-25)

Monroe conceded that she may be one of the people who benefited from this transition stating, "I'm not sure that I would be directing today if some of those changes hadn't happened" (Monroe Interview, 2002, p. 25). 
As one of the original inner cirde of group relations leaders, Gould offered some insight into his friend and colleague, Shapiro, and evaluated some of the events that occurred:

Like most things in this field-and I just don't mean group relations, I mean psychological work--It was quite an over-determined event. This particular man, [Shapiro] indeed at times is extremely arrogant, has been characterized as narcissistic, he is somewhat larger than life, very powerful...So there certainly was a background context and he wasn't a beloved object in the Institution. So that's the sense that I mean that it was over determined. Even that alone made him certainly a target. People were just waiting to find a rap to hand him and he obviously provided it in some ways...If you had asked me at that time who do I think is the best and the brightest, I would have said for all of his difficulties and arrogance [Shapiro]. (Gould Interview, 2002, p. 48-53)

Gould developed a hypothesis about how the group dynamics played out at the 1990 conference, and ultimately in the AKRI organizationally. Gould theorized that Shapiro-who was also a White, male, Jewish, psychoanalyst-was used as a stand-in for the founding generation which had fostered so much competition and envy amongst the AKRI membership:

The hypothesis was that the organization can no longer get to Larry Gould, or to Ed Klein, or to Roger Shapiro, or to Garrett O'Connor...But because this man was younger and still actively involved, he essentially 
was the stand in for the founding generation. So they could get to us by killing him off, killing off the favorite son...It was a patriarchal murder, in a sense, if you want to put it in psychoanalytic terms. The primal fathers had to be killed. (Gould Interview, 2002, p. 48-53)

Klein, another early leader of the group relations movement, had similar comments to make about Shapiro and his tendency to attract projections:

Ed [Shapiro] is aggressive, impossible, since I have had him on staff, he is a pain in the ass, I can say that. But I also think he lent himself to things and a lot of crap got projected on him that had to do with lots of people's unconscious and maybe not so unconscious, feelings about their role in the organization...So, it is like Bion has this notion that we have valences to be certain ways. I think [Shapiro] was like the flight/fight leader and got it...But I think a lot of other things in the larger organization got played out. (Klein interview, 2002, p. 28)

Klein has his own hypothesis about the underlying organizational dynamics and frustrations that may have gotten played out at the 1990 conference.

I think there was an outburst around the ' 90 conference, about getting other things going, and people feeling they couldn't move up enough, and feeling frustrated and that the rice crispies,--the senior people--were holding them down. (Klein interview, 2002, p. 32-33) 
Conversely, many of the older generation felt that their organization, which they had worked so hard developing, had become hijacked by an unworthy and disrespectful younger generation. Gould recalled:

Margaret Rioch who was also incredibly incensed by this, begged me to start an alternate AKRI, begged me. And Margaret was very persistent, I am also quite stubborn thankfully. This went on for about a year. She said she could not tolerate herself what had happened. She said 'Listen Larry, you have all these friends and colleagues who you know and love together. How many people do you need to start an institution. Why do we have to live with this for?' (Gould Interview, 2002, p. 52)

Monroe offered yet a different hypothesis about what this generational split may have represented and the future challenges for the younger generation:

There are generational shifts going on. How do you take the best and learn the most from your elders, those who have gone before, without discounting their contributions, really valuing their contributions and yet moving along. So I think that that is the [future] challenge. (Monroe Interview, 2002, p. 20)

\section{AKRI History Project: A Retrospective}

On May 11, 1995 the AKRI held a meeting during which they examined the history of their organization through a series of presentations by representatives from each of its ten centers. The premise of this meeting was that if AKRI could understand each center's culture, it could then better 
understand the AKRI's larger culture. This meeting was held in part, because previous discussions had demonstrated that no one individual had knowledge of the entire history of the AKRI, yet many individuals had significant pieces that they could contribute (AKRI history video, 1995).

AKRI leadership found that there was little agreement about their history and the result of this disagreement was that the AKRI appeared unorganized and chaotic to the outside world, making it difficult to attract new members. These leaders agreed that they needed a common view of where AKRI had been in order to know where AKRI was potentially going. They were eager to develop a vision which they could then use to solicit new members to join their institute. Interestingly, the six-hour video of the proceedings of this meeting was never edited for more widespread dissemination and no papers were published as a result of this event.

\section{"A Center That Holds": Where is AKRI Headed Now?}

As the AKRI enters the twenty-first century and addresses the many new challenges that await it, many old challenges continue to haunt it. In a restructuring move the AKRI leadership voted to change their bylaws at its 2001 Board of Directors' retreat. Two changes were made, both of which resembled changes that had occurred in the NTL in the 1970 s.

One change was to abandon AKRI's thirty year tradition of being both a professional membership organization and an organization with educational goals. These two organizational purposes had at times caused a conflict over 
organizational priorities for the AKRI as they had for the NTL. As NTL President Porter so clearly explained, one of the main challenges during the NTL's restructuring was balancing the membership-education organizational purpose and establishing organizational priorities. She noted:

Do we do our programs for our own benefit, and the people who pay to come to them just happen to be necessary bystanders to help pay for this experience? Who do we serve? Do we serve our clients, or do we serve ourselves? And I think we are still wrestling with that question today. (Porter Interview, 2002, p. 4)

As a result of similar conflicts around organizational priorities, AKRI leaders elected to pursue a clearer focus on its educational pursuits.

The second move reminiscent of that of the NTL in the 1970s, was AKRI national's attempt to reintegrate their local centers into one national organization. The proposed 2001 bylaw changes make no provisions for the continuation of the separate AKRI centers in an effort to "become an increasingly significant educational enterprise" (B. Winderman, personal correspondence, February 25, 2002, p. 2).

These latest changes to the AKRI organizational structure can be viewed as attempts by current leadership to transition away from the charismatic leadership model, discussed in chapter five and six, which was established by Rioch and her inner court, and strengthen the weak organizational infrastructure, 
described in chapter six. White described her observations of current AKRI leadership and their organizational ethos:

[AKRI has] gone into a kind of phobic mode. That is, now, the people who are managing the AKRI organization are the third, fourth, and fifth generations of people who have been excluded. So what they are doing is being extremely inclusive. So it's like getting rid of the founders, getting rid of the bad blood, getting rid of the kind of elitist clubbiness is the primary task of the current leadership...The second generation, third generation folks are just gone...My position is I am still a member in spirit, and I am going to pay my dues, until the next generation comes along and provides us with some leadership--because this stuff is not what you call leadership. This is some other form of elitism which is terrifying-because it gets to harming people. Ed Shapiro was harmed by the events, his reputation was harmed. His sense of efficacy was squashed, his feelings were hurt. And nobody can explain what the standard was that he had not met...But I do think that somebody is going to lead us out of this sixth generation to provide us with a 'center that holds.' Currently the center, the heart of the organization doesn't hold well. It did when Margaret was around but it was its own kind of myth. (White Interview, 2002, p. 13-15)

Therefore, it appears that the future challenge is clear for the AKRI: transition from an organization once based on a charismatic leadership model to one of 
greater indusion-yet not at the expense of the traditions and reputations of its founders.

\section{Changing Group Relations Approaches}

Simultaneous with developments in the Tavistock and Tavistock-inspired group relations movement, new thinking about approaches to group relations theory and methods were emerging in Great Britain and the United States. In this section some of these approaches will be briefly described. The ways that these approaches might meet the needs of changing organizations will also be described. Once again, however, the stage must be set for the discussion that will follow.

\section{A new setting: Flattening of organizational structures. Today's}

organizations tend to be much flatter than in the 1950 s when the Tavistock model emerged and in the 1960 s when the AKRI methods evolved. Organizations during this era had more hierarchical and homogenous designs. Within these organizations, the typical work setting was one where tasks were delineated specifically; workers usually reported to one boss, and often remained employed at the same organization their entire working lives.

Organizations have changed markedly since then. Work tasks now tend to be more complex, require people to work in teams, and to communicate via networks. The composition of the workforce has also changed considerably, becoming more ethnically and sexually diverse. These changes in organizational 
life have implications for the group relations movement. In response, new ways of thinking and new ways of working have emerged.

The emergence of new group relations models. From the earliest days of the group relations movement, in fact, people called for the need to continue to develop theories and new ways of working with groups to meet the changes of organizational life. Recognizing this, Neuman, Holvino, and Braxton (2000) wrote, "We believe that these changing organizational demands require abilities that can be usefully developed through combining insights, knowledge and skills" (p. 2). In response, a number of different group relations theories and models have emerged over the years. One of the earliest examples of this is that of Harold Bridger and his Double-Task Method.

The Double-Task Model. Harold Bridger was one of the first to experiment with merging and expanding the traditional group relations models, developing his own Double-Task Model as early as the 1950 s based on his experiences with socio-technical methods ${ }^{6}$. A central figure at the historic Northfield Experiments during World War II, Bridger was one of the co-founders of the Tavistock Institute and an early shaper of the Tavistock model including directing the Leicester conference (Harrison, 2000; Neumann et. al., 2000). Gould discussed Bridger's model and compared it to other models of working with groups:

I think there are two levels at which [Bridger] took some exception to the Tavistock Conference, and this is where I think he linked more closely to

\footnotetext{
${ }^{6}$ Described in chapter two.
} 
NTL. I think he thought that the tone of the group relations conference was a little too stiff, a little too formal, a little too hard edged, and a little too focused on transference to the consultant or the staff to the exclusion of other processes. And I think he felt that that was a mistake in the emphasis, especially with regard to the application of this kind of learning to organizational life...So you might say Harold had a more democratic, softer ethos about the conference which made his work more congenial with NTL which was really based on a more American/democratic view where there was almost no emphasis whatsoever on authority or concepts like role for example. (Gould Interview, 2002, p. 6-8)

A merger of models, Bridger, who is now approaching ninety years old, has worked collaboratively with the NTL since 1957 when he brought "his version of Socio-technical Systems Theory to Bethel" (Freedman, 1999, p. 130). To this day, he gives two lectures and training every July at the NTL facility in Bethel, Maine (Porter Interview, 2002).

The Third Way to group consultancy. In the 1970s, group relations scholars such as Klein and Astrachan (1971) continued the call for the development of new theoretical approaches and a merging of the traditional models. In an apparent answer to this call two decades later, a hybrid approach emerged that incorporated, and expanded on, both the NTL and Tavistock theories and practices. Outlined by Neumann et. al. (2000) in Evolving a "Third Way" to Group Consultancy: Bridging Two Models of Theory and Practice, these 
authors described how today's changing organizational demands require different strategies for working with groups and offered an alternative approach they called the third way. The foundational premise of this approach is that most groups and organizations need a variety of processes to operate at peak efficiency. Therefore, the goal of the third way approach is to combine elements of both the NTL and Tavistock traditions as warranted when working experientially with groups.

Complexity theory. Yet another group relations approach has been provided by Ralph Stacey, professor of management at the Business School of the University of Hertfordshire in the United Kingdom. In 1989, Stacey began to write a book that eventually would bring him into contact with Eric Miller at the Tavistock Institute and expose him to the Tavistock model. In his complexity theories, Stacey built upon the Tavistock's system psychodynamic approach? , yet questioned the Tavistock model's relevance to creativity, contending that its relative inflexibility hampered harnessing change. Stacey (2001) wrote: "I am arguing that the formal Tavistock model, with its intersystemic formulation, its emphasis on clarity of primary task, and its distinction between work and basicassumption group has difficulty in accommodating the whole question of creativity" (p. 100). Stacey's approach encouraged creativity over conformity within organizations, emphasizing that it is possible to find order out of chaos by

\footnotetext{
${ }^{7}$ Described in chapter two.
} 
harnessing "the creative potential of disorder, so giving new insights into the process of change" (Stacey, 2001, p. 94).

The San Diego ModeP. The last emerging approach to be discussed in this dissertation builds upon, yet modifies, previous innovations. The San Diego mode/ has been under development for the past four years at the University of San Diego in California, under the direction of Theresa Monroe, professor of Leadership Studies. This model is a hybrid group relations approach based loosely on the Tavistock tradition as well as the influence of Monroe's Harvard mentor, Ronald Heifetz. Monroe observed some of the ways that she feels her approach is different from other group relations traditions:

I think that I do a kind of hybrid. I have continued to work on trying to develop a different kind of vocabulary. I think I give people a lot more theory, in terms of leadership theory anyway...It's a kind of combination of a lot of the things I've been talking about. There are theoretical underpinnings to it in terms of a particular view of leadership and authority that supports the work. There is a way of looking that emphasizes improvisation much more than rigid structure. There are experiments that I run every conference; I've never been to a conference that had observers, but there is a particular reason that I have asked some people to be observers; the seminars that I introduced; the way of

\footnotetext{
${ }^{8}$ The term the San Diego Model was first coined after the 2001 summer group relations conference at USD by AKRI group relations scholar and former Bryn Mawr Conference Director Zachary Green in an email dated July 18, 2001. In this email to conference staff, Green outlined "the beauty and elegance with which the 'San Diego Model' of group relations is emerging" ( $p$. $1)$.
} 
structuring and ordering authority; the authorization of staff members that act on my behalf. (Monroe interview, 2002, p. 15)

Recognizing the modernity of this approach and its relevance to the changing organizational structures of today, Green (Z. Green, personal correspondence, July 18, 2001) compared the San Diego model to the Tavistock model and its interpretations of authority:

It seems to me that the 'San Diego Model,' given the emphasis on intersubjective interpretation, is actually more about the space created in the relationship between consultants and members than authority per se. In this respect what [Monroe] is doing is more akin to the networked organizations that are now found in many settings. (p. 3-4)

Green observed the San Diego model's movement away from the more orthodox Tavistock methods by noting a leaning towards "the valence end of the spectrum...There was much talk about the individual behavior, personal responsibility and self-authorization. In this light, the role that people play on behalf of the group and what they represent can get obscured" (Green, 2001, p. 5).

This observation can make the San Diego model appear strikingly similar to the third way approach because it incorporates both the overt--more individual behavioral elements from the $N T L$ model--and the covert--unconscious elements from the Tavistock model. Yet, the San Diego model also contains elements of Stacey's (2001) complexity theories, emphasizing the exploration of 
the "edge of chaos" reflected in conference titles such as: "Leadership for Change: Chaos, Complexity, Resistance, and Courage" (July 2001), "Human Relations for Leaders: Chaos, Conflict, and Courage" (January 2001), and "Leadership and Authority for the $21^{\text {st }}$ century: Chaos, Conflict, and Courage" (January 2000). Therefore, it seems clear that changing organizational structures and the influence of the Tavistock, NT, third way, and complexity models are all apparent in the emerging San Diego model.

\section{Conclusion}

This chapter represented a third, and final, telling of the Tavistock-inAmerica tale. Building upon the first version of the story, which focused on the influential people in the group relations movement, and the second telling of the tale, which brought institutional/structural and organizational/cultural factors front and center, this chapter focused on a changing AKRI, changing times, changing faces, and the changing group relations movement in America in the 1980s, 1990s, and early 2000s. The next and final chapter of this dissertation will offer further analysis of the AKRI and the evolution of the group relations movement in the United States as well as recommendations of areas that warrant further research. 
Chapter VIII: Analysis and Recommendations for Further Research

\section{Introduction}

This dissertation began by detailing the intellectual foundations of the Tavistock Institute's group relations model. It discussed the impact of the theories of Freud, Klein, Bion, Rice, Miller and others on the burgeoning field of group relations. Chapter three considered how war-time experiences and changing cultural assumptions and social values shaped the emergence of the Tavistock model of group relations in England after World War II. Chapters four through seven explored the circumstances that led to the transportation of the Tavistock model to the United States in 1965, and assessed the factors that influenced the evolution of the group relations movement in the United States.

This chapter is organized around, and directly addresses, the three research questions presented in chapter one. Because much of this analysis has already been introduced in the earlier substantive chapters, critical findings will be presented only in summary form here.

Research Question 1: What were the Historical Origins of the Tavistock Model of Group Relations in the United Kingdom?

The historical origins of the Tavistock model of group relations in the early twentieth century can be traced to four critical factors in the United Kingdom: 
emerging intellectual foundations; the influence of war; changing social values and cultural constructs in the post-war period; and the influence of another model of working experientially with groups, that of the National Training Laboratories (NTL) in the United States.

\section{Emerging Intellectual Foundations}

The Tavistock method is an amalgam of two intellectual traditions which were emerging in the late nineteenth and early twentieth century in Europe: the psychoanalytic tradition and the tradition of open systems theory. Through the influence of these intellectual traditions a symbiotic relationship between group relations theory and practice emerged, resulting in the development of an experiential learning model designed to study authority, leadership, and people's behavior in groups which became known as the Tavistock model.

\section{The Infiuence of War}

Prior to World War I, awareness of the causes or symptoms of mental illness was still negligible. World War I increased people's awareness of the mental stresses of armed conflict and necessitated the development of ways to treat large numbers of "shell-shocked" soldiers. Psychotherapy, especially group psychotherapy, began to be used more extensively in response to critical shortages of manpower during World War II and the need to treat soldiers expeditiously in order to return them to the battle-front. After the war, lessons learned by British army psychiatry were further refined at the Tavistock Clinic, and then at the Tavistock Institute, where innovative methods of group 
treatment were expanded to include civilians, as well as soldiers, in the post-war period.

Some of the lessons learned from army psychiatry's war-time experiences included the advantages of applying group treatment over individual therapy; using non-medical personnel to run treatment groups; treating patients outside of a medical system; bringing treatment to the patient rather than relocating the patient to the hospital; including a range of interdisciplinary backgrounds in the staff; maintaining an application orientation; and requiring the patients to run their own therapeutic communities. These elements remained central to the ethos of Tavistock Institute and in the development of the Tavistock model. Changing Social Values and Cultural Constructs

In addition to the direct effects of war, changing social values and cultural constructs of the post-war period also influenced the emerging Tavistock model. The devastation caused by World War II was especially pronounced in Great Britain where daily bombings became routine, rationing was a way of life, and a labor shortage blurred the lines between what constituted women's and men's work. Previous assumptions about class distinctions also were called into question.

The post-war construction of a British welfare state, in part a response to an increased awareness of the inequities of pre-war class distinctions, significantly changed the material structure of most English people's lives. Yet, in some people's opinions, these positive changes had a down side because they 
were accompanied by an increase in the prevalence and involvement of government institutions. Some war-weary British were left feeling overcome by a sense of alienation, powerlessness, and fragmentation by these changes. The time was ripe for the development of a way to study leadership, authority, and organizations in an effort to rehumanize life within the ubiquitous institutions and organizations emerging in England's modem society. The Tavistock Institute provided just such a method as a way to help the population better cope with these new institutional anxieties.

\section{The Influence of Lewin and the NTZ}

Further research and refinement of the ideas developed by British army psychiatrists, along with the influence of Lewin and his theories represented by the NTL and its human laboratory, influenced the development of the Tavistock model and the Tavistock Institute's group relations conference in the 1950s. Although the Tavistock Institute continued to work in many different arenas throughout the 1960 s and 1970 s, the group relations conference, made famous by its annual occurrence at the University of Leicester, became synonymous with the Tavistock model of group relations from the time of its initiation in 1957.

\section{Summary}

The historical origins of the Tavistock group relations model can be traced to: influential intellectual traditions, war-time necessity; psychiatry's efforts to mitigate post-war psychic wounds; and further socio-technical applications to organizations. 
Research Question 2: What Circumstances led to the Tavistock Mode/'s Transportation to the United States?

There were three circumstances that set the stage for the transportation of the Tavistock model of group relations to the United States in 1965: the reputation of the Tavistock Institute; the social climate in the United States; and powerful and charismatic leaders to launch a group relations movement in the United States.

Reputation of the Tavistock Institute

The first circumstance that influenced the transportation of the Tavistock model of group relations to the United States was the growing worldwide reputation of the Tavistock Institute itself. This reputation attracted a charismatic and politically powerful woman, Margaret Rioch, to the Leicester Conference in 1963. Her experiences there convinced her that the Tavistock model of group relations would be a valuable "new injection into the American bloodstream" (Rioch, 1996, p. 12).

The Social Climate

The second circumstance that influenced the importation of the Tavistock model to America was the existence of a fertile social climate in which to plant a new group relations movement and a population eager to question authority based on their prior political and social activist experiences. In addition, by the time that the Tavistock model of group relations was imported to the United States in 1965, many Americans were already intrigued with the notion of 
experiential leaming thanks to the foundational work of the indigenous NTL model and the proliferation of encounter groups. The nationwide exposure that the $\mathrm{NTL}$ and encounter groups provided helped, in part, to create a receptive soil into which the Tavistock model was transplanted.

Powerful and Charismatic Leaders

While the explosive growth of the group relations movement and the rapid development of the A. K. Rice Institute (AKRI) in America in the 1960 s and 1970s can be attributed, in part, to the Tavistock Institute's reputation and a ripe American social climate, another factor was the influence of the powerful and charismatic founders of the group relations movement in the United States. Rioch's personal connections to famous and influential people, her persuasive, charismatic personality, and her ability to attract and retain a loyal Prince/y court set the stage for the transportation of the Tavistock model of group relations to the United States.

Research Question 3: What Factors Influenced the Evolution of the Group Relations Movement in the United States?

The answer to this third research question will be addressed in two parts. The first part details the factors that contributed to the group relations movement's fast rise in popularity in the 1960 s and 1970 s in the United States. The second part details the factors that contributed to the stagnation of the group relations movement in the 1980 s and 1990 s, more specifically, as a result of the AKRI closed system. 


\section{The Group Relations Movement's Fast Rise in Popularity}

Ironically, the very factors that allowed the Tavistock model and the AKRI to enjoy such early popular success in the United States also contributed to the organizations later stagnation and inability to sustain its viability long-term. In other words, the power of the Tavistock name, the ripe American social climate, and the charismatic personalities that allowed the Tavistock model and the AKRI to thrive in the 1960 s and 1970 s in the United States, also contributed to the building of an organization with: (a) little formal infrastructure, (b) leadership norms based on patterns of exclusion, (c) a predominantly charismatic leadership style inattentive to succession, (d) a sole purpose of holding group relations conferences, (e) a history based on oral traditions of the "organization-in-themind," ( $f$ ) a loose confederation of centers, and $(g)$ closed cultural norms. These seven factors and their effects on the organization, discussed in detail in chapter five, six, and seven, critically distinguished AKRI from the Tavistock tradition, which AKRI nonetheless continued to claim as its lineage.

\section{The Stagnation Period of the Group Relations Movement}

Numerous informants including Carr, Gould, Klein, Sher, and White alluded to a stagnation period in the group relations movement in the United States in the 1980 s and 1990s, where previously active members "just stopped doing the work, they just drifted away" (White Interview, 2002, p. 11). Although this stagnation can be attributed, in part, to changes in political, economic, and social patterns in the United States, as discussed in chapters four and seven, 
these are not the only factors which influenced the AKRI's ability to perform its primary task'. I argue that through a lack of attention to its relatedness with its physical and social environment, AKRI devolved into an organizational structure that Rice, himself, would have seen as having less than adequate attention to the primary task. Rice also, I suspect, would have viewed AKRI as primarily a closed system ${ }^{2}$.

Import-conversion-export model derived from open systems theory. As detailed in chapter two, the way that Rice $(1963 ; 1965)$ categorized a system was to examine the permeability of its boundaries. The basic model Rice (1963) used for this analysis was what he termed the "import-conversion-export model derived from open systems theory" (p. 16). In this model, Rice pointed out that it is not only important for an organization to import-convert-export-as virtually every organization does-but to accomplish this process in relation to its primary task. Rice wrote, "An enterprise, like an organism, must work to live...must be related to their physical and social environments if they are to survive" (p. 179180).

In other words, an open system is a living organization relating and responding to physical and social environments in a healthy way. Therefore, for AKRI to be an open system it must accomplish its primary task: "to advance the understanding of covert processes affecting leadership and authority in groups

\footnotetext{
${ }^{2}$ Rice (1965) defined the primary task as that task which an organization or group "must perform if it is to survive" (p. 17).

2 As we saw in chapter three, Rice (1963) defined an open system as one which "maintains itself by the exchange of materials with its environment. By contrast a physical closed system is mechanically self-sufficient, neither importing nor exporting" (p. 16).
} 
and organizations...using the Tavistock group relations tradition of open systems and psychodynamic theories" (AKRI Membership Directory, 2002, p. 1) through its relatedness to, and exchange of materials with, its physical and social environment.

Yet, a more accurate depiction of the AKRI structure is what Rice called a closed-system, where "the organizational problems of an enterprise can be analyzed by reference only to its internal environment and that any change in the external environment can be accommodated within the existing organization" (Rice, 1963, p. 183). An example of this mode of operation within AKRI was evidenced by the organizational implosion that occurred during, and after, the 1990 AKRI National Conference (discussed in chapter eight): "in a physical dosed system, final equilibrium is obtained only when maximum entropy is reached, that is, when all energy has been converted into heat and the result is thermodynamic equilibrium. In such an equilibrium the system can do no more work" (Rice, 1963, p. 183).

Rice (1963) described another element of a closed system as "the use of concepts of imbalance or dysfunction in the system to ensure that the system continues to work" (p. 183). As described in chapter five, six and seven of this dissertation, there were many dysfunctional elements within the AKRI that kept the organization focused on its own internal dynamics rather than responding flexibly to its environment, as an open system might. For example, in response to accusations by members that patterns of exclusion were emerging within the 
AKRI leadership, the leadership nevertheless allowed an informal Princely court to continue to rein. This decision further amplified the dynamics of exclusion perpetuating the imbalance, as a close system, rather than responding to the changes evident in the social and political environment in which the organization existed, as an open system would.

A brief examination of the process by which AKRI completed the importconversion-exportation process, in comparison to the Tavistock Institute upon which it claimed its roots, is warranted as further evidence of AKRI's closed nature. Historically, AKRI imported its organizational leaders, conference consultants, and directors almost exclusively from the field of mental health while the Tavistock Institute imported its leaders, consultants, and directors from a wide range of interdisciplinary backgrounds.

The AKRI conversion process occurred almost exclusively through group relations conferences (although there were occasional scientific meetings and some other forms of training programs conducted on the local level via centers). In comparison, the Tavistock Institute was involved in a range of activities, detailed in chapter three, of which only a small percentage were specifically delineated as group relations conferences.

Carr provided further support for the difference between the AKRI and the Tavistock Institute import-conversion-export process:

Part of the problem with the AKRI setup, again compared with ours--but I don't want to make the comparison too strong-[is that] all of the 
members go back usually to some sort of area where there's an institute waiting for them to join--Boston, Texas, whatever it is, GREX. Whereas in England, they just go--and we never see them again or very rarely. (Carr Interview, 2002, p. 35)

As a result of the limited scope of AKRI's import-conversion process, its ability to export back into the environment was also severely impacted, thus ensuring a self-fulfilling cycle of little exchange with its environment-a closed system. In contrast, the Tavistock Institute's interdisciplinary import process and diverse conversion processes resulted in a wide application for its work in the export process, ensuring an exchange with its environment and preserving the interdisciplinary nature of its import process.

AKRI: A closed system. Based on the evidence presented in this dissertation, Rice attempted to influence the AKRI towards becoming an open system by modeling how to relate to the physical and social environments. This conclusion is based, in part, on the events of the 1969 AKRI Mount Holyoke Conference detailed in chapter seven. In this example Rice recognized that in an open system issues that were alive within America at that time, such as race, would pass through the permeable boundary and be alive within the conference as well. He understood that the permeability of the organizational boundary was allowing a healthy exchange between the temporary conference institution and the American political and social environment. Therefore, as Gould (2000) noted: 
[Rice] had decided to meet with the black members alone, outside the working session boundaries of the conference, to engage them in an exploration of their relatedness to the conference institution, both in the here and now, and in the future. (italics added; p. 45)

This exploration of the organizations "relatedness" is a clear sign of healthy operations within an open system.

Yet, after Rice's death in 1969 it appears that the AKRI established itself as an organization with: (a) little formal infrastructure, (b) leadership norms based on patterns of exclusion, (c) a predominantly charismatic leadership style inattentive to succession, (d) a sole purpose of holding group relations conferences, (e) a history based on oral traditions of the "organization-in-themind," ( $f$ ) a loose confederation of centers, and $(g)$ closed cultural norms. These seven factors are evidence of AKRI's inner focus, a lack of relatedness to its physical and social environments, and the organization's drift away from its roots in the Tavistock tradition. Miller (1979) noted:

One fruitful proposition derived from the [open systems] model is that a change in the relatedness of a system to its environment requires internal changes within the system: it must shift to a new steady state if it is to survive. (p. 218)

I suggest that this is precisely what AKRI failed to accomplish: By not relating to the changes in its external environment in the 1970 s and focusing primarily on internal dimensions, AKRI failed to "shift to a new steady state." As new AKRI 
leaders in the 1980 s started challenging AKRI's closed system to become more related to its external environment, an organizational implosion occurred in 1990 because the closed system could not respond. In Rice's (1963) words, maximum entropy was reached and the system could do no more work (p. 183).

\section{Summary of Analysis}

In conclusion, findings presented in this dissertation evidenced that when the Tavistock model of group relations was transported from England to the United States it began to change. As one might expect, political, social, economic, and cultural influencers all came into play effecting group relations theories and methods when they arrived in America. In addition, the leadership of charismatic personalities, who influenced the importation of the Tavistock methods to America and the establishment of the AKRI, impacted the development of the group relations theories and methods in America. As a consequence of these factors, the resultant group relations work in America, in particular the AKRI, has drifted so far from the orthodoxy of the Tavistock model in England that it might be best thought of as a new model, distinct from either the Tavistock model or the NTL model (while retaining elements of each).

\section{Recommendations for Further Research}

First, because this dissertation evidenced that the group relations work of the AKRI has drifted so far from its roots in the Tavistock tradition that it might 
be best thought of as a separate model, there is a need to define the elements which identify this AKRI mode/ of group relations.

Second, because many of the pivotal group relations experts, and the people who knew them well, are progressing into old age, it is imperative to conduct further oral histories with these key figures while time permits. For example, during the course of this study, two prominent figures in the group relations movement died: Roger Shapiro, one of Rioch's Princes, and Eric Miller, Director of the Tavistock Institute and its Group Relations Training Programme. Currently there are people still alive, such as Isabel Menzies Lyth and Harold Bridger, who knew Wilfred Bion well; or people like Larry Gould and Ed Klein who knew Ken Rice and Margaret Rioch intimately. These people's memories of the experience of knowing and working with these early founders of the group relations movement must not go undocumented.

Third, because Dicks (1970) wonderfully comprehensive history of the Tavistock Clinic and Institute stopped at approximately 1960, there is a need to continue historical analysis to present day in order to further understand the history of the group relations movement in the United Kingdom. This dissertation has laid the foundation for this further analysis.

Fourth, because new group relations models have been emerging, (such as the third way, complexity, and San Diego models) further research into how to define and compare new models is warranted. 
Fifth, by focusing on the group relations movement in England and America, this dissertation provided one perspective on the history of the group relations movement. Further global exploration and elaboration of group relations theories, practices, models, and institutions worldwide is warranted.

\section{Conclusion}

In conclusion, the development of the Tavistock and Tavistock-inspired group relations movement in Great Britain and the United States has influenced the ways in which scholars understand and study people's behavior in groups. As a result, group relations theories and practices have made an important contribution to our understanding about the nature of leadership and authority. As scholars draw from and expand on research in group relations, closing the gap in our knowledge about this important field, it is clear that group relations will continue to inform the field of leadership studies and enhance its ability to contribute to the leadership needs of today. 


\section{Bibliography}

A. K. Rice Institute website (2001). www.akriceinstitute.org.

Anthony, E. J. (1972). The history of group psychotherapy. In Kaplan, H. I. \& Sadock, B. J. (Eds.), The evolution of group therapy. New York: E.P. Dutton \& Co., Inc.

Appley, D. G. \& Winder, A. E. (1973). T-groups and therapy groups in a changing society. San Francisco: Jossey-Bass Publishers.

Armstrong, D. (1997). The 'institution in the mind': reflections on the relation of psycho-analysis to work with institutions. Free Associations, 7(41), 1-14.

Arrow, H., McGrath, J. E., \& Berdahl, J. L. (2000). Small groups as complex systems: Formation, coordination, development, and adaptation. Thousand Oaks, CA: Sage.

Ary, D., Jacobs, L. C., \& Razavieh, A. (1996). Introduction to research in education ( $5^{\text {th }}$ ed.). New York: Harcourt Brace College Publishers.

Back, K. W. (1972). Beyond words: The story of sensitivity training and the encounter movement. New York: Russell Sage Foundation.

Banet, A. G. \& Hayden, C. (1977). A Tavistock primer. The 1977 Annual Handbook for Group Facilitators. San Diego, CA: University Associates, 155-167. 
Barrett, F. J. \& Srivastva, S. (1991). History as a mode of inquiry in organizational life: A role for human cosmogony. Human Relations, 44, (3). 231-245.

Barzun, J. \& Graff, H. F. (1992). The modern researcher ( $5^{\text {th }}$ ed.). New York: Harcourt Brace Jovanovich College Publishers.

Beatfest2002. (2002). www.beatfest2002.com.

Benne, K. D., Bradford, L. P., Gibb, J. R., \& Lippitt, R. O. (1975). The laboratory method of changing and learning theory and application. Palo Alto, CA: Science and Behavior Books, Inc.

Bernheimer, C. \& Kahane, C. (Eds.) (1985). In Dora's case: Freud-hysteriafeminism. New York: Columbia University Press.

Bion, F. (1982). Foreword. In W. R. Bion, (1982). The long week end 1897-1919: Part of a life. London: Karnac Books.

Bion, W. R. (1957). Group dynamics: A review. In M. Klein, P. Heimann, \& R. E. Money-Kyrle, (Eds.), New directions in psycho-analysis. New York: Basic Books, Inc.

Bion, W. R. (1957). Language and the schizophrenic. In M. Klein, P. Heimann, \& R. E. Money-Kyrle, (Eds.), New directions in psycho-analysis. New York: Basic Books, Inc.

Bion, W. R. (1961). Experiences in groups. London: Routledge.

Bion, W. R. (1982). The long week-end 1897-1919: Part of a life. London: Karnac Books. 
Bolman, L. G. \& Deal, T. E. (1997). Reframing organizations: Artistry choice, and leadership (2n ed.). San Francisco: Jossey-Bass.

Bradford, L. P. (1967). The biography of an institution. The Journal of Applied Behavioral Science, 3(2), 127-143.

Bradford, L. P., Gibb, J. R., \& Benne, K. D. (1964). T-Group Theory and Laboratory Method. New York: John Wiley \& Sons.

Bridger, H. (1985). Northfield revisited. In M. Pines (Ed.). Bion and group psychotherapy. London: Routledge \& Kegan Paul.

Burton, A. (Ed). (1969). Encounter. San Francisco: Jossey-Bass Inc.

Cohn, N. (1994). Attending to emotional issues on a special care baby unit. In A. Obholzer \& V. Z. Roberts (Eds.), The unconscious at work. London: Routledge.

Colman, A. D. \& Bexton, W. H. (Eds.). (1975). Group Relations Reader 1. Jupiter, FL: A. K. Rice Institute.

Continents (2002). http://www.continents.com/rioch.htm

Cooper, C. L., \& Alderfer, C. P. (Eds.). (1978). Advances in experiential social processes, volume I. New York: John Wiley \& Sons.

Coulson, W. R. (1972). Groups, gimmicks and instant gurus: An examination of encounter groups and their distortions. New York: Harper \& Roe, Publishers.

De Mare, P. B. (1985). Major Bion. In M. Pines (Ed.). Bion and group psychotherapy. London: Routledge \& Kegan Paul. 
Dicks, H. V. (1970). Fifty years of the Tavistock dinic. London: Routledge and Kegan Paul.

Donaldson-Pressman, S. \& Pressman, R. M. (1994). The narcissistic family. New York: Lexington Books.

Durkin, H. E. (1964). The group in depth. New York: International Universities Press, Inc.

Egan, G. (1970). Encounter: Group processes for interpersonal growth. Belmont, CA: Brooks/Cole Publishing Company.

Eisold, K. (1993). Changing group relations: Some problems and symptoms. In T. W. Hugg, N. M. Carson, R. M. Lipgar (Eds.), Changing group relations: The next twenty-five years in America. Jupiter, FL: The A. K. Rice Institute.

Emery, F. (1997). The next thirty years: Concepts, methods and anticipations. In E. Trist, F. Emery \& H. Murray (Eds.), The social engagement of social science: A Tavistock anthology, volume III: The socio-ecological perspective. Philadelphia: The University of Pennsylvania Press.

Emery, F. E. \& Trist, E. L. (1973). Towards a social ecology. London: Plenum Press.

Fairholm, G. W. (1994). Leadership and the culture of trust. Westport, CT: Praeger.

Forsyth, D. R. (2000). One hundred years of group research: introduction to the special issue. Group Dynamics: Theory, Research, and Practice, 4(1), 3-6. 
Foulkes, S. H. \& Anthony, E. J. (1957). Group psychotherapy: The psychoanalytic approach. London: Penguin Books.

Freedman, A. M. (1996). The values and legacy of the founders of NTL: An interview with Ken Benne. Joumal of Applied Behavioral Science, 32 (3), 332-344.

Freedman, A. (1999). The history of organization development and the NTL institute: what we have learned, forgotten, and rewritten. The Psychological Manager Joumal, 3(2), 125-141.

Freeman, J. (Ed.). (1983). Social movements of the sixties and seventies. New York: Longman.

Freeman, J. \& Johnson, V. (Eds.). (1999). Waves of protest: Social movements since the sixties. Lanham, MD: Rowman \& Littlefield Publishers.

French, R., \& Vince, R. (Eds.). (1999). Group relations, management, and organization. New York: Oxford University Press.

Freud, S. (1959). Group psychology and the analysis of the ego. New York: Liveright Publishing Corporation.

Gabriel, Y. (1999). Organizations in depth. Thousand Oaks, CA: Sage.

Giges, B., \& Rosenfeld, E. (1976). In M. Rosenbaum \& A. Snadowsky (Eds.), The intensive group experience. New York: The Free Press.

Gillette, J., \& McCollom, M. (Eds.). (1987). Groups in context. New York: University Press of America Inc. 
Gilliss, B. E. (1993). Organizations of the future: An analysis of current literature and a new model. Unpublished doctoral dissertation, University of San Diego, California.

Gilroy, P. (1987). 'There aint no black in the union jack. 'London: Hutchinson. Gitlin, T. (1987). The sixties: years of hope, days of rage. New York: Bantam Books.

Glesne, C. (1999). Becoming qualitative researchers (2nd ed.). New York: Longman.

Gold, M. (1999). (Ed.). The complete social scientist: A Kurt Lewin reader. Washington DC: American Psychological Association.

Gould, L. (2000). A. K. Rice in America: Leadership and legacy. Organisational \& Social Dynamics, 1, p. 42-53.

Gray, S. G. (1970). The Tavistock Institute Of Human Relations. In H. V. Dicks. Fifty years of the Tavistock clinic. London: Routledge and Kegan Paul.

Gould, L. Stapley, L. F. \& Stein, M. (Eds.) (2001). The system psychodynamics of organizations. New York: Karnac

Hale, N. G. (1995). The rise and crisis of psychoanalysis in the United States. Oxford: Oxford University Press.

Harrison, T. (2000). Bion, Rickman, Foulkes and the Northfield Experiments: Advancing on a different front. London: Jessica Kingsley Publishers. 
Hayden, C. \& Molemkamp, R. J. (in press). Tavistock primer II. In S. Cytrybaum and D. A. Noumair (Eds.), Group Reader 3. Jupiter, FL: The A. K. Rice Institute.

Heifetz, R. A. (1994). Leadership without easy answers. Cambridge, Mass: The Belknap Press of Harvard University Press.

Heifetz, R. A., \& Laurie, D. L. (1997, January-February). The work of leadership. Harvard Business Review, 124-134.

Hennessy, P. (1993). Never again Britain, 1945-1951. New York: Pantheon Books.

Hershey, P., \& Blanchard, K. H. (1993). Management of organizational behavior. Englewood Cliffs, NJ: Prentice Hall.

Higgin, G. \& Bridger, H. (1965). The psychodynamics of an inter-group experience. London: Tavistock Publications.

Hirschhorn, L. (1997, June). The primary task. Paper presented at The International Society for the Psychoanalytic Study of Organizations, 1997 Symposium.

Howard, J. (1970). Please touch: A guided tour of the human potential movement. New York: Dell Publishing.

Hugg, T. W., Carson, N. M., \& Lipgar, R. M. (1993). (Eds.). Changing group relations: The next twenty-five years in America. Jupiter, FL: The A. K. Rice Institute. 
Hughes, R. L., Ginnett, R. C., \& Curphy, G. J. (1996). Leadership: Enhancing the lessons of experience. Chicago: Irwin.

Jaquette, J. S. (2002). Rethinking Machiavelli: Feminism and citizenship. Unpublished manuscript, Occidental College, Los Angeles.

Jones, E. (1955). The life and work of Sigmund Freud. New York: Basic Books.

Jones, K. B. (1993). Compassionate authority: Democracy and the representation of women. New York: Routledge.

Kahn, W. A. (1992). To be fully there: Psychological presence at work. Human Relations, 45, 321-50.

Klein, E. B. \& Astrachan, B. M. (1971). Learning in groups: a comparison of study group and t-groups. The Journal of Applied Behavioral Science, $7(6), 659-$ 683.

Klein, E. B. (1978). An overview of recent Tavistock work in the United States. In C. L. Cooper, \& C. P. Alderfer (Eds.), Advances in experiential social processes, volume I. New York: John Wiley \& Sons.

Klein, M. (1946). Notes on some schizoid mechanisms. In J. Mitchell (Ed.), The selected Melanie Klein. London: Penguin Books.

Klein, M., Heimann, P., \& Money-Kyrle, R. E. (1957). (Eds.). New directions in psycho-analysis. New York: Basic Books, Inc.

Ketchum, L. D., \& Trist, E. (1992). All teams are not created equal: How employees empowerment really works. London: Sage Publications. 
Khaleelee, O. \& Miller, E. (1985). Beyond the small group: Society as an intelluble field of study. In M. Pines, (Ed.), Bion and group psychotherapy. London: Routledge \& Kegan Paul.

Kotter, J. P. (1978). Organizational dynamics: Diagnosis and intervention. Reading, Mass: Addison-Wesley Publishing Company.

Krantz, J. (1993). On the future of group relations work. In T. W. Hugg, N. M. Carson, R. M. Lipgar (Eds.), Changing group relations: The next twentyfive years in America. Jupiter, FL: The A. K. Rice Institute.

Kreeger, L. (Ed.) (1975). The large group. London: The Anchor Press Ltd.

Lakin, M. (1972). Interpersonal encounter: Theory and practice in sensitivity training. New York: McGraw-Hill Book Company.

Lakin, M. (1976). The human relations training laboratory: A special case of the experiential group. In M. Rosenbaum \& A. Snadowsky (Eds.), The intensive group experience. New York: The Free Press.

Lakin, M. (1979). Introduction. The Journal of Applied Behavioral Science, 265270.

Lasch, C. (1978). The culture of narcissism. New York: W.W. Norton \& Company, Inc.

Lawrence, W. G. (Ed.) (1979). Exploring individual and organizational boundaries: A Tavistock open systems approach. New York: John Wiley \& Sons. 
Le Bon, G. (1896). The crowd: A study of the popular mind. London: Ernest Benn Limited.

Lewin, R. \& Regine, B. (2000). The soul at work. New York: Simon \& Schuster. Lieberman, M. A., Yalom, I. D., \& Miles, M. B. (1973). Encounter groups: First Facts. New York: Basic Books, Inc.

Lincoln, Y. S. \& Guba, E. G. (1985). Naturalistic inquiry. Beverly Hills, CA: Sage Publications.

Lippitt, L. L. (1998). Preferred futuring. San Francisco: Berrett-Koehler Publishers, Inc.

Lofgren, D. P. (1993). A psychoanalytic perspective on the benefits of charisma and charismatic leadership. In S. Cytrybaum \& S. A. Lee, Transformations In Global And Organizational Systems. Proceedings of the Tenth Scientific Meeting of the A. K. Rice Institute. Jupiter, FL: A. K. Rice Institute Press.

Lynd, R. S. (1939). Knowledge for what? The place of social science in American culture. Princeton: Princeton University Press.

Lyons, D. (1997). The feminine in the foundations of organizational psychology. Journal Of Applied Behavioral Science, 33(1), 7-26.

Manchester, W. (1973). The glory and the dream: A narrative history of America 1932-1972. Boston: Little, Brown and Company.

Machiavelli, N. (1961). The prince. New York: Penguin Books. (Original work published in 1515). 
Marrow, A. J. (1967). Events leading to the establishment of the National Training laboratories. The Joumal of Applied Behavioral Science, 3(2), 144-150.

Mathison, S. (1988). Why triangulate? Educational Researcher, 17(2). 13-17.

Mawson, C. (1994). Containing anxiety in work with damaged children. In A. Obholzer \& V. Z. Roberts (Eds.), The unconscious at work. London: Routledge.

McDougall, W. (1920). The group mind. New York: G. P. Putnam's Sons.

McGrath, J. E., \& Altman, I. (1966). Small group research: A synthesis and critique of the field. New York: Holt, Rinehart, \& Winston, Inc.

McMahan, E. M. \& Rogers, K. L. (Eds.). (1994). Interactive oral history interviewing. Hillsdale, N]: Lawrence Erlbaum Associates, Publishers.

McPhail, C. (1991). The myth of the madding crowd. New York: Aldine De Gruyter.

Merriam, S. B. (1998). Qualitative research and case study applications in education. San Francisco: Jossey-Bass Publishers.

Miller, E. J. (1979). Open systems revisited: A propostion about development and change. In W. G. Lawrence (Ed.), Exploring individual and organizational boundaries: A Tavistock open systems approach. New York: John Wiley \& Sons. 
Miller, E. J. (1989). The Leicester model: Experiential study of group and organizational processes. THR Occasional Paper No. 10. London: The Tavistock Institute of Human Relations.

Miller, E. J. (1990). Experiential learning in groups I: The development of the Leicester model. In E. Trist \& H. Murray (Eds.), The social engagement of social science: Volume 1: The socio-psychological perspective. London: Free Association Books.

Miller, E. J. (1990). Experiential Learning in groups II: Recent developments in dissemination and application. In E. Trist \& H. Murray (Eds.), The social engagement of social science: Volume 1: The socio-psychological perspective. London: Free Association Books.

Miller, E. (1993). AKRI: Past and future. In T. W. Hugg, N. M. Carson, R. M. Lipgar (Eds.), Changing group relations: The next twenty-five years in America. Jupiter, FL: The A. K. Rice Institute.

Miller, E. (1993). From dependency to autonomy: Studies in organization and change. London: Free Association Books.

Miller, E. J. (1998). A note on the protomental system and "groupishness": Bion's basic assumptions revisited. Human Relations, 51, (12). 1495-1508.

Miller, E. (1999). Dependency, alienation, or partnership? The changing relatedness of the individual to the enterprise. In $R$. French \& $R$. Vince (Eds.), Group relations, management, and organization. Oxford: Oxford University Press. 
Miller, E. J., \& Rice, A. K. (1967). Systems of organization. London: Tavistock Publications Limited.

Mitchell, J. (Ed.). (1986). The selected Melanie Klein. London: Penguin Books.

Monroe, T. M. (1999). Authority: The shifting context for ministry in the Roman Catholic Church. Unpublished doctoral qualifying paper.

Moylan, D. (1994). The dangers of contagion: Projective identification processes in institutions. In A. Obholzer \& V. Z. Roberts (Eds.), The unconscious at work. London: Routledge.

National Training Laboratories Institute for Applied Behavioral Science website (2001). www.ntl.org.

Neumann, J. E., Holvino, E., \& Braxton, E. T. (2000). Evolving a third way to group consultancy: Bridging two models of theory and practice. Manuscript submitted for publication.

Obholzer, A. (1994). Authority, power and leadership. In A. Obholzer \& V. Z. Roberts (Eds.), The unconscious at work. London: Routledge.

Obholzer, A. (1994). Fragmentation and integration in a school for physically handicapped children. In A. Obholzer \& V. Z. Roberts, (Eds.), The unconscious at work. London: Routledge.

Obholzer, A., \& Roberts, V. Z. (Eds.). (1994). The unconscious at work. London: Routledge.

Patton, M. Q. (1990). Qualitative evaluation and research methods ( $2^{\text {nd }}$ ed.). Newbury Park, CA: Sage Publications. 
Person, E. S. (Ed.). (2001). On Freud's "group psychology and the analysis of the ego". Hillsdale, NJ: The Analytic Press.

Piazza, D. (1995). A developmental model of charismatic leadership. In K. L. West, C. Hayden, \& R. M. Smith (1995). Community and chaos. Proceedings of the Eleventh Scientific Meeting of the A. K. Rice Institute. Jupiter, FL: A. K. Rice Institute Press.

Pines, M. (Ed.) (1982). The individual and the group: Boundaries and interrelations. New York: Plenum Press.

Pines, M. (Ed.). (1983). The evolution of group analysis. London: Routledge \& Kegan Paul.

Pines, M. (Ed.). (1985). Bion and group psychotherapy. London: Routledge \& Kegan Paul.

Pocock, J. G. A. (1975). The Machiavellian moment. Princeton: Princeton University Press.

Rees, J. R. (1945). The shaping of psychiatry by war. New York: W. W. Norton \& Company, Inc.

Rice, A. K. (1958). Productivity and social organization: The Ahmedabad experiment. London: Tavistock Publications Limited.

Rice, A. K. (1963). The enterprise and its environment. London: Tavistock Publications Limited.

Rice, A. K. (1965). Learning for leadership. London: Tavistock Publications Limited. 
Rice, A. K. (1970). The modern university. London: Tavistock Publications Limited.

Rioch, M. J. (1975). Group relations: Rationale and technique. In A. D. Colman \& W. H. Bexton (Eds.). Group relations reader 1. Jupiter, FL: A. K. Rice Institute Press.

Rioch, M. J. (1979). The A. K. Rice group relations conferences as a reflection of society. In W. G. Lawrence (Ed.), Exploring individual and organizational boundaries: A Tavistock open systems approach. New York: John Wiley \& Sons.

Rioch, M. J. (1986). Fifty years at the Washington School of Psychiatry. Psychiatry, 49, 33-44.

Rioch, M. J. (1993). On directing "Holyoke". In T. W. Hugg, N. M. Carson, \& R. M. Lipgar (Eds.). Changing group relations: The next twenty-five years in America. Jupiter, FL: The A. K. Rice Institute Press.

Rioch, M. J. (1996) "Personal perspectives". (In memoriam reprinted from Models of achievements: Reflections of eminent women in psychology, 1983, New York: Columbia University Press.)

Roach, C. F. \& Behling, O. (1984). Functionalism: Basis for an alternate approach to the study of leadership. In J. G. Hunt, D. M. Hosking, C. A. Schriesheim, \& R. Stewart (Eds.), Leaders and managers: International perspectives on managerial behavior and leadership. Elmsford, NY: Pergamon. 
Roberts, V. Z. (1994). Caring and uncaring in work with the elderly. In A.

Obholzer \& V. Z. Roberts (Eds.), The unconscious at work. London: Routledge.

Rogers, C. (1970). Cart Rogers on encounter groups. New York: Harper \& Row, Publishers.

Rosenbaum, M. (1976). Group psychotherapy. In M. Rosenbaum \& A. Snadowsky (Eds.), The intensive group experience. New York: The Free Press.

Rost, J. C. (1991). Leadership for the twenty-first century. Westport, CT: Praeger.

Roszak, T. (1995). The making of a counter culture. Berkeley: University of California Press.

Rubin, H. J. \& Rubin, I. S. (1995). Qualitative interviewing: The art of hearing data. Thousand Oaks, CA: Sage Publishing.

Schein, E. H. (1985). Organizational culture and leadership. San Francisco: Jossey-Bass Publishers.

Schimke, G. L. R. (1972). Encounter groups: Theory, techniques and criticisms. Unpublished master's thesis, California State University, San Diego.

Senge, P. M. (1990). The fifth discipline. New York: Doubleday.

Shapiro, E. R. \& Carr, A. W. (1991). Lost in familiar places. New Haven: Yale University Press.

Sherry, M. S. (1995). In the shadow of war: The United States since the 1930's. New Haven: Yale University Press. 
Singer, W. (1997). Creating histories: Oral narratives and the politics of historymaking. Oxford: Oxford University Press.

Siroka, R. W., Siroka, E. K., \& Schloss, G. A. (1971). Sensitivity training \& group encounter. New York: Grosset \& Dunlap.

Skolnick M. R. \& Green, Z. (2001, August). Diversity, group relations and the denigrated other. Unpublished paper presented at the A.K. Rice Institute Conference, Bryn Mawr College, Philadelphia, PA.

Smith, G. (1987). When Jim Crow met John Bull: Black American soldiers in World War II Britain. New York: St. Martin's Press.

Smith, K., \& Berg, D. (1987). Paradoxes of group life. San Francisco: JosseyBass.

Speck, P. (1994). Working with dying people: On being good enough. In A. Obholzer \& V. Z. Roberts, (Eds.), The unconscious at work. London: Routledge.

Spradley, J. P. (1979). The ethnographic interview. New York: Harcourt Brace Jovanovich College Publishers.

Stacey, R. (2001). Complexity at the "edge" of the basic assumption group. In L. Gould, L. F. Stapley, \& M. Stein, (Ed.), The system psychodynamics of organizations. New York: Karnac

Stein, M. (2002, Summer). A tribute to Eric Miller (1924-2002). AKRI Newsletter, 12-13. 
Sutherland, J. D. (1985). Bion revisited: Group dynamics and group

psychotherapy. In M. Pines (Ed.), Bion and group psychotherapy. London: Routledge \& Kegan Paul.

Szaluta, J. (1999). Psychohistory: Theory and practice. New York: Peter Lang.

Talamo, P. B., Borgogno, F., \& Mercai, S. A. (Eds.). (1997). Bion's legacy to groups. London: Karnac Books.

Talamo, P. B., Borgogno, F., \& Mercai, S. A. (Eds.). (2000). W. R. Bion between past and future. London: Karnac Books.

Thelan, H. A. (1985). Research with Bion's concepts. In M. Pines (Ed.), Bion and group psychotherapy. London: Routledge \& Kegan Paul.

Trist, E. L. \& C. Sofer (1959). Exploration in group relations. Leicester: Leicester University Press.

Trist, E. (1985). Working with Bion in the 1940s: The group decade. In M. Pines (Ed.), Bion and group psychotherapy. London: Routledge \& Kegan Paul.

Trist, E. \& Murray, H. (1990). Historical overview: The foundation and development of the Tavistock Institute to 1989. In E. Trist \& H. Murray (Eds.), The social engagement of social science, volume I: The sociopsychological perspective. London: Free Association Books.

Trist, E., \& Murray, H. (Eds.). (1990). The social engagement of social science: A Tavistock anthology, volume I: The socio-psychological perspective. Philadelphia: University of Pennsylvania Press 
Trist, E., \& Murray, H. (Eds.). (1993). The social engagement of social science: A Tavistock anthology, volume II: The socio-technical perspective. Philadelphia: University of Pennsylvania Press

Trist, E., Emery, F., \& Murray, H. (Eds.). (1997). The social engagement of social science: A Tavistock anthology, volume III: The socio-ecological perspective. Philadelphia: University of Pennsylvania Press

Vansina, J. (1961). Oral Tradition: A study in historical methodology. Chicago: Aldine Publishing Company.

Veldman, M. (1994). Fantasy, the bomb, and the greening of Britain: Romantic protest, 1945-1980. Cambridge: Cambridge University Press.

Wing, K. T. (1989). Fieldwork in social invention: A comparative analysis of five traditions. Unpublished master's thesis, University of Pennsylvania.

Winnicott, D. W. (1975). Through paediatrics to psycho-analysis: Collected papers. New York: Brunner/Mazel, Publishers.

Zander, A. (1979). The study of group behavior during four decades. The Joumal of Applied Behavioral Science, 272-282. 


\section{The History of Group Relations}

Interview Guide

Informant: Location

Date:

102

- How and when did YOU first become involved in the group relations' movement?

- What would you consider the historical origins of the group relations' movement?

- Who were the most significant/influential people; What were the most significant/influential events?

- How has the group relations' movement changed over time?

- Literature gap about the growth of the Tavistock approach to group relations in the US. Why? Who were the most significant/influential people, and what were the most significant/influential events during this period?

- What is the history and significance of the AKRI having separate centers? Has this caused any problems?

- Some experts think that AKRI has "lost its roots" and become "too PC". Do you agree/disagree?

- GR often appears to consist of a perpetual struggle between psychiatric and non-psychiatric professionals. Any thoughts on this ideological struggle or any predictions about the future of GR? 
- Could you briefly describe any ideas/memories about the following people, their personalities, or anecdotes about their lives: Rice, Rioch, Bion, Lewin, Miller, Trist, Turquet.

- What did you think about the "human potential movement"? How did these groups effect other group relations work?

- How, if at all, does the group relations' movement have implications for leadership studies and/or organizational development?

- Why are we so poor at the very thing we aim to teach: inter-, and intragroup relations?

- Who were the Princes? Princess ?

- What/where is the future of GR?

Conclusion:

- Who else would you recommend that I talk with about these topics and questions? (snowball sampling)

- What would you recommend that I ask them?

- Do you have any group relations' movement artifacts or photographs that I could look at? 
A. K. Rice Institute Scientific Meetings ${ }^{1}$

\begin{tabular}{|c|c|c|c|}
\hline \# & Date & Title & Location \\
\hline $1^{\text {st }}$ & $\begin{array}{l}\text { April 29- } \\
30,1976\end{array}$ & The National Scientific Meeting of the AKRI & $\begin{array}{l}\text { Minneapolis, } \\
\text { MN }\end{array}$ \\
\hline $2^{\text {nd }}$ & $\begin{array}{l}\text { April 28- } \\
29,1977\end{array}$ & Second Annual Scientific Meeting of the AKRI & $\begin{array}{l}\text { Washington } \\
\text { DC }\end{array}$ \\
\hline $3^{\text {rd }}$ & 1978 & unknown & \\
\hline $4^{\text {th }}$ & $\begin{array}{l}\text { March 22- } \\
24,1979\end{array}$ & Fourth Scientific Meeting of the AKRI & Houston, $\mathrm{TX}$ \\
\hline $5^{\text {th }}$ & $\begin{array}{l}\text { April 2-4, } \\
1981\end{array}$ & Fifth Scientific Meeting of the AKRI & $\begin{array}{l}\text { Washington } \\
\text { DC }\end{array}$ \\
\hline $6^{\text {th }}$ & $\begin{array}{l}\text { April 21- } \\
24,1983\end{array}$ & The State of the Art in American Tavistock & \begin{tabular}{|l|} 
San \\
Francisco, CA \\
\end{tabular} \\
\hline $7^{\text {th }}$ & $\begin{array}{l}\text { April 28- } \\
20,1985\end{array}$ & The Seventh Scientific Meeting of the AKRI & $\begin{array}{l}\text { Washington } \\
\text { DC }\end{array}$ \\
\hline $8^{\text {th }}$ & $\begin{array}{l}\text { April 30- } \\
\text { May 2, } \\
1987 \\
\end{array}$ & $\begin{array}{l}\text { Working with Irrationality in Social \& } \\
\text { Organizational Life }\end{array}$ & Boston, MA \\
\hline & $\begin{array}{l}\text { July 15- } \\
18,1988\end{array}$ & $\begin{array}{l}\text { Contributions to Social and Political Science: } \\
\text { First International Symposium on Group } \\
\text { Relations: }\end{array}$ & Oxford, UK \\
\hline $9^{\text {th }}$ & $\begin{array}{l}\text { May 12- } \\
14,1989\end{array}$ & $\begin{array}{l}\text { Changing Group Relations: The Next Twenty- } \\
\text { Five Years in America }\end{array}$ & New York, NY \\
\hline & 1990 & $\begin{array}{l}\text { Second International Symposium on Group } \\
\text { Relations }\end{array}$ & Spa, Belgium \\
\hline $10^{\text {th }}$ & $\begin{array}{l}\text { May 31- } \\
\text { June 2, } \\
1991\end{array}$ & $\begin{array}{l}\text { Transformation in Global and Organizational } \\
\text { Systems: Changing Boundaries in the } 90^{\prime} \text { s }\end{array}$ & ST. Louis, MO \\
\hline $11^{\text {th }}$ & \begin{tabular}{|l|} 
May 6-9, \\
1993 \\
\end{tabular} & Community or Chaos & $\begin{array}{l}\text { Los Angeles, } \\
\text { CA }\end{array}$ \\
\hline & $\begin{array}{l}\text { August } \\
14-19, \\
1993\end{array}$ & $\begin{array}{l}\text { Exploring Global Social Dynamics: Third } \\
\text { International Group Relations \& Scientific } \\
\text { Conference }\end{array}$ & \begin{tabular}{|l|} 
Victoria, \\
Australia
\end{tabular} \\
\hline $12^{\text {th }}$ & \begin{tabular}{|l|} 
May $10-$ \\
13,1995 \\
\end{tabular} & $\begin{array}{l}\text { Leadership as Legacy: Transformation at the } \\
\text { Turn of the Millennium }\end{array}$ & $\begin{array}{l}\text { Washington, } \\
\text { DC }\end{array}$ \\
\hline $13^{\text {th }}$ & $\begin{array}{l}\text { April 3-6, } \\
1997 \\
\end{array}$ & $\begin{array}{l}\text { Taking Stock: Society and Its Institutions at } \\
\text { the Close of the } 20^{\text {th }} \text { Century }\end{array}$ & Houston, $\mathrm{TX}$ \\
\hline & $\begin{array}{l}\text { July 29- } \\
\text { Aug 2, }\end{array}$ & $\begin{array}{l}\text { Pleasure \& Pain in Our Working Life-Between } \\
\text { Tradition \& Transformation: Fourth }\end{array}$ & $\begin{array}{l}\text { College Park, } \\
\text { MD }\end{array}$ \\
\hline
\end{tabular}

\footnotetext{
1 Thanks to Anne-Marie Kirkpatrick for researching AKRI scientific meeting brochures and compiling this information.
} 


\begin{tabular}{|l|l|l|l|}
\hline & 1998 & International Group Relations Symposium & \\
\hline & $\begin{array}{l}\text { June 24- } \\
27,2002\end{array}$ & $\begin{array}{l}\text { Exploring Being in Global Systems: Fifth } \\
\text { International Group Relations Symposium }\end{array}$ & $\begin{array}{l}\text { Victoria, } \\
\text { Australia }\end{array}$ \\
\hline $14^{\text {th }}$ & $\begin{array}{l}\text { Sept 18- } \\
21,2003\end{array}$ & $\begin{array}{l}\text { From the Personal to the Collective: The } \\
\text { Dimensions of Leadership and Authority in } \\
\text { Uncertain Times }\end{array}$ & Boston, MA \\
\hline
\end{tabular}


The A. K. Rice Institute's Centers

(Group Relations Brochure, 1975-1979; 1984; 1991; 1995; 2002)

\begin{tabular}{|c|c|c|c|c|}
\hline Location & Name & Founders & $\begin{array}{l}\text { Incorp } \\
\text { Date } \\
\text { (Circa) }\end{array}$ & $\begin{array}{l}\text { Un- } \\
\text { Incorp } \\
\text { Date }\end{array}$ \\
\hline $\begin{array}{l}\text { Washington, } \\
\text { DC }\end{array}$ & $\begin{array}{l}\text { Washington- } \\
\text { Baltimore Center }\end{array}$ & $\begin{array}{l}\text { Margaret Rioch, } \\
\text { Roger Shapiro, } \\
\text { Garrett O'Connor }\end{array}$ & 1966 & Wy \\
\hline Topeka, KS & Topeka Center & Roy Menninger, & 1969 & 1977 \\
\hline $\begin{array}{l}\text { Minneapolis, } \\
\text { MN }\end{array}$ & Minnesota Center & William Hausman & 1969 & 1978 \\
\hline $\begin{array}{l}\text { San } \\
\text { Francisco, CA }\end{array}$ & GREX & $\begin{array}{l}\text { Lars Lofgren, Arthur } \\
\text { Coleman, Lowell } \\
\text { Cooper, Richard } \\
\text { Shadoan } \\
\end{array}$ & 1969 & ment \\
\hline $\begin{array}{l}\text { New Haven, } \\
\text { CT }\end{array}$ & $\begin{array}{l}\text { Center for the } \\
\text { Education of Groups } \\
\text { and Organizations } \\
\text { (CEGO) }\end{array}$ & $\begin{array}{l}\text { Jim Miller, Ed Klein, } \\
\text { Nancy French }\end{array}$ & 1969 & 1978 \\
\hline $\begin{array}{l}\text { New York, } \\
\text { NY }\end{array}$ & $\begin{array}{l}\text { Institute for the } \\
\text { Applied Study of } \\
\text { Social Systems } \\
\text { (IASOSS) }\end{array}$ & $\begin{array}{l}\text { Larry Gould, Jay } \\
\text { Seaman, Dave } \\
\text { Singer }\end{array}$ & 1971 & 1978 \\
\hline Houston, TX & Texas Center & $\begin{array}{l}\text { Glenn Cambor, } \\
\text { Manuel Ramirez }\end{array}$ & 1971 & \\
\hline $\begin{array}{l}\text { Los Angeles, } \\
\text { CA }\end{array}$ & $\begin{array}{l}\text { Study Center for } \\
\text { Organizational } \\
\text { Leadership and } \\
\text { Authority (SCOLA) }\end{array}$ & $\begin{array}{l}\text { Garrett O'Connor, } \\
\text { Lars Lofgren, Kay } \\
\text { West, Charla } \\
\text { Hayden Zoltan } \\
\text { Gross }\end{array}$ & 1973 & 1980 \\
\hline $\begin{array}{l}\text { Columbia, } \\
\text { MO }\end{array}$ & Central States Center & $\begin{array}{l}\text { Louesa Danks, } \\
\text { Elizabeth } \\
\text { Heimburger, Bob } \\
\text { Baxter, Tim Dolan }\end{array}$ & 1974 & 1999 \\
\hline $\begin{array}{l}\text { New York, } \\
\text { NY }\end{array}$ & North Central Center & $\begin{array}{l}\text { William Hausman, } \\
\text { Marian Hall, Jim } \\
\text { Gustafson, and } \\
\text { John Maurel }\end{array}$ & 1975 & 1977 \\
\hline $\begin{array}{l}\text { Cincinnati, } \\
\mathrm{OH}\end{array}$ & Mid-West Center & Edward Klein & 1977 & \\
\hline Boston, MA & $\begin{array}{l}\text { Center for the Study } \\
\text { of Groups and Social }\end{array}$ & $\begin{array}{l}\text { Leigh Estabrook, } \\
\text { Edward Shapiro, }\end{array}$ & 1982 & +2 \\
\hline
\end{tabular}

Appendix C 


\begin{tabular}{|l|l|l|l|}
\hline & Systems (CGSS) & $\begin{array}{l}\text { Sten Lofgren, and } \\
\text { Mary Wright }\end{array}$ & $\begin{array}{l}\text { Harold Bernard, Ken } \\
\text { Eisold, Leslie } \\
\text { Freedman, } \\
\text { Lawrence Jacobson, } \\
\text { Avi Nutkevitch }\end{array}$ \\
\hline Chicago, IL & $\begin{array}{l}\text { Chicago Center for } \\
\text { the Study of Groups } \\
\text { and Organizations } \\
\text { (CCSGO) }\end{array}$ & $\begin{array}{l}\text { Solomon } \\
\text { Cytrynbaum, Robert } \\
\text { Lipgar; }\end{array}$ & 1990 \\
\hline $\begin{array}{l}\text { Philadelphia, } \\
\text { PA }\end{array}$ & $\begin{array}{l}\text { Philadelphia Center } \\
\text { for Organizational } \\
\text { Dynamics (PCOD) }\end{array}$ & Rose Miller & 1994 \\
\hline
\end{tabular}

